
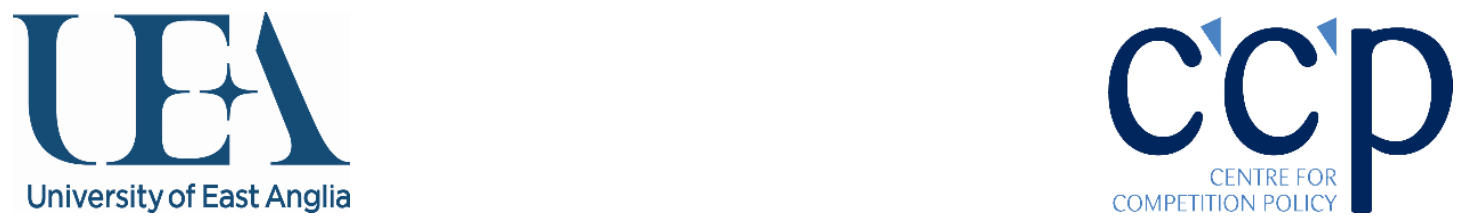

\title{
Micro and Small Businesses' Satisfaction with the UK Energy Market: Policy Implications
}

\author{
David Deller \\ Centre for Competition Policy \\ University of East Anglia \\ Amelia Fletcher \\ Centre for Competition Policy \\ Norwich Business School \\ University of East Anglia
}

CCP Working Paper 18-9

\begin{abstract}
While householders' ability to navigate the domestic retail energy market has generated considerable debate, little attention has been given to micro and small businesses' (MSBs) purchasing of energy. This paper provides the first academic assessment of MSBs' satisfaction with the UK's retail energy market. Using survey data from the UK energy regulator we find that while intermediaries are central to MSBs switching energy supplier, the quantity of marketing contact received from them is a key source of dissatisfaction. This dissatisfaction with marketing contact has direct policy relevance as the Competition and Market Authority's 2016 Energy Market Investigation recommended that a database of 'disengaged' MSBs be established to enable marketing communications from rival suppliers to prompt MSBs to switch. We also query whether the need for more MSB engagement is obvious, given the prevalence of multi-year energy contracts among MSBs, suggesting that the 'optimal' switching level of MSBs likely differs from that of householders. Our evidence suggests that there could be benefits from increased regulatory oversight of intermediaries' behaviour. Furthermore we note that existing data fail to address an issue of importance for regulatory decision making: the overlap between households and MSBs and the potential choice for MSBs between domestic and non-domestic contracts. Overall, the paper exemplifies the types of insights that can be obtained by regulators providing wider access to the surveys they commission. We recommend that UK regulatory agencies share anonymised raw survey data by default to enhance the transparency, and potentially quality, of their decision making.
\end{abstract}

Contact Details:

David Deller

david.deller@uea.ac.uk 


\title{
Micro and Small Businesses' Satisfaction with the UK Energy Market: Policy Implications
}

\author{
David Deller and Amelia Fletcher ${ }^{1}$
}

December 2018

\begin{abstract}
While householders' ability to navigate the domestic retail energy market has generated considerable debate, little attention has been given to micro and small businesses' (MSBs) purchasing of energy. This paper provides the first academic assessment of MSBs' satisfaction with the UK's retail energy market. Using survey data from the UK energy regulator we find that while intermediaries are central to MSBs switching energy supplier, the quantity of marketing contact received from them is a key source of dissatisfaction. This dissatisfaction with marketing contact has direct policy relevance as the Competition and Market Authority's 2016 Energy Market Investigation recommended that a database of 'disengaged' MSBs be established to enable marketing communications from rival suppliers to prompt MSBs to switch. We also query whether the need for more MSB engagement is obvious, given the prevalence of multi-year energy contracts among MSBs, suggesting that the 'optimal' switching level of MSBs likely differs from that of householders. Our evidence suggests that there could be benefits from increased regulatory oversight of intermediaries' behaviour. Furthermore we note that existing data fail to address an issue of importance for regulatory decision making: the overlap between households and MSBs and the potential choice for MSBs between domestic and non-domestic contracts. Overall, the paper exemplifies the types of insights that can be obtained by regulators providing wider access to the surveys they commission. We recommend that UK regulatory agencies share anonymised raw survey data by default to enhance the transparency, and potentially quality, of their decision making.
\end{abstract}

\section{Introduction}

In 2016 the Competition and Market Authority's (CMA) investigation into the UK energy market concluded that there was room for improvement in the energy market for micro and small businesses (MSBs). ${ }^{2}$ The CMA's conclusions for the MSB energy market were based on analysis of descriptive statistics. Using data from Ofgem's (the UK energy regulator) 2014 and 2015 market monitoring surveys, this paper provides the first econometric investigation of MSBs' satisfaction with the retail energy market. By considering only descriptive statistics, rather than performing multivariate analysis, policymakers risk basing policy decisions on patterns that are non-robust.

Policy concern around MSBs and their energy purchases relates to perceived limits on their capacity to negotiate commercial energy markets, reflecting that MSBs may exhibit capabilities and behaviours which are closer to those of domestic customers than to large corporate undertakings. Over recent years, such concerns have led Ofgem to introduce a number of regulatory protections for MSBs which

\footnotetext{
${ }^{1}$ Corresponding author: Dr David Deller, Centre for Competition Policy (CCP), University of East Anglia, Norwich Research Park, Norwich, Norfolk, NR4 7TJ, email: david.deller@uea.ac.uk. The support of Research Associate Glen Turner is gratefully acknowledged, as are the comments of Kai-Uwe Kuhn and members of CCP's 'Equity and Justice in Energy Markets' project team. This paper forms part of the UK Energy Research Centre's (UKERC) research programme. Professor Amelia Fletcher (also at CCP) is a Non-Executive Director on the Boards of the UK Financial Conduct Authority, Competition and Markets Authority and Payment Systems Regulator, and a decision-maker on enforcement cases at Ofgem. The views expressed here do not necessarily reflect the views of any organisation with which she is associated.

${ }^{2}$ See CMA (2016a). While the CMA specifically refers to microbusinesses there is no universally agreed cut-off between micro and small businesses. That the boundary is poorly delineated is reflected in Ofgem's microbusiness definition where a microbusiness is defined either by firm size or low consumption i.e. a large firm with low energy consumption would be counted as a microbusiness. Ofgem defines a microbusiness as a non-domestic customer who: (i) has fewer 10 full time employees or equivalent and an annual turnover (or balance sheet) of no more than $€ 2 \mathrm{~m}$, or (ii) annual electricity consumption below $100,000 \mathrm{kWH}$, or (iii) annual gas consumption below 293,000kWh (see pgA16.1-2, CMA, 2016b).
} 
are similar to those in place for residential customers. Nonetheless, price comparisons in the nondomestic market have been more challenging than in the domestic market. This is due to an absence of price comparison websites and energy prices, at least in theory, being the result of individual price negotiations.

This paper reports three main findings. First, the descriptive statistics on engagement and satisfaction suggest the energy market for MSBs is performing reasonably well. However, one exception is the marketing behaviour of energy brokers and suppliers. Additionally, that over half of MSBs are on multiyear fixed term energy contracts indicates that assessing MSB engagement in the same way as for domestic consumers, i.e. by focussing on the 12 -month switching rate, is likely to be problematic.

Second, ordered logit regressions indicate that an increase in the number of broker approaches recalled by MSBs is associated with reduced odds of an MSB reporting a positive overall opinion of energy brokers. This result holds even after controlling for whether an MSB used an energy broker as the main method to select their current energy supplier. These results are significant as the use of a broker in selecting an MSB's current energy deal is associated with a greater probability of having switched in the previous 5 years (see Appendix A for logit regressions detailing this finding). If MSBs have a low opinion of brokers, the main route for MSBs to search and switch in the non-domestic energy market will appear undesirable for them.

Third, MSBs with the very lowest energy expenditures have higher odds of reporting greater satisfaction with their current supplier's value for money and overall service compared to MSBs with moderate to large energy expenditures. The most straightforward explanation for this result is that for MSBs with the lowest energy expenditures the salience of energy is low and so, as long as a basic service is always provided, they are unlikely to express significant dissatisfaction with their supplier. These results suggest that MSBs with the lowest energy expenditures may have limited motivation to engage with the energy market and it is not clear these MSBs will respond to prompts to switch or appreciate receiving the prompts.

These results are directly relevant to the conclusions and policy recommendations of the CMA's market investigation. Mirroring its conclusion for the domestic retail market, the CMA concluded that increasing firms' engagement with the energy market would be beneficial. The CMA proposed a range of measures to improve the functioning of the non-domestic energy market; our results speak to two in particular: (i) a proposal to establish a database of 'disengaged' MSBs' contact details so that energy suppliers can send them marketing materials to encourage them to switch, and (ii) a proposal to require increased price transparency for smaller microbusinesses. ${ }^{3}$

Our results regarding MSBs' dislike of energy brokers' marketing contact suggests they are unlikely to welcome the CMA's database proposal if it involves significant additional marketing contact. When implementing this proposal, it seems important for Ofgem to limit the quantity of marketing material sent, for example, by using a 'trusted source' to send a limited number of communications identifying the cheapest deals on the market.

The dislike of excessive marketing, but the importance of brokers to MSB switching, also supports the case for greater regulatory oversight of third party intermediaries (TPIs). The challenge is to limit the

\footnotetext{
${ }^{3}$ Paragraph 17.20, pg 1144-1145, CMA (2016a). Noting the contrast with Ofgem's microbusiness definition in footnote 2, the CMA's price transparency remedy will only apply to microbusinesses customers meeting all of the following criteria: (i) electricity customers in profile classes 1 to 4, with consumption below 50,000kWh per annum and on 'simple' meters, and (ii) gas customers with 'small' supply points and consumption of less than 73,200kWh per annum.
} 
broker contact considered problematic without significantly impeding those communications that help MSBs to move to better energy deals. As noted by CMA (2016a), Ofgem does intend to implement a Code of Practice regarding non-domestic TPIs. . In addition, the CMA's price transparency remedy is intended to reduce the reliance of MSBs on TPIs when switching supplier.

Exploration of Ofgem's survey data raises two broader policy points. First, the sampling procedure means the survey only captures firms who are directly responsible for a non-domestic energy contract. MSBs where a landlord manages energy purchases are excluded. Moreover, in sampling only MSBs using a non-domestic contract, the survey does not capture MSBs who are on domestic supply contracts. Overall, it is estimated around half of all MSBs in the UK are excluded from the sampling frame (see BMG, 2015 for detail). Not sampling MSBs on domestic supply contracts means Ofgem's survey data cannot investigate how MSBs choose between domestic and non-domestic contracts.

Second, our analysis highlights the potential benefits from regulators' allowing academics and other parties access to the survey data they collect using public money. External parties can identify insights from, and methodological issues with, survey data that a regulator may not have the resources to explore itself. Maximising the insights from existing survey data should hopefully ensure high quality information is used to take regulatory decisions thereby helping to ensure the best outcomes are achieved for consumers. We propose a presumption in favour of sharing the anonymised raw survey data commissioned by UK regulators, with a public explanation to be provided where this is not possible. UK regulators' current approach appears inconsistent. The current analysis utilised anonymised raw survey data to which we were given special access by Ofgem and, even then, data on MSBs' current supplier was withheld. By contrast, Ofcom (the UK telecoms regulator) makes the equivalent raw survey data regarding Small and Medium-Sized Enterprises (SMEs) engagement with the telecoms market publicly available on its website, including data on MSBs' current supplier.

The paper proceeds as follows: Section 2 reviews the existing literature, before Section 3 describes the main econometric method and Section 4 describes the data. Section 5 reports results and Section 6 delivers policy-relevant conclusions. Appendix A reports results from logit regressions looking at factors associated with MSBs having switched in the five years prior to the survey. A range of additional appendices provide further detail on the data used and supporting results.

\section{Background and Literature Review}

We believe this paper provides the first econometric assessment of MSBs' satisfaction and engagement with the retail energy market. Focusing on the retail energy market marks a departure from earlier academic work investigating MSBs' energy efficiency investments.

Since 2012 Ofgem has commissioned annual surveys of non-domestic customers in the British retail energy market. ${ }^{4}$ These reports typically focus on whether satisfaction and engagement vary by firm size, and are the result of increased concern following Ofgem's Retail Market Review around MSBs' ability to navigate the non-domestic energy market. This concern for MSBs is also reflected in the CMA's Energy Market Investigation. ${ }^{5}$ Significantly, the CMA's decision making appears reliant on analysis of descriptive statistics, primarily from the Ofgem survey reports detailed above. The current multivariate analysis therefore marks an advance beyond existing policymaking by assessing whether

\footnotetext{
${ }^{4}$ Carried out by Accent Scotland (2012), The Research Perspective/Element Energy (2014), BMG (2015), BMG (2016) and Quadrangle (2017). A qualitative survey (Harris International, 2011) was conducted in 2011.

${ }^{5}$ See Sections 16 and 17 of CMA (2016a), and CMA (2016b).
} 
conclusions from the descriptive statistics of individual variables are robust to controlling for a large number of variables.

Beyond Ofgem's MSB survey evidence, we are aware of survey evidence from the Federation of Small Businesses (FSB) (2014) and Cornwall Energy (2013). Compared to the Ofgem data, the FSB survey is less representative, being a self-selected sample of FSB members, while the Cornwall Energy survey is noticeably smaller in scale. Among other sector regulators, Ofcom has conducted Small and MediumSized Enterprise (SME) ${ }^{6}$ engagement surveys in 2010, 2014 and 2016 ${ }^{7}$, while smaller scale surveys and qualitative research on SMEs and financial service products have been commissioned by the CMA and FCA. ${ }^{8}$

While the policymaking literature focuses on the retail purchasing of energy, the academic literature focuses on firms' energy use and efforts to reduce consumption, primarily through energy efficiency investments. Andrews and Johnson (2016) note that, beyond energy efficiency, there has been relatively little research into the energy behaviours of business organisations. The current paper therefore expands the academic understanding of MSB's energy behaviours to market engagement.

Papers looking at energy efficiency investments among SMEs include: Cagno and Trianni (2013), Cooremans (2011), Cooremans (2012), Fleiter et al (2012), Trianni and Cagno (2012), Trianni et al (2013a), Trianni et al (2013b) and Trianni et al (2016). ${ }^{9}$ Central to this literature is consideration of the barriers to firms investing in energy efficiency projects that on paper offer positive financial returns. As this literature considers an investment decision, some of the barriers are less relevant to energy market engagement, in particular, access to financing and the methods used to assess projects' financial returns. However, other issues are relevant, in particular, MSBs' capacity to analyse 'technical' information, the time available to consider energy costs, and the inclination of MSBs' managers to consider energy issues. For example, Coles et al (2016) and Trianni et al (2013a) note energy management is generally not a strategic imperative for firms.

The present paper also speaks to research looking at SMEs' satisfaction with service providers beyond the energy market. Given the primacy of financing to SMEs' growth/survival, a particular focus has been satisfaction with banks. Papers include: Chaston (1993), Binks and Ennew (1997), Madill et al (2002), Ibbotson and Moran (2003) and Lundahl et al (2009). Apart from Binks and Ennew and Madill et al, these papers use noticeably smaller samples than our analysis. Our research has a different emphasis to these papers as it investigates whether satisfaction varies across customer characteristics and their interactions with intermediaries rather than by supplier behaviour.

The banking studies also reflect the relative complexity of banking compared to energy, with satisfaction being framed around the banking 'relationship' rather than the purchase of a defined product. Ennew and Binks (1996), Binks and Ennew (1997), Howarth et al (2003), Lam and Burton (2005), Lam and Burton (2006) and Lam et al (2009) go beyond the factors associated with satisfaction to consider how satisfaction is associated with SMEs' switching behaviour. Here the emphasis is on helping banks to retain customers rather than addressing broader regulatory questions. Beyond banking, Bennett and Robson (2005) and Ramsden and Bennett (2005) consider SMEs' satisfaction

\footnotetext{
${ }^{6}$ Most of the literature uses the term SMEs rather than MSBs. As with definitions of MSBs, definitions of SMEs likely vary between studies.

${ }^{7}$ See Jigsaw (2014) and Jigsaw (2017). Ofcom has also commissioned the following qualitative research: Jigsaw (2015) and Analysys Mason (2015).

${ }^{8}$ See Quadrangle (2015), Research Works (2015) and CMA (2015).

${ }^{9}$ Policy papers covering SMEs and energy efficiency investments include: DECC (2012), DECC (2014) and IEA (2015).
} 
with business advisory services and Suarez et al (2016) consider satisfaction with internet and mobile phone services in Spain.

\section{Methodology}

The main econometric analysis involves ordered logit models where the dependent variables are different satisfaction metrics. Generalised ordered logit models are also used as a robustness check. In Appendix A a logit model for whether or not a firm has switched in the 5 years prior to the survey is reported.

\subsection{Ordered Logit Model for Satisfaction Variables}

After dropping Don't Know/Not Applicable observations, the categories of the satisfaction variables have a clear order: Very Satisfied lies above Neither Satisfied nor Dissatisfied etc.; this means an ordered logit model is appropriate. Ordered logit models can be motivated by assuming an underlying latent variable, $y^{*}$, running from $-\infty$ to $\infty$ which can be modelled as:

$$
y_{i}^{*}=\boldsymbol{x}_{\boldsymbol{i}}^{\prime} \boldsymbol{\beta}+\varepsilon_{i}
$$

where $y_{i}^{*}$ is the value of the latent variable for firm $i, \boldsymbol{x}_{\boldsymbol{i}}$ is the vector of explanatory variables for firm $i, \boldsymbol{\beta}$ is the vector of coefficients to be estimated and $\varepsilon_{i}$ is the error term for firm $i$. Rather than observing $y_{i}^{*}$, we observe $y_{i}$ which is divided into $J$ ordinal categories such that:

$$
y_{i}=m \text { if } \tau_{m-1} \leq y_{i}^{*}<\tau_{m} \text { for } m=1 \text { to } J
$$

where $m$ is the category observed, e.g. Satisfied, and the thresholds $\tau_{1}$ to $\tau_{J-1}$ are estimated. Supposing $y_{i}$ represents satisfaction, the observed categories can be linked to the latent variable in the following way:

$$
y_{i}=\left\{\begin{array}{cl}
1, \text { Very Dissatisfied } & \text { if }-\infty \leq y_{i}^{*}<\tau_{1} \\
2, \text { Quite Dissatisfied } & \text { if } \tau_{1} \leq y_{i}^{*}<\tau_{2} \\
3, \text { Neither Satisfied nor Dissatisfied } & \text { if } \tau_{2} \leq y_{i}^{*}<\tau_{3} \\
4, \text { Quite Satisfied } & \text { if } \tau_{3} \leq y_{i}^{*}<\tau_{4} \\
5, \text { Very Satisfied } & \text { if } \tau_{4} \leq y_{i}^{*}<\infty
\end{array}\right.
$$

The probability of observing a given category, $y_{i}=m$, is the probability that $y_{i}^{*}$ falls between the relevant thresholds:

$$
\begin{gathered}
\operatorname{Prob}\left(y_{i}=m \mid \boldsymbol{x}_{\boldsymbol{i}}\right)=\operatorname{Prob}\left(\tau_{m-1} \leq y_{i}^{*}<\tau_{m} \mid \boldsymbol{x}_{\boldsymbol{i}}\right) \\
=\operatorname{Prob}\left(\tau_{m-1} \leq \boldsymbol{x}_{\boldsymbol{i}}^{\prime} \boldsymbol{\beta}+\varepsilon<\tau_{m} \mid \boldsymbol{x}_{\boldsymbol{i}}\right) \\
=F\left(\tau_{m}-\boldsymbol{x}_{\boldsymbol{i}}^{\prime} \boldsymbol{\beta}\right)-F\left(\tau_{m-1}-\boldsymbol{x}_{\boldsymbol{i}}^{\prime} \boldsymbol{\beta}\right)
\end{gathered}
$$

where $F$ is the cumulative density function of $\varepsilon_{i}$, which in the ordered logit model is the logistic distribution. Maximum likelihood estimation is used and the regression's intercept is set to zero so each of the thresholds are estimated.

In ordered logit models the relationship between the signs of the regression coefficients and the marginal effects of being in a particular category are only unambiguous for the highest and lowest categories. It is easiest to interpret the model by taking the exponent of the coefficients to obtain odds ratios.

Consider the odds, $\Omega$, of reporting Very Satisfied relative to Quite Satisfied or less: 


$$
\Omega\left(\boldsymbol{x}_{i}\right) \equiv \frac{\operatorname{Prob}\left(y_{i}>\text { Quite Satisfied } \mid \boldsymbol{x}_{i}\right)}{\operatorname{Prob}\left(y_{i} \leq \text { Quite Satisfied } \mid \boldsymbol{x}_{i}\right)}
$$

For an ordered logit model containing $k$ explanatory variables, the exponent of the regression coefficient, $\beta_{k}$, shows the multiplicative effect of a unit change in the variable $x_{k}$ on the odds $\Omega$. The exponent of $\beta_{k}$ is the odds ratio; if greater than one, increasing $x_{k}$ increases the odds of a higher satisfaction level occurring, while if less than one, increasing $x_{k}$ reduces the odds of a higher satisfaction level occurring.

The ordered logit model incorporates the proportional odds assumption. ${ }^{10}$ This assumption is the main difference between ordered logit and multinomial logit models and results in the ordered logit model having only one set of coefficients. The proportional odds assumption implies that regardless of the categories used to define $\Omega$ a unit change in $x_{k}$ will have the same impact on $\Omega$. The main analysis thus assumes the proportional odds assumption holds.

To check the results' robustness to relaxing the proportional odds assumption important regressions are re-run using the generalised ordered logit model. Relaxing the proportional odds assumption means we allow $\beta$ to vary for each boundary between satisfaction categories such that equation (1) becomes:

$$
\operatorname{Prob}\left(y_{i}=m \mid \boldsymbol{x}_{\boldsymbol{i}}\right)=F\left(\tau_{m}-\boldsymbol{x}_{\boldsymbol{i}}^{\prime} \boldsymbol{\beta}_{\boldsymbol{m}}\right)-F\left(\tau_{m-1}-\boldsymbol{x}_{\boldsymbol{i}}^{\prime} \boldsymbol{\beta}_{\boldsymbol{m}-\mathbf{1}}\right)
$$

Given the relatively small sample size and the large number of categorical variables it is important the number of coefficients being estimated is minimised. Hence, we run the generalised ordered logit model as a partial proportional odds model. Here the final model run allows $\beta$ to vary for those variables where the proportional odds assumption is violated and holds $\beta$ fixed for those variables where the proportional odds assumption is not rejected. A stepwise process is used to determine which variables are constrained to have proportional odds. Initially no variables are constrained and then repeated Wald tests are performed to determine for which variables the proportional odds assumption is rejected. Due to the large number of categorical variables in the regressions the Wald tests are performed at the $1 \%$ significance level; in other words, only if the hypothesis of proportional odds is rejected at the $1 \%$ level, are the coefficients of a particular variable left unconstrained.

\subsection{Explanatory Variables}

The main explanatory variables of interest are: (i) annual energy expenditure ${ }^{11}$, (ii) the recalled number of broker approaches received in the last 12 months, and (iii) an MSB's main method for selecting their current energy deal. The control variables are split into two sets: (i) demographic and (ii) engagement variables. The full set of demographic control variables are: GB nation, sole or joint responsibility for energy, number of employees, sector, whether a franchise or not, turnover, whether a home-based business, whether the MSB has a single energy supplier and whether the questionnaire referred to gas or electricity. The full set of engagement control variables are: whether the MSB has switched in the past five years, recollection of receiving a bill, number of broker approaches, whether the MSB reviews energy supply arrangements on receipt of a bill, whether the MSB has a smart meter, payment method, main method for choosing current deal, knowledge of contract end date and whether the current contract has been read.

\footnotetext{
${ }^{10}$ More generally ordinal regression models involve the parallel regression assumption.

${ }^{11}$ If a respondent failed to report electricity (gas) expenditure in continuous form, they were prompted to indicate the category into which their expenditure fell. To create the total energy expenditure variable, where a respondent only gave a categorical response, the mid-point of their expenditure category was used.
} 
We run: (i) univariate regressions, (ii) regressions with demographic controls, and (iii) regressions with both demographic and engagement controls. Running regressions without the engagement controls shows the associations without the risk of endogeneity issues that may be introduced by some of the engagement variables. The univariate regressions in Appendix B show the strength of association between important explanatory variables and the dependent variables when all controls are excluded and the risk of multi-collinearity is removed. ${ }^{12}$

\section{Data}

This paper utilises survey data from the energy regulator in Great Britain, Ofgem. Access was provided to data from 2014 and 2015, with the main analysis using data collected in October and November 2014. The surveys were designed to be representative of private sector MSBs (defined as businesses with 49 employees or fewer) in Great Britain who were responsible for energy purchases and on nondomestic energy supply contracts. Excluding firms on domestic contracts implies smaller home-based businesses with low energy consumption, e.g. consultancies run from home offices or trades people working at customer properties, are likely excluded from the sample. Also, firms in premises where a landlord manages energy contracts are excluded. Despite these issues, the data is the most representative available for assessing MSB's satisfaction and engagement with the British energy market. The survey methodology is described in full in Appendix 3 of BMG (2015) and BMG (2016). All references to MSBs refer to the subset of MSBs sampled by Ofgem unless stated otherwise.

The sampling was designed to achieve a minimum number of interviews for firms operating in different sectors and with different numbers of employees; firms possessing 5 or more employees were oversampled. While not representative of the full MSB population, the sample design likely ensures the MSBs of greatest economic significance are covered. In total 1,502 firms were sampled in 2014.

The regression analysis uses an unweighted dataset, but the oversampling of larger MSBs means descriptive statistics representative of MSBs on non-domestic supply contracts requires the application of weights. Even after applying weights it is likely the survey was completed by relatively engaged firms; BMG (2015) reports $40 \%$ of contacted firms refused to take part, a refusal rate they considered high.

A complication of the survey design is that, after questions on business characteristics, most of the questionnaire referred to only one fuel, either electricity or gas. ${ }^{13}$ Since $53.7 \%$ of respondent firms only consumed electricity, in the regression analysis we only consider data for firms providing answers applicable to their electricity supplier. The analysed data in 2014 therefore comprises three types of MSBs: (i) those only consuming electricity, (ii) those purchasing both electricity and gas from the same supplier, and (iii) those purchasing electricity and gas from separate suppliers where the questionnaire referenced electricity. We include dummy variables in the regressions indicating when firms had a single energy supplier and when the questionnaire referenced gas.

The regressions in the main text consider four dependent variables:

\footnotetext{
${ }^{12}$ Appendix $C$ reports the small number of cases where the proportional odds assumption is violated in the univariate regressions in Appendix $B$.

${ }^{13}$ If a firm used both fuels, the interviewer was supposed to randomly select the fuel to refer to in the questionnaire.
} 


\section{Overall view of energy brokers}

2. Satisfaction with the ease of comparing prices in the energy market

3. Satisfaction with current supplier's value for money

4. Satisfaction with current supplier's overall service

Each of the variables are five-point lickert scales. For variable 1 the scale runs from Very Negative to Very Positive, while for variables 2 to 4 the scale runs from Very Dissatisfied to Very Satisfied. To ensure a consistent dataset across the regressions we drop firms answering Don't Know/Not Applicable to any of the dependent variables. ${ }^{14}$ To ensure valid responses we also drop observations where the respondent did not have responsibility for all fuels at all sites and where firms were recorded as without a gas connection but which were nevertheless recorded as answering questions referencing gas. The final analysed sample comprises 1,083 firms.

Appendix E illustrates the key differences between the firms analysed in the regressions and the estimated characteristics of the population targeted by the survey. Beyond the skew to larger firms reflected in their number of employees, turnover and energy expenditures, Figure E3 shows differences between the sectors of analysed firms and the target population with. Most notably, $15.5 \%$ of firms in the analysed sample are from the Retail/Wholesale sector compared to a population estimate of $28.0 \%$.

Turning to the dependent variables (see Appendix F), the distribution of responses to the satisfaction indicators is broadly similar when comparing the analysed sample and population estimates. The main difference is the deliberate removal of Don't Know/Not Applicable responses from the analysed sample. This has a larger impact for the market indicators than for the current supplier indicators; the population estimate for the proportion of firms not rating their current supplier's value for money is $2.7 \%$ compared to $7.4 \%$ for the competitive of prices in the market. Potentially related to the removal of uncertain responses, Table E2 shows analysed firms are more engaged than the population estimates. For example, $65.7 \%$ of analysed firms report switching in the previous 5 years compared to a population estimate of $59.8 \%$.

We focus on the 2014 survey data as it is more amenable to analysis than the data from 2015. First, the 2014 dataset reports whether the interviewer referenced electricity or gas in the questionnaire. Second, in 2014, number of employees, turnover, electricity expenditure, gas expenditure and number of broker approaches are recorded as continuous as well as categorical variables. Nevertheless, the 2015 data is used as a robustness check for the main 2014 results.

A condition of our data access was that the identity of respondent firms' energy supplier(s) were not provided. As a result, the regressions do not control for individual suppliers' idiosyncratic characteristics.

\section{Results and Discussion}

In this section, we set the scene with some descriptive statistics before turning to our main regression results. Our regressions focus on the associations of (i) the quantity of broker contact and (ii) energy expenditure with MSBs' satisfaction with brokers and suppliers.

\footnotetext{
${ }^{14}$ Firms failing to answer whether they had switched in the last 5 years are also dropped.
} 


\subsection{Descriptive Statistics}

The descriptive statistics below provide an overview of the MSB energy market and contextualise the CMA's remedy proposals. The reported descriptive statistics are weighted population estimates, unless stated otherwise. Appendix E provides descriptive statistics covering the characteristics of the analysed MSBs. The descriptive statistics in the main text cover three areas: (i) the switching rate, (ii) satisfaction with current supplier, and (iii) satisfaction with the market. The message from (i) and (ii) appears broadly positive. Once the length of contracts is accounted for, the annualised switching rate appears high (compared to the residential market) and the percentage of respondents satisfied with their current energy supplier noticeably outnumbers the percentage who are dissatisfied. If the majority of consumers are satisfied with their supplier and switch reasonably frequently, it is not immediately obvious that the MSB market is 'failing' and requires significant intervention. However, especially with the switching rate, this positive impression may be affected by the sampling methodology.

Satisfaction with 'the market' is more neutral and there is a significant dissatisfaction with the sales approaches of energy suppliers and brokers. However, more MSBs report satisfaction with the ease of switching supplier than report dissatisfaction.

\subsubsection{The Switching Rate}

Debate about the residential energy market often focuses on the rate of switching between suppliers, generally assessed over a 12-month period. In contrast to the residential market, where almost all fixed-term contracts cover 12 months, when considering MSBs' switching rate it is necessary to account for multi-year fixed-term contracts. $53.9 \%{ }^{15}$ of MSBs are estimated to have a fixed-term contract lasting 2 years or more. Also, while residential contracts can be broken by paying a relatively small penalty fee, non-domestic contracts can only be broken by paying the contract's full value. ${ }^{16}$ Due to the prevalence of multi-year fixed term contracts the dependent variable in Appendix $A$ is whether firms switched at least once in the 5 years prior to the survey. ${ }^{17}$

In 2014 the estimated percentage of firms switching at least once in the previous 5 years was $59.8 \%$ $(65.7 \%$ in the analysed sample), while the estimated 12 -month switching rate was $23.4 \%(26.3 \%$ in the analysed sample). This is almost double the estimated 12-month residential switching rate of $13 \%$ for electricity and gas in 2014. ${ }^{18}$ Accounting for multi-year contracts gives a 12-month MSB switching rate that is higher still.

An approximate adjustment to the 12-month switching rate, to account for multi-year contracts, can be made by considering the proportion of firms free to switch in a given year. For example, for firms with two-year contracts a reasonable starting assumption is that $50 \%$ can switch in any 12 -month period, while for firms with three year contracts one might expect $33.3 \%$ can switch in a given year.

\footnotetext{
${ }^{15}$ Those with evergreen contracts or who were unsure about the nature of their contract are included in the denominator (not the numerator) for this percentage.

${ }^{16}$ Paragraph 29(a)(i), pg A16.1-13, CMA (2016b)

${ }^{17}$ However, considering the five year switching rate introduces other issues, in particular, that some small firms will not have been in operation for five years.

${ }^{18}$ See pg10, Ipsos MORI (2014), a survey for Ofgem. BEIS's aggregate switching data indicates a slightly lower residential switching rate of $10.9 \%$ for electricity and $10.3 \%$ for gas in 2014 ( Table 2.7 .1 'Transfer statistics in the domestic gas and electricity markets in Great Britain (annual)', available at:

https://www.gov.uk/government/statistical-data-sets/quarterly-domestic-energy-switching-statistics). The slightly higher survey switching rate likely reflects survey response bias: more 'engaged' consumers are more likely to participate in surveys.
} 
Multiplying the percentage of firms with a given contract length by the likely fraction of firms who can switch per year and then summing across the different contract lengths gives the total percentage of firms able to switch in a 12-month period. This method indicates $68 \%$ of firms were likely to have been able to switch in the 12 months prior to the 2014 survey. ${ }^{19}$ Using $68 \%$ as the base for the switching rate gives a 12 -month switching rate of $34.3 \%$ (39.5\% in the analysed sample).

While these switching rates present a positive story about MSBs' engagement, the conclusions need to be tempered by recognising how survey design and response may influence the results. First, BMG $(2015)^{20}$ note the survey refusal rate was considered high at $40 \%$. In particular, BMG report that many refusals resulted from 'a lack of time' and also some difficulties were encountered convincing potential participants that the survey was genuine and not a disguised sales call. A conservative starting assumption would be that survey respondents are more engaged than the underlying population of MSBs.

Second, we note that there is a significant increase in the switching rate between the 2013 and 2014 Ofgem surveys ${ }^{21}$, and that the sampling methodology also changed between these two years. In 2013 the recorded switching rates were noticeably lower: the 12-month switching rate was no more than $18 \%$, while the five year switching rate was no higher than $40 \% .{ }^{22}$ That the five-year switching rate is around 20 percentage points lower in 2013 than 2014 is striking. In 2013 the sampling method did not explicitly exclude firms on domestic contracts or where the landlord held the energy supply contract, instead it simply required that firms did not operate exclusively from a residential address. ${ }^{23}$

Third, the 2014 switching rate is substantially above that obtained from aggregate switching statistics. Using aggregate switching data, Ofgem (2015) reports the annual switching rate between July 2014 and June 2015 was 13\% for non-half-hourly metered electricity, 15\% for half-hourly metered electricity and $19 \%$ for gas. ${ }^{24}$

\footnotetext{
${ }^{19}$ To be conservative these figures assume all firms without a fixed-term contract or who did not know their contract type/length can freely switch at any time. Also, firms who could not recall their switching behaviour are assumed not to have switched.

${ }^{20}$ See pg81.

${ }^{21}$ BMG (2014) cautions that the 2013 and 2014 results are not comparable, i.e. differences in the results may be influenced by the surveys' designs.

22 Table 17, pg42, The Research Perspective/Element Energy (2013).

${ }^{23}$ pg11, The Research Perspective/Element Energy (2013).

24 para 3.55, pg 34, Ofgem (2015). Since this aggregate data is based on firms of all sizes (not only MSBs), in theory, the difference to the survey figures might be possible to reconcile. However, we are not aware of any evidence that actually suggests the two sets of figures can be reconciled.
} 


\subsubsection{Satisfaction with current supplier}

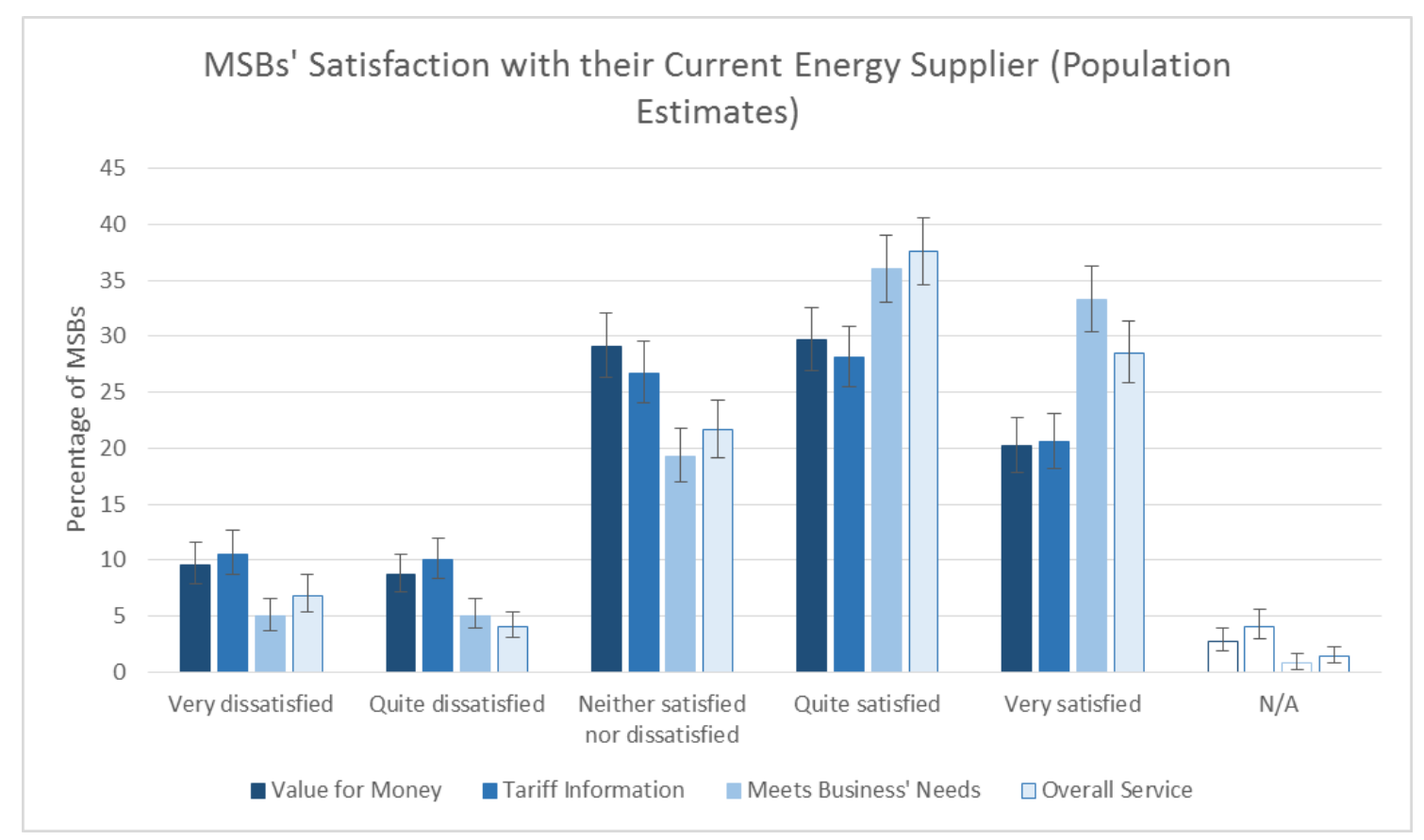

Figure 1: MSBs' satisfaction with their current energy supplier ${ }^{25}$

Figure 1 shows the consistently positive view of respondents regarding their current energy supplier. The percentage of respondents Quite Satisfied or Very Satisfied with their current supplier is between 2.4 times (for information on tariffs/options) and 6.9 times (for meeting business' needs) the percentage who are Quite Dissatisfied or Very Dissatisfied.

\subsubsection{Satisfaction with the market}

While firms appear satisfied with their current suppliers, their view of the market is less positive, and varies noticeably between indicators. Where the market is considered in general terms, the responses are broadly neutral, as shown in Figure 2 .

However, when suppliers and brokers are referenced the views becomenegatively skewed, as shown in Figure 3. This negativity is particularly strong for brokers with 31.5\% of MSBs being Very Dissatisfied with brokers' sales approach and $27.1 \%$ of MSBs having a Very Negative overall view of brokers. The percentage of firms who report being Quite Dissatisfied or Very Dissatisfied with brokers' sales approach is 2.6 times the percentage who report being Quite Satisfied or Very Satisfied, while the percentage with a Quite Negative or Very Negative overall opinion of brokers is 2.2 times those holding a Quite Positive or Very Positive opinion.

\footnotetext{
${ }^{25} \mathrm{~N} / \mathrm{A}$ refers to responses of Don't Know and Refused. In all figures in this paper, the 'whiskers' represent the $95 \%$ confidence interval around the population estimate.
} 


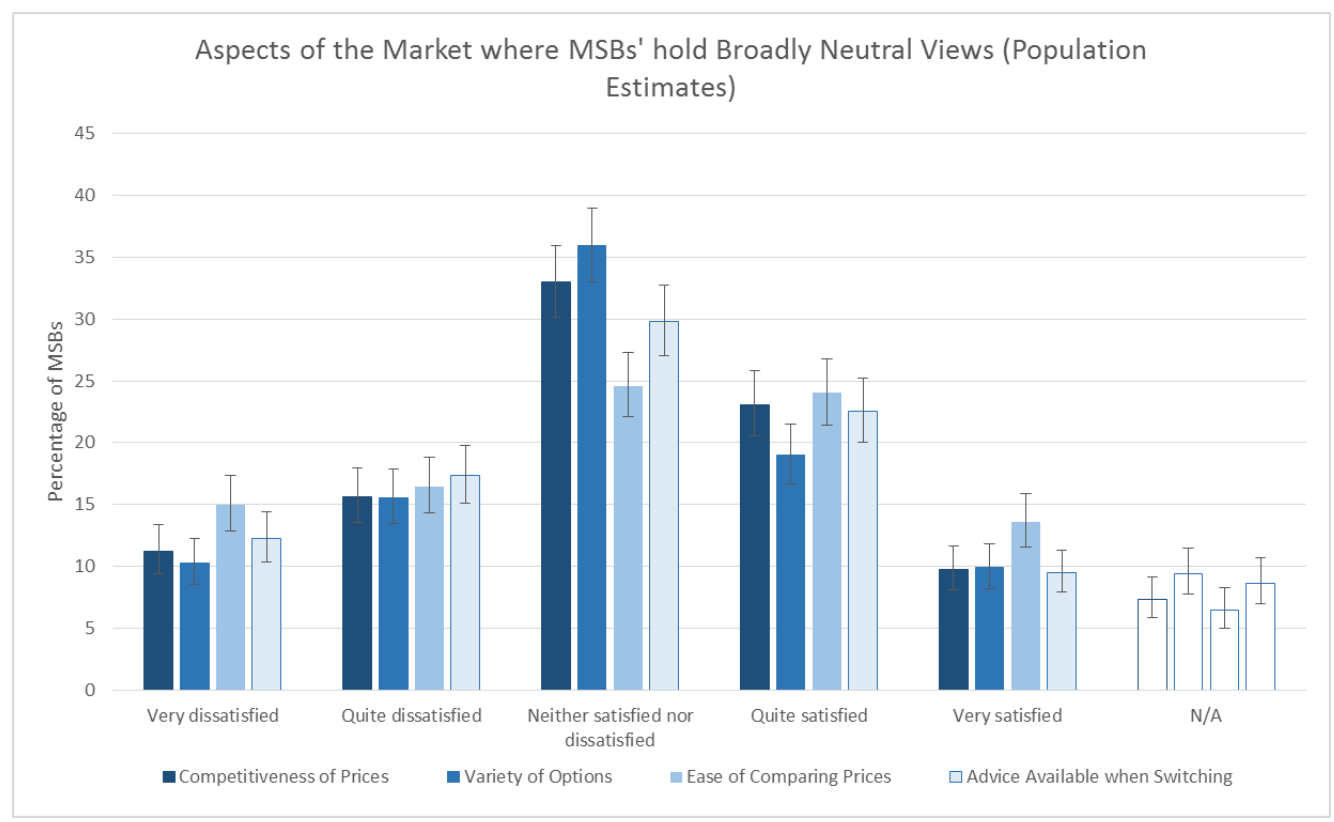

Figure 2: Aspects of the market where MSBs' views are broadly neutral

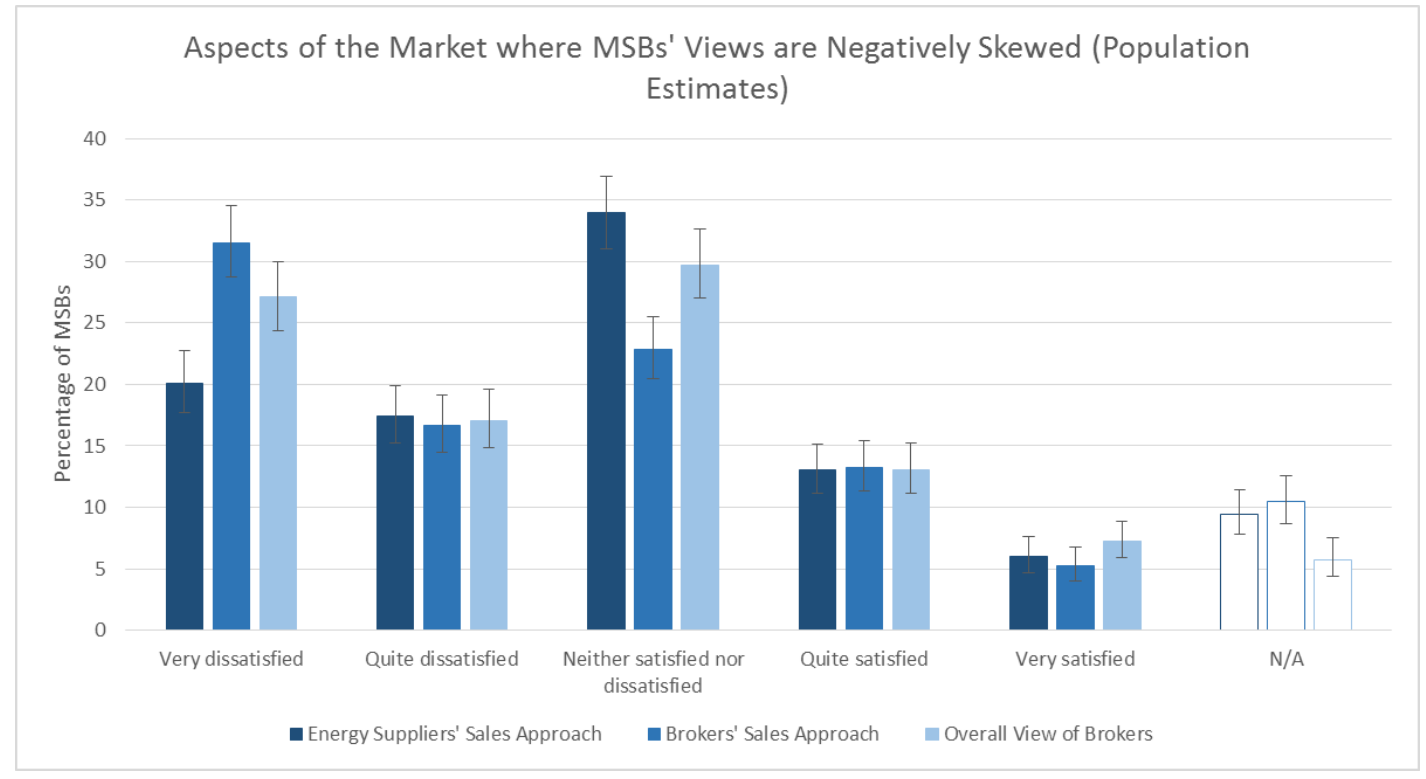

Figure 3: Aspects of the market where MSBs' views are negatively skewed ${ }^{26}$

Figure 4 shows there is also one aspect of the market where MSBs' views are positively skewed: the ease of switching supplier. The percentage of MSBs' reporting being Quite Satisfied or Very Satisfied with the ease of switching supplier is 1.9 times the percentage reporting Quite Dissatisfied or Very Dissatisfied. While there may be room for improvement, this result does not provide obvious support for a general policy need to make switching easier or policy interventions that carry downside risks.

\footnotetext{
${ }^{26}$ In the survey questionnaire the scale for the Overall View of Brokers ran from Very negative to Very positive and N/A was Don't Know.
} 
However, the high percentage of MSBs not rating the ease of switching (14.1\%) relates to firms that have not switched in the recent past ${ }^{27}$, these inactive MSBs may benefit from an engagement remedy.

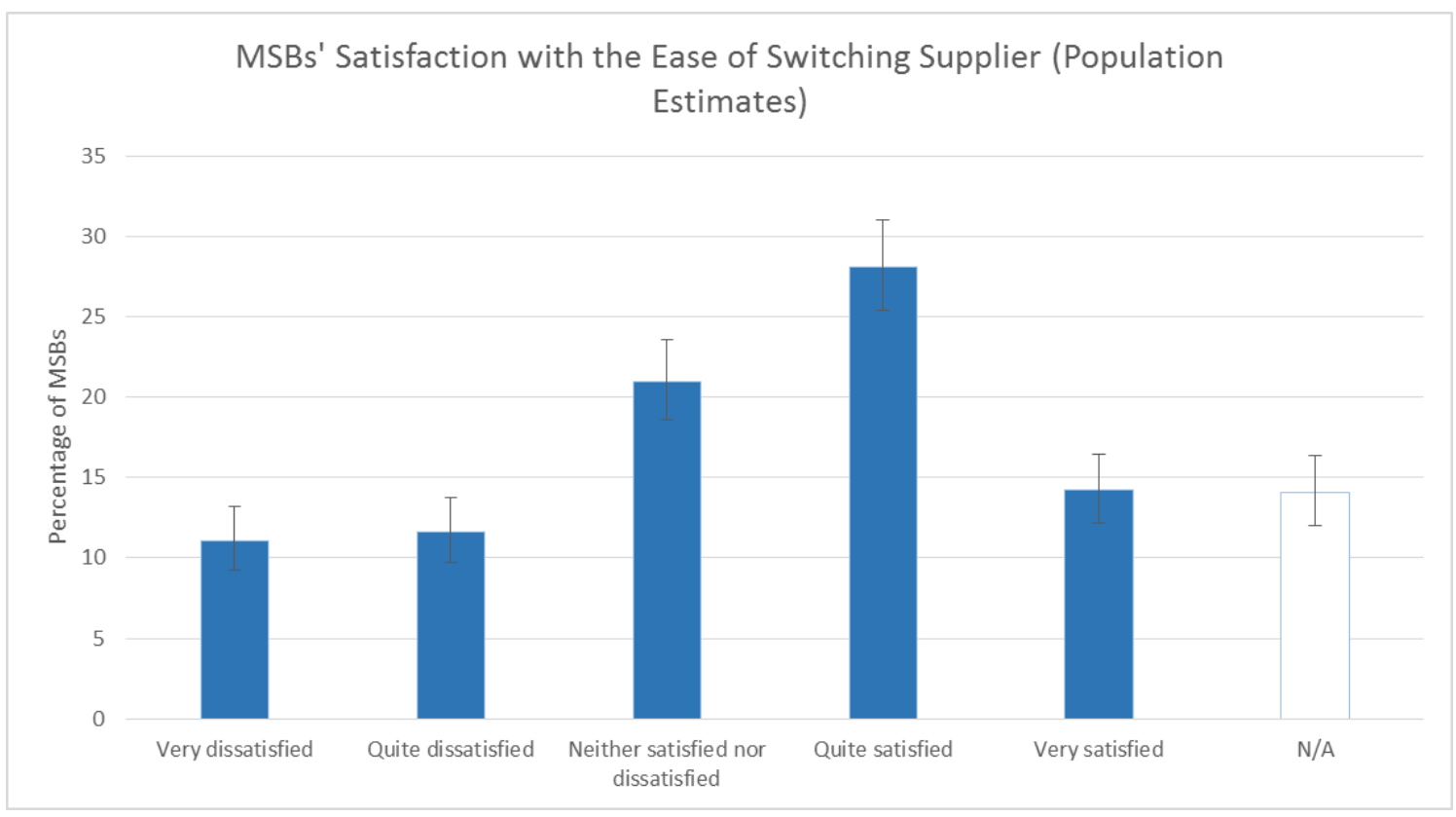

Figure 4: MSBs' view of the ease of switching supplier

It is also possible to test formally whether MSBs have systematically more positive or negative views of particular issues by applying a matched pairs sign test ${ }^{28}$. Focusing on the analysed sample and the dependent variables used in the regressions, one can state that MSBs' satisfaction with their current supplier's value for money and overall service is higher than with all the market characteristics in Figure 2 at the $1 \%$ level. MSBs' overall opinion of brokers is lower than their satisfaction with the market characteristics in Figure 2 at the 1\% level, while MSBs' satisfaction with the ease of switching is higher than their satisfaction with Figure 2's market characteristics.

\subsubsection{Detail on MSBs' View of Brokers}

The logit regressions in Appendix A (see Table A1) indicate a strong association between an MSB having used a broker to select their current energy supply deal and having switched in the five years prior to interview. Among those MSBs who had switched in the five years prior to interview, the most common method of choosing their current deal was by using a broker; $36.7 \%$ of those who had switched used a broker. ${ }^{29}$ Equally, the regressions suggest that receiving a large number of approaches from brokers is not associated with an increased probability of having switched. Here we present further descriptive statistics regarding MSBs' opinion of brokers. The policy challenge is to minimise brokers' marketing contact, which MSBs dislike, while still ensuring that MSBs access brokers that provide a useful service.

\footnotetext{
$2780.6 \%$ of those responding N/A are estimated to have not switched in the five years prior to the survey, even among those who were Very Dissatisfied with the ease of switching the rate of not having switched was only $39.4 \%$.

${ }^{28}$ Here a numerical value is used for each category, in this instance from 1 for Very Dissatisfied running to 5 for Very Satisfied. The matched pairs sign test tests whether the median value of the difference between two of the indicators is zero.

${ }^{29}$ The next most common choice method was consulting a range of suppliers, with $24.7 \%$ of switchers using this method.
} 
$25.8 \%$ of MSBs used a broker as their main method to choose their current supplier/tariff, while another $29.9 \%$ of firms had contacted or been approached by a broker but used an alternative method to select their current supplier/tariff. Significantly, but unsurprisingly, Figure 5 shows firms' opinion of brokers varies with the nature of their contact with brokers.

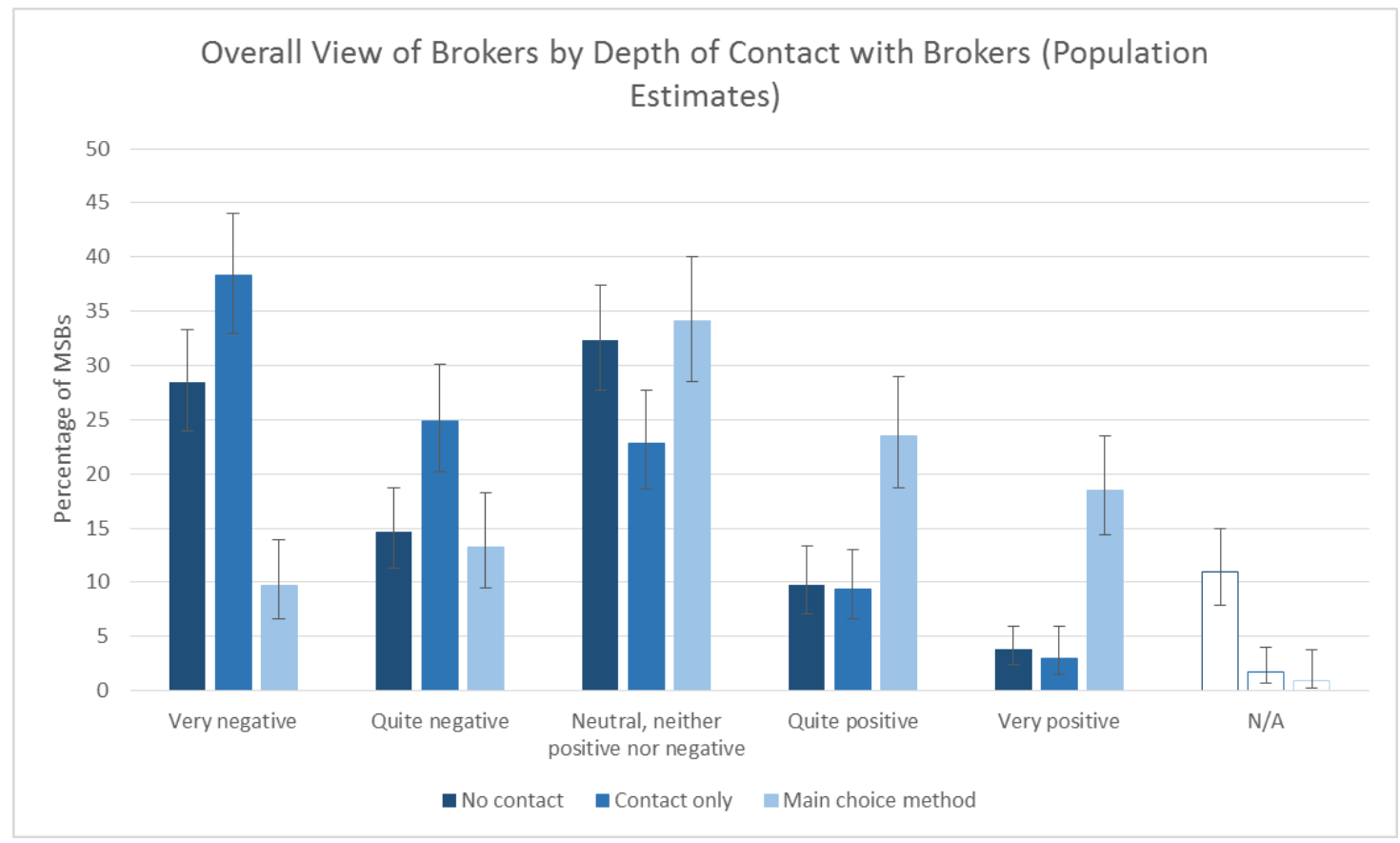

Figure 5: Overall view of brokers by MSBs' use of brokers when selecting current supplier/tariff

First, firms who used a broker as their main choice method tend to have a positive view of brokers. This could reflect the fact that brokers, when used to perform a search of the market, provide a good service. Certainly, it suggests that removing brokers from the market entirely would not be justified: for a subset of firms they appear to provide a valued service. However, the $30 \%$ of firms who had contact with a broker ${ }^{30}$, but did not use a broker as their main choice method, had the lowest opinion of brokers: $38.3 \%$ have a Very Negative view of brokers. This result is due to those MSBs who had a negative experience of brokers when contacted by them, being particularly unlikely to use them for their main choice method. However, it is not entirely clear whether this 'negative experience' is simply receiving unwelcome marketing contact or something more fundamental with the service of provided by brokers.

Figure 6 shows that the number of broker approaches appears strongly associated with negative views of brokers. While $15.7 \%$ of MSBs recalling 1 to 5 broker approaches reported a Very Negative view of brokers, this figure rises to $32.9 \%$ for MSBs receiving 11 to 20 approaches and $52.7 \%$ for firms receiving over 50 approaches/too many approaches to remember. However, one might question how accurately respondents can recall the precise number of approaches received, especially when the stated number is large. Also, reporting a large number of approaches may reflect a particular dislike of broker contact.

\footnotetext{
${ }^{30}$ We do not know the proportion of firms that initiated contact with the broker they used to select their current deal compared to where the initial contact was unsolicited.
} 


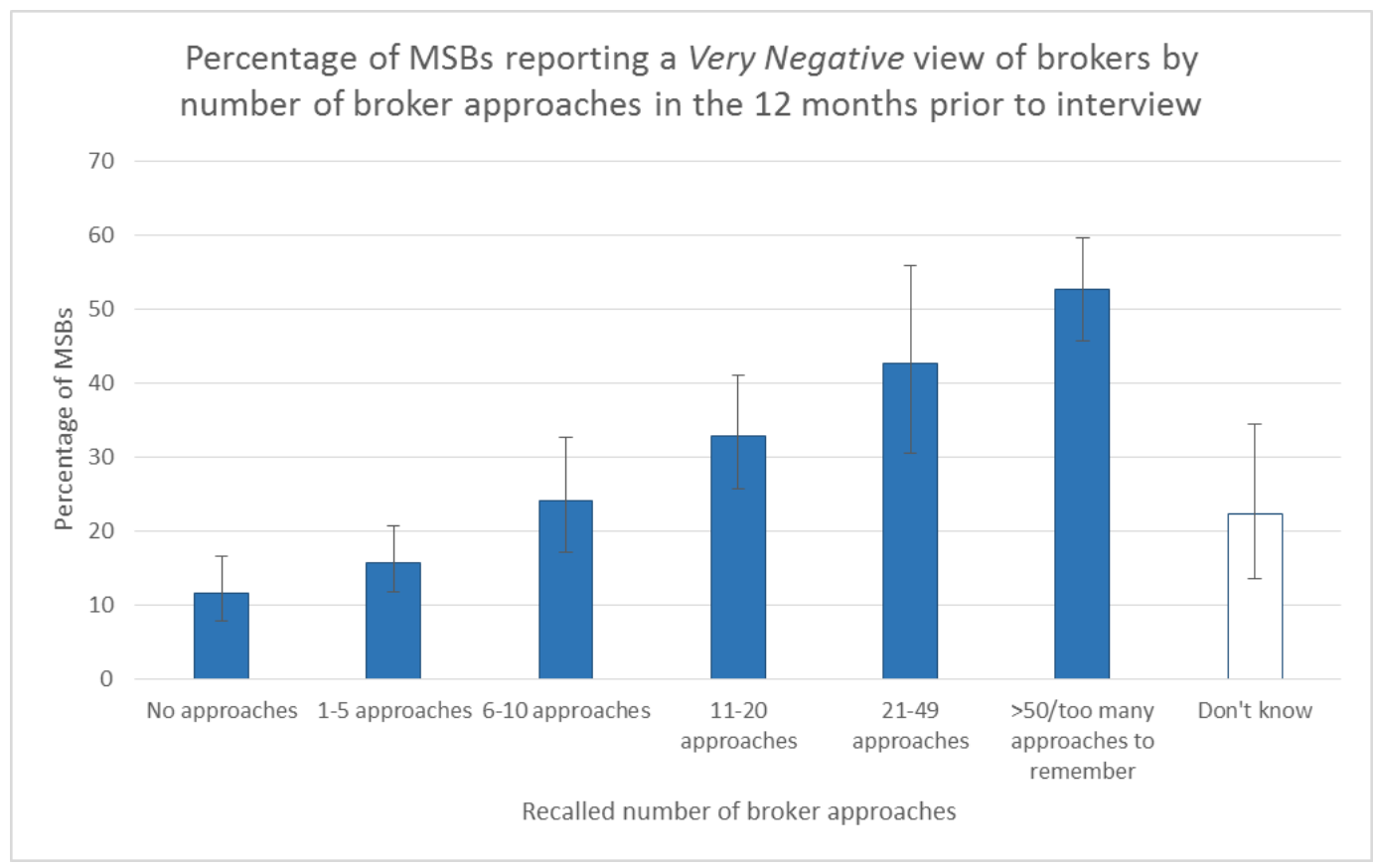

Figure 6: Percentage of MSBs with a Very Negative view of brokers by the number of broker approaches they recall receiving in the 12 months prior to interview

\subsection{Regression Results - The impact of broker contact}

In this section, we report the results of regressions which seek to show the association between the quantity of broker approaches and (i) MSBs' overall view of brokers and (ii) their satisfaction with the ease of comparing prices in the market, after controlling for a wide range of factors.

We note that for all the regressions a common theme is that firm characteristics, e.g. turnover and sector, have limited associations with the satisfaction variables. While this suggests limited variation in satisfaction across firms with different characteristics, this finding should not be overplayed given the survey's relatively small sample size.

\subsubsection{Broker contact and MSBs' opinion of brokers}

Table 1 reports the odds ratios for respondents reporting a more positive view of energy brokers. The main finding, confirming the finding from the descriptive statistics in section 5.1.4, is that recalling a greater number of broker approaches is strongly associated with reduced odds of having a more positive view of energy brokers. ${ }^{31}$ When the number of broker approaches is treated as a categorical variable, reporting the receipt of 6-10 broker contacts compared to 1-5 broker approaches is associated with the odds of having a more positive view of energy brokers falling by more than $40 \%$. Indeed, reporting over 50 contacts or that there were too many contacts to remember, implies the odds of having a more positive view of brokers is at least five times lower than for someone reporting 1-5 broker contacts. When the number of broker approaches is treated as a continuous variable (columns 5, 9 and 11), each additional broker approach is associated with a 1.2 percent drop in the odds of having a more positive view of brokers. These associations regarding broker approaches are consistently significant at the $1 \%$ level.

Significantly, the results in columns 6-11 of Table 1 occur after controlling for the main choice method used by respondents to select their current deal. In other words, even if a firm used a broker as their

${ }^{31}$ This finding mirrors the univariate regressions in Table B6 in Annex B. 
main method to select their current deal, reporting a higher number of broker approaches is associated with a lower overall view of brokers. The regression results also confirm that MSBs who used a method other than a broker to select their current energy deal have reduced odds of having a positive view of brokers.

\begin{tabular}{|c|c|c|c|c|c|c|c|c|c|c|c|}
\hline Selected Explanatory Variables & (1) & (2) & (3) & (4) & (5) & (6) & (7) & (8) & (9) & $(10)^{\#}$ & $(11)^{\#}$ \\
\hline Number of employees & $1.023^{* * *}$ & "1.018** & 1.018** & $1.022^{* * *}$ & $1.020^{* *}$ & $1.013^{*}$ & $1.018^{* *}$ & $1.019^{* *}$ & $1.017^{* *}$ & $1.021^{* * *}$ & "1.017** \\
\hline Energy Expenditure: $f 500$ or less & 1.133 & & & & & & & & & & \\
\hline nergy Expenditure: $€ 501-1,000$ & 1.042 & & & & & & & & & & \\
\hline nergy Expenditure: $\mathbf{f 1 - 2 . 5 k}$ & - & & & & & & & & & & \\
\hline nergy Expenditure: $f 2.5-5 \mathrm{k}$ & 0.862 & & & & & & & & & & \\
\hline nergy Expenditure: $£ 5-10 \mathrm{k}$ & 1.051 & & & & & & & & & & \\
\hline nergy Expenditure: f10-15k & 0.796 & & & & & & & & & & \\
\hline nergy Expenditure: f15-25k & 0.856 & & & & & & & & & & \\
\hline nergy Expenditure: f25-50k & $2.043 * *$ & & & & & & & & & & \\
\hline nergy Expenditure: f50k+ & 1.545 & & & & & & & & & & \\
\hline nergy Expenditure: Don't & & & & & & & & & & & \\
\hline now/Refused & $1.0 / 3$ & & & & & & & & & & \\
\hline Continuous: Log Energy Expenditure & & 1.036 & 1.024 & 1.031 & 1.009 & 1.004 & 1.003 & 0.987 & 0.951 & 0.988 & 0.939 \\
\hline Not switched in last 5 years & & & - & & & & - & - & - & - & - \\
\hline Has Switched in Last 5 Years & & & $1.312^{* *}$ & & & & 0.912 & 0.865 & 0.816 & 0.880 & 0.836 \\
\hline No. Broker Approaches: None & & & & 0.912 & & & 1.163 & 1.284 & & 1.164 & \\
\hline No. Broker Approaches: 1-5 & & & & - & & & - & - & & - & \\
\hline No. Broker Approaches: 6-10 & & & & $0.566^{* * *}$ & & & $0.573^{* * *}$ & $0.563^{* * *}$ & & $0.540^{* * *}$ & \\
\hline No. Broker Approaches: $11-20$ & & & & $0.298 * * *$ & & & $0.343^{* * *}$ & $0.346 * * *$ & & $0.341^{* * *}$ & \\
\hline No. Broker Approaches: $21-30$ & & & & $0.227^{* * *}$ & & & $0.275^{* * *}$ & $0.273^{* * *}$ & & $0.277^{* * *}$ & \\
\hline No. Broker Approaches: 31 to 50 & & & & $0.095^{* * *}$ & & & $0.118^{* * *}$ & $0.102^{* * *}$ & & $0.116^{* * *}$ & \\
\hline $\begin{array}{l}\text { No. Broker Approaches: } 50+/ \text { too } \\
\text { many to remember }\end{array}$ & & & & $0.174 * * *$ & & & $0.200 * * *$ & $0.197 * * *$ & & $0.198 * * *$ & \\
\hline No. Broker Approaches: Don't know & & & & $0.509^{* *}$ & & & 0.697 & 0.755 & & 0.707 & \\
\hline Continuous: No. Broker Approaches & & & & & $0.988^{* * *}$ & & & & $0.988 * * *$ & & $0.988^{* * *}$ \\
\hline hain choice method: Broker & & & & & & - & - & - & - & - & - \\
\hline $\begin{array}{l}\text { Main choice method: } \\
\text { CW/telephone service }\end{array}$ & & & & & & $0.274^{* * *}$ & $0.298 * * *$ & $0.296 * * *$ & $0.271^{* * *}$ & $0.305^{* * *}$ & $0.285^{* * *}$ \\
\hline $\begin{array}{l}\text { Main choice method: Range of } \\
\text { uppliers }\end{array}$ & & & & & & $0.151^{* * *}$ & $0.162^{* * *}$ & $0.154^{* * *}$ & $0.134^{* * *}$ & $0.166^{* * *}$ & $0.151^{* * *}$ \\
\hline $\begin{array}{l}\text { Main choice method: Current } \\
\text { supplier only }\end{array}$ & & & & & & $0.175^{* * *}$ & $0.162^{* * *}$ & $0.162^{* * *}$ & $0.141^{* * *}$ & $0.172^{* * *}$ & $0.158^{* * *}$ \\
\hline Main choice method: Other & & & & & & $0.070^{* * *}$ & $0.084^{* * *}$ & $0.080^{* * *}$ & $0.070 * * *$ & $0.086^{* * *}$ & $0.079 * * *$ \\
\hline Main choice method: Don't know & & & & & & 0.516 & 0.484 & 0.541 & $0.378^{*}$ & 0.638 & 0.498 \\
\hline Log likelihood & -1603.19 & -1506.68 & -1504.23 & -1440.11 & -1394.64 & -1415.81 & -1356.27 & -1350.55 & -1297.89 & -1358.4 & -1313.94 \\
\hline -value, LR test joint significance & 0.018 & 0.074 & 0.034 & 0.000 & 0.000 & 0.000 & 0.000 & 0.000 & 0.000 & 0.000 & 0.000 \\
\hline Firm Demographic Controls & Yes & Yes & Yes & Yes & Yes & Yes & Yes & Yes & Yes & Yes $^{\#}$ & Yes $^{\#}$ \\
\hline Engagement Controls & No & No & No & No & No & No & No & Yes & Yes & Yes $^{\#}$ & Yes $^{\#}$ \\
\hline $\mathrm{N}$ & 1083 & 1011 & 1011 & 1011 & 961 & 1011 & 1011 & 1011 & 961 & 1011 & 961 \\
\hline \multicolumn{12}{|c|}{$\begin{array}{l}\text { Notes: * indicates statistical significance at the } 10 \% \text { level, } * * \text { indicates significance at the } 5 \% \text { level, and } * * * \text { indicates signifcance at the } 1 \% \text { level. Bold } \\
\text { indicates the base category for categorical variables. \# indicates only those control variables that showed some statistical significance in column } 9 \text { are } \\
\text { retained (specifically only knowledge of contract end date was retained). Columns } 1-9 \text { report odds ratios from ordered logit regressions where the odds } \\
\text { are defined as the probability of having a more positive view of brokers relative to the probability of having a less positive view. Column } 10 \text { and } 11 \text { report } \\
\text { odds ratios from a generalised ordered logit model where a partial parallel odds assumption is allowed and the reported odds ratios relate to whether } \\
\text { MSBs hold a Very Negative view of brokers versus a more positive view. In columns where no figures for a particular variable are reported, the variable } \\
\text { was not included in the relevant column's regression. In columns } 2 \text { to } 11 \text { where a continuous log energy expenditure variable is used } 71 \text { observations are } \\
\text { dropped as responses of Don't Know/Refused can no longer be used and one observation is dropped for having a value of zero. When treating energy } \\
\text { expenditure as continuous } 224 \text { observations involved taking the mid-point of a category. Similarly in columns } 2,9 \text { and } 1150 \text { observations were dropped as } \\
\text { the continuous number of broker approaches variable cannot include the responses of Don't Know/Refused. Variables frequently significant across } \\
\text { regressions at the } 5 \% \text { level or above but not reported are (direction of association reported in brackets): does not know when contract ends (negative, } \\
\text { columns } 8-10 \text { ) and does not have a fixed term contract (negative, columns 8-10). }\end{array}$} \\
\hline
\end{tabular}

Table 1: Odds ratios for reporting a more positive overall view of energy brokers

Across all the regressions in Table 1, having more employees is associated with increased odds of reporting a more positive view of brokers. Each additional employee is associated with around a two percent increase in the odds of reporting a more positive view of brokers. That MSBs with more employees are more likely to have a more positive view of brokers may suggest the benefits of brokers are more obvious, or easier to access, for more 'sophisticated' firms. A possible explanation is that MSBs with more employees are more likely to have an individual with dedicated responsibility for procurement who may be more comfortable with the process of comparing prices and interacting with brokers. 
In column 11 where the generalised ordered logit model is used and broker approaches are treated as continuous, for no variables was the parallel odds assumption violated; in other words, the ordered logit model is valid. In column 10 where the number of broker approaches was treated as a categorical variable, the proportional odds assumption was only violated by a single category of the number of broker approaches variable. For this one category the odds ratios vary by the opinion level used to define the odds. In particular, when considering whether MSBs hold a Very Positive view relative to less positive views, reporting not receiving any broker approaches was associated with a $91.6 \%$ increase in the odds of having a Very Positive view compared to reporting 1-5 broker approaches (significant at the $5 \%$ level).

Table D1 confirms the strong negative association between the number of broker approaches recalled and MSBs' overall view of energy brokers also holds for the 2015 data.

\subsubsection{Contact and the ease of comparing prices}

As the CMA noted, price transparency has historically been limited in the non-domestic energy market. This means that brokers play an important role in MSBs' searches for good energy deals. A possible fear may be that the negative impact of brokers' marketing behaviour not only affects MSBs' view of brokers but also their satisfaction with the ease of comparing prices (searching) in the energy market more generally. Table 2 provides some evidence that a greater number of broker approaches is associated with reduced satisfaction with the ease of comparing prices, although, this is weaker than in Table 1. When the number of broker approaches is treated as a continuous, one additional broker approach is associated with a 0.2 percent reduction in the odds of reporting higher satisfaction with the ease of comparing prices (columns 5, 9 and 11). However, not only is this effect's magnitude rather small, it is also only significant at the $10 \%$ level.

Considering the number of broker approaches as a categorical variable shows the association with satisfaction regarding the ease of comparing prices is uneven. ${ }^{32}$ Compared to reporting 1-5 broker approaches reporting no broker approaches is associated with around a 60 percent increase in the odds of reporting higher satisfaction with the ease of comparing prices (columns 4, 7, 8 and 10). This may reflect that many MSBs only choose to use a broker if they feel a broker offers an easier/better route to identify good deals in the market, i.e. searching the market unassisted is a relatively difficult task.

Also, reporting 21-30 broker approaches or 50+/too many to remember are associated with a 35-50 percent drop in the odds of reporting higher satisfaction with the ease of comparing prices compared to reporting 1-5 approaches. However, the odds ratios for other numbers of broker approaches are generally statistically insignificant at the $10 \%$ level.

In Table 2 there is no evidence that using a broker to select one's current energy deal increases satisfaction with the ease of comparing prices, apart from relative to the unspecified method of 'other'. Also, unlike in Table 1, there is no association between the number of employees and the odds of reporting greater satisfaction with the ease of comparing prices. This lack of relationship may be influenced by the fact that larger MSBs are performing more extensive/complex searches that are harder to complete.

Last, the generalised ordered logit regressions in columns 10 and 11 did not identify any violations of the proportional odds assumption and so the ordered logit model is appropriate.

\footnotetext{
32 The limited significance of the number of broker approaches variable mirrors the univariate regression results in Table B6.
} 


\begin{tabular}{|c|c|c|c|c|c|c|c|c|c|c|c|}
\hline Selected Explanatory Variables & (1) & (2) & $(3)$ & (4) & (5) & (6) & (7) & $(8)$ & (9) & $(10)^{\#}$ & $(11)^{\#}$ \\
\hline Number of employees & 1.012 & 1.009 & 1.009 & 1.012 & 1.008 & 1.008 & 1.011 & 1.011 & 1.006 & 1.010 & 1.007 \\
\hline Energy Expenditure: $£ 500$ or less & 1.026 & & & & & & & & & & \\
\hline Energy Expenditure: $£ 501-1,000$ & 0.897 & & & & & & & & & & \\
\hline Energy Expenditure: $\mathbf{f 1 - 2 . 5 k}$ & - & & & & & & & & & & \\
\hline Energy Expenditure: $£ 2.5-5 \mathrm{k}$ & 0.823 & & & & & & & & & & \\
\hline Energy Expenditure: $£ 5-10 k$ & $0.645^{* *}$ & & & & & & & & & & \\
\hline Energy Expenditure: $£ 10-15 k$ & 0.768 & & & & & & & & & & \\
\hline Energy Expenditure: $£ 15-25 k$ & $0.504^{* *}$ & & & & & & & & & & \\
\hline Energy Expenditure: $£ 25-50 k$ & 0.700 & & & & & & & & & & \\
\hline Energy Expenditure: $£ 50 \mathrm{k}+$ & 1.056 & & & & & & & & & & \\
\hline Energy Expenditure: Don't & & & & & & & & & & & \\
\hline Know/Refused & $0.623^{*}$ & & & & & & & & & & \\
\hline Continuous: Log Energy Expenditure & & 0.919 & 0.920 & 0.914 & 0.923 & 0.917 & 0.914 & $0.897^{*}$ & $0.904^{*}$ & $0.911^{*}$ & $0.909^{*}$ \\
\hline Not switched in last 5 years & & & - & & & & - & - & - & - & - \\
\hline Has Switched in Last 5 Years & & & 0.998 & & & & 0.955 & 0.894 & 0.902 & 0.923 & 0.917 \\
\hline No. Broker Approaches: None & & & & $1.549 * *$ & & & $1.610^{* *}$ & $1.639 * *$ & & $1.578^{* *}$ & \\
\hline No. Broker Approaches: 1-5 & & & & - & & & - & - & & - & \\
\hline No. Broker Approaches: 6-10 & & & & $0.730^{*}$ & & & 0.740 & $0.700 *$ & & $0.724^{*}$ & \\
\hline No. Broker Approaches: $11-20$ & & & & 0.866 & & & 0.879 & 0.851 & & 0.825 & \\
\hline No. Broker Approaches: 21-30 & & & & $0.504^{* *}$ & & & $0.534^{* *}$ & $0.498^{* *}$ & & $0.510^{* *}$ & \\
\hline No. Broker Approaches: 31 to 50 & & & & 1.483 & & & 1.541 & 1.594 & & 1.609 & \\
\hline $\begin{array}{l}\text { No. Broker Approaches: } 50+/ \text { too } \\
\text { many to remember }\end{array}$ & & & & $0.609 * * *$ & & & $0.637 * * *$ & $0.599 * * *$ & & $0.636 * * *$ & \\
\hline No. Broker Approaches: Don't know & & & & 1.036 & & & 1.095 & 1.120 & & 1.065 & \\
\hline Continuous: No. Broker Approaches & & & & & $0.998 *$ & & & & $0.998^{*}$ & & $0.998^{*}$ \\
\hline Main choice method: Broker & & & & & & - & - & - & - & - & - \\
\hline $\begin{array}{l}\text { Main choice method: } \\
\text { PCW/telephone service }\end{array}$ & & & & & & 1.043 & 1.059 & 1.065 & 1.067 & 1.091 & 1.078 \\
\hline $\begin{array}{l}\text { Main choice method: Range of } \\
\text { suppliers }\end{array}$ & & & & & & 0.789 & 0.807 & 0.789 & 0.794 & 0.839 & 0.852 \\
\hline $\begin{array}{l}\text { Main choice method: Current } \\
\text { supplier only }\end{array}$ & & & & & & 0.799 & 0.765 & 0.780 & 0.787 & 0.787 & 0.800 \\
\hline Main choice method: Other & & & & & & $0.424 * *$ & $0.448^{* *}$ & $0.404^{* *}$ & $0.408^{* *}$ & $0.417^{* *}$ & $0.411^{* *}$ \\
\hline Main choice method: Don't know & & & & & & 0.792 & 0.815 & 0.794 & 0.620 & 1.062 & 0.822 \\
\hline Log likelihood & -1676.40 & -1571.01 & -1571.01 & -1556.73 & -1490.45 & -1566.50 & -1552.48 & -1542.21 & -1479.92 & -1556.30 & -1493.53 \\
\hline P-value, LR test joint significance & 0.101 & 0.106 & 0.132 & 0.001 & 0.045 & 0.058 & 0.001 & 0.000 & 0.060 & 0.000 & 0.011 \\
\hline Firm Demographic Controls & Yes & Yes & Yes & Yes & Yes & Yes & Yes & Yes & Yes & Yes $^{\#}$ & Yes $^{\#}$ \\
\hline Engagement Controls & No & No & No & No & No & No & No & Yes & Yes & Yes $^{\#}$ & Yes $^{\#}$ \\
\hline $\mathrm{N}$ & 1083 & 1011 & 1011 & 1011 & 961 & 1011 & 1011 & 1011 & 961 & 1011 & 961 \\
\hline
\end{tabular}

Notes: ${ }^{*}$ indicates statistical significance at the $10 \%$ level, ${ }^{* *}$ indicates significance at the $5 \%$ level, and ${ }^{* * *}$ indicates signifcance at the $1 \%$ level. Bold indicates the base category for categorical variables. \# indicates only those control variables that showed some statistical significance in column 9 are retained (specifically country, sector, whether has a smart meter and whether read their contract were retained). Columns 1-9 report odds ratios from ordered logit regressions where the odds are defined as the probability of being more satisfied with the ease of comparing prices in the market relative to the probability of being less satisfied. Column 10 and 11 report odds ratios from a generalised ordered logit model where a partial parallel odds assumption is allowed and the reported odds ratios relate to whether MSBs are Very Dissatisfied with the ease of comparing prices or are more satisfied. In columns where no figures for a particular variable are reported, the variable was not included in the relevant column's regression. In columns 2 to 11 where a continuous log energy expenditure variable is used 71 observations are dropped as responses of Don't Know/Refused can no longer be used and one observation is dropped for having a value of zero. When treating energy expenditure as continuous 224 observations involved taking the mid-point of a category. Similarly in columns 2, 9 and 1150 observations were dropped as the continuous number of broker approaches variable cannot include the responses of Don't Know/Refused. Variables frequently significant across regressions at the $5 \%$ level or above but not reported are (direction of association reported in brackets): located in Scotland (positive); in the transport, food and accomodation sector (negative); and has read contract (positive, columns 8 11).

Table 2: Odds ratios for reporting greater satisfaction with the ease of comparing prices in the market

\subsection{Regression Results - The Salience of Energy}

Here we consider factors associated with MSBs' satisfaction with their current energy supplier. In particular, we note that MSBs with the very lowest energy expenditures seem are associated with higher satisfaction than other MSBs, after controlling for other factors. A potential explanation is that for firms with the lowest energy expenditures the salience of energy, and its cost, is low so that simply ensuring that 'the lights stay on' is sufficient for an MSB to be reasonably satisfied with their energy supplier. Another, far more complex, explanation regarding differing rates of VAT on energy is discussed in Appendix G.

That MSBs with low energy expenditures have higher satisfaction levels is potentially significant for the questions of whether the engagement of MSBs can or should be increased. Higher satisfaction 
with their current supplier will likely reduce the motivation of an MSB to switch supplier as the benefit from switching will appear lower. This reduced motivation to switch for MSBs with low energy expenditures may explain why in Table B4 and some regressions in Table A1 higher energy expenditures are associated with a greater probability of having switched in the 5 years prior to the survey. Even if the higher satisfaction of MSBs with low energy expenditures is due to energy having limited salience among firms, it is not automatic that prompts to engage will be beneficial for MSBs. Those running all MSBs have a time allocation problem: they need to allocate the limited time available to maximise profits/utility ${ }^{33}$. The lower are energy expenditures, the more likely it is that in the time taken to switch supplier an alternative activity is available that delivers a greater return in terms of profits/utility. In other words, the lower are energy expenditures, the more likely it is that an MSB rationally chooses not to engage with the energy market. However, steps to reduce the amount of time required to search/switch are still potentially beneficial as they potentially increase the return from allocating a given amount of time to search/switching.

\subsubsection{Satisfaction with current supplier's value for money}

Table 3 shows energy expenditure's statistically significant association with MSBs' satisfaction with their current energy supplier's value for money. Reporting expenditure of $£ 5,000-10,000$ per annum compared to expenditure of $f 1,000-2,500$ is associated with the odds of greater satisfaction with suppliers' value for money being reduced by over $40 \%$ (see columns 1 and 6 ). However, rather than a stable decline in satisfaction as energy expenditures increase, it appears that above the expenditure category of $f 1,000-2,500$ there is a steep drop to a lower, but relatively stable, level of satisfaction with suppliers' value for money. This non-linearity is reflected in the relationship between log energy expenditure and value for money satisfaction being significant at the $1 \%$ level in Table 3 . The odds ratio for log energy expenditure indicates that each $1 \%$ increase in energy expenditure is associated with around a $20 \%$ drop in the odds of an MSB reporting a higher level of value for money satisfaction.

In columns 9 and 10, where generalised ordered logit regressions are reported, the odds ratio relate to the odds comparing the probability of being Very Satisfied relative to the probability of being in a lower satisfaction category. Challenges were encountered running the generalised ordered logit model for this dependent variable and so the only control variables were dummy variables representing the specific categories of the control variables in column 6 that were found to be significant. Nevertheless, Column 10 shows the relationship between log energy expenditure and value for money satisfaction is robust to the relaxation of the parallel odds assumption. Column 9 indicates that when energy expenditure is a categorical variable, there is a noticeable loss of significance compared to equivalent regressions in the ordered logit model (columns 1 and 6). ${ }^{34}$ However, treating energy expenditure as continuous is preferred as it maximises the information contained in the data.

The 2015 data in Table D3 also show that the MSBs with the very lowest electricity expenditures, i.e. those with expenditures below $f 500$, have greater odds of higher satisfaction than MSBs with electricity expenditures in the range $£ 2,500-25,000$. However, if the base expenditure category is set as electricity expenditures of $£ 1,000-2,500$ the statistical significance of the odds ratios for higher electricity expenditure categories largely disappears in 2015.

\footnotetext{
${ }^{33}$ Some MSBs may be run in a manner other than to strictly maximise profits.

${ }^{34}$ The proportional odds assumption does not hold for the expenditure category $f 5,000-10,000$. The odds ratio is less than one and statistically significant at the $5 \%$ level when defined with reference to: (i) the Neither Satisfied nor Dissatisfied/Quite Satisfied boundary and (ii) the Quite Dissatisfied/Neither Satisfied nor Dissatisfied boundary.
} 
If one considers the salience of energy costs as potentially influencing firms' satisfaction with their energy supplier, one question is whether energy costs in absolute terms, or relative to turnover/total costs, is the more appropriate way to assess salience. To investigate this, univariate regressions ${ }^{35}$ were run considering energy expenditures as a percentage of turnover. ${ }^{36}$ When the log of this fraction is placed in a univariate regression, it has an association with value for money satisfaction significant at the $1 \%$ level. A one percent increase in the value of energy expenditure as a fraction of turnover is associated with a 14 percent reduction in the odds of reporting higher value for money satisfaction. When log turnover and log energy expenditure are included as separate variables in a single regression, log energy expenditure has an association with value for money satisfaction significant at the $1 \%$ level, while log turnover is only significant at the $5 \%$ level. In summary, it is not clear whether the salience of energy expenditure is best assessed in absolute or percentage terms, however, both treatments show a negative association with value for money satisfaction when the appropriate functional form is adopted. ${ }^{37}$

\footnotetext{
${ }^{35}$ For brevity we do not report the full results of these regressions, although, they are available from the authors on request.

${ }^{36}$ This reduces the sample size to 775 due to the large number of firms reporting Don't Know or Refused to the turnover question.

${ }^{37}$ The survey also included two categorical questions asking the percentage of a firm's costs accounted for by electricity/gas. Both when looking solely at electricity, and when combining the response to look at energy as a percentage of a firm's costs, in univariate regressions a degree of support is found for firms devoting a higher proportion of costs to electricity/energy having lower odds of reporting greater value for money satisfaction. However, in each case only one percentage cost category is found to be statistically significant at the $5 \%$ level. Compared to MSBs where electricity accounts for less than $10 \%$ of costs, reporting that electricity forms 20 $29 \%$ of costs reduces the odds of reporting higher value for money satisfaction by around 40 percent.
} 


\begin{tabular}{|c|c|c|c|c|c|c|c|c|c|c|}
\hline Selected Explanatory Variables & (1) & $(2)$ & (3) & (4) & (5) & (6) & (7) & (8) & $(9)^{\#}$ & $(10)^{\#}$ \\
\hline Energy Expenditure: $£ 500$ or less & 1.441 & & & & & 1.531 & & & 1.442 & \\
\hline Energy Expenditure: $₫ 501-1,000$ & 1.067 & & & & & 1.083 & & & 1.048 & \\
\hline Energy Expenditure: $£ 1-2.5 k$ & - & & & & & - & & & - & \\
\hline Energy Expenditure: $f 2.5-5 \mathrm{k}$ & $0.615^{* * *}$ & & & & & $0.617 * * *$ & & & $0.635 * * *$ & \\
\hline Energy Expenditure: $£ 5-10 k$ & $0.566 * * *$ & & & & & $0.546 * * *$ & & & 0.813 & \\
\hline Energy Expenditure: $£ 10-15 k$ & $0.505^{* * *}$ & & & & & $0.468 * * *$ & & & $0.560 * *$ & \\
\hline Energy Expenditure: $£ 15-25 k$ & $0.568 * *$ & & & & & $0.558^{* *}$ & & & 0.724 & \\
\hline Energy Expenditure: f25-50k & $0.497 * *$ & & & & & $0.477^{* *}$ & & & $0.578^{*}$ & \\
\hline Energy Expenditure: $£ 50 \mathrm{k}+$ & 0.700 & & & & & 0.616 & & & 0.78 & \\
\hline $\begin{array}{l}\text { Energy Expenditure: Don't } \\
\text { Know/Refused }\end{array}$ & 0.704 & & & & & $0.619 *$ & & & 0.706 & \\
\hline $\begin{array}{l}\text { Continuous: Energy Expenditure } \\
\text { ( } ₫ 500 \text { units) }\end{array}$ & & 0.996 & & & & & 0.995 & & & \\
\hline $\begin{array}{l}\text { Continuous: Energy Expenditure } \\
\text { Squared ( } ₫ 500 \text { units) }\end{array}$ & & 1.000 & & & & & 1.000 & & & \\
\hline Continuous: Log Energy Expenditure & & & $0.808^{* * *}$ & $0.811^{* * *}$ & $0.812 * * *$ & & & $0.796 * * *$ & & $0.855^{* * *}$ \\
\hline Not switched in last 5 years & & & & - & - & - & - & - & - & - \\
\hline Has Switched in Last 5 Years & & & & 0.909 & 0.956 & 0.913 & 0.893 & 0.894 & 0.908 & 0.909 \\
\hline No. Broker Approaches: None & & & & & 1.073 & 0.966 & 1.097 & 1.079 & 1.367 & $1.551 *$ \\
\hline No. Broker Approaches: 1-5 & & & & & - & - & - & - & - & - \\
\hline No. Broker Approaches: 6-10 & & & & & 1.034 & 1.020 & 1.025 & 1.001 & 1.080 & 1.066 \\
\hline No. Broker Approaches: 11-20 & & & & & 0.841 & 0.829 & 0.780 & 0.800 & 0.880 & 0.866 \\
\hline No. Broker Approaches: 21-30 & & & & & 0.844 & 0.817 & 0.850 & 0.827 & 1.470 & 1.721 \\
\hline No. Broker Approaches: 31 to 50 & & & & & 1.157 & 1.489 & 1.172 & 1.225 & 1.717 & 1.371 \\
\hline $\begin{array}{l}\text { No. Broker Approaches: } 50+/ \text { too } \\
\text { many to remember }\end{array}$ & & & & & $0.747^{*}$ & 0.764 & $0.736^{*}$ & $0.736^{*}$ & 0.816 & 0.782 \\
\hline No. Broker Approaches: Don't know & & & & & 0.820 & 0.873 & 0.824 & 0.824 & 0.855 & 0.834 \\
\hline Main choice method: Broker & & & & & - & - & - & - & - & - \\
\hline $\begin{array}{l}\text { Main choice method: } \\
\text { PCW/telephone service }\end{array}$ & & & & & 1.255 & 1.260 & 1.340 & 1.266 & 1.302 & 1.272 \\
\hline $\begin{array}{l}\text { Main choice method: Range of } \\
\text { suppliers }\end{array}$ & & & & & 1.248 & 1.218 & 1.255 & 1.251 & 1.203 & 1.209 \\
\hline $\begin{array}{l}\text { Main choice method: Current } \\
\text { supplier only }\end{array}$ & & & & & 1.221 & 1.241 & $1.338^{*}$ & 1.279 & 1.203 & 1.207 \\
\hline Main choice method: Other & & & & & 0.563 & 0.609 & 0.581 & 0.565 & 1.030 & 0.581 \\
\hline Main choice method: Don't know & & & & & 0.875 & 1.017 & 1.070 & 0.963 & 0.948 & 0.889 \\
\hline Log likelihood & -1593.67 & -1497.09 & -1490.7 & -1490.4 & -1484.61 & -1574.57 & -1480.77 & -1474.29 & -1549.69 & -1456.96 \\
\hline P-value, LR test joint significance & 0.002 & 0.033 & 0.002 & 0.002 & 0.006 & 0.001 & 0.027 & 0.003 & 0.000 & 0.000 \\
\hline Firm Demographic Controls & Yes & Yes & Yes & Yes & Yes & Yes & Yes & Yes & Yes $^{\#}$ & Yes $^{\#}$ \\
\hline Engagement Controls & No & No & No & No & No & Yes & Yes & Yes & Yes $^{\#}$ & Yes $^{\#}$ \\
\hline $\mathrm{N}$ & 1082 & 1011 & 1010 & 1010 & 1010 & 1082 & 1011 & 1010 & 1082 & 1010 \\
\hline
\end{tabular}

Notes: ${ }^{*}$ indicates statistical significance at the $10 \%$ level, ${ }^{* *}$ indicates significance at the $5 \%$ level, and $* * *$ indicates signifcance at the $1 \%$ level. Bold indicates the base category for categorical variables. \# indicates only the categories in the control variables that showed some statistical significance in column 6 are retained (specifically country, sector, turnover, business operated from a home, whether has a smart meter, payment method and whether read their contract were retained). Columns 1-8 report odds ratios from ordered logit regressions where the odds are defined as the probability of an MSB being more satisfied with their current supplier's value for money relative to the probability of being less satisfied. Columns 9 and 10 report odds ratios from a generalised ordered logit model where a partial parallel odds assumption is allowed and the reported odds ratios relate to whether MSBs are Very Satisfied with their current supplier's value for money or are less satisfied. In columns where no figures for a particular variable are reported, the variable was not included in the relevant column's regression. In all columns one observation is dropped for being perfectly determined. In columns 2-5, 7, 8 and 10 where a continuous energy expenditure variable is used 71 observations are dropped as responses of Don't Know/Refused can no longer be used. In columns 3-5, 8 and 10 where the log of energy expenditure is taken one observation is dropped for having a value of zero. When treating energy expenditure as continuous 224 observations involved taking the mid-point of a category. In column 96 observations had a predicted outcome probability less than zero. Variables frequently significant across regressions at the $5 \%$ level or above but not reported are (direction of association reported in brackets): located in Wales (positive); jointly responsible for energy supply (positive); in the transport, food and accomodation sector (negative); turnover of $£ 250,000-499,000$ (negative); payment method - standard credit (negative, columns 6-10); and has read contract (positive, columns 6-10).

\section{Table 3: Odds ratios for reporting greater satisfaction with current energy supplier's value for money}

\subsubsection{Satisfaction with current supplier's overall service}

As with value for money satisfaction, in Table 4 there is a consistently significant negative, but nonlinear, association between energy expenditure and satisfaction with a current supplier's overall service. When energy expenditure is treated as a categorical variable, firms reporting moderately high energy expenditure have lower odds of reporting higher satisfaction. That the odds ratios for the 
categories $£ 25,000-50,000$ and $£ 50,000+$ are statistically insignificant may relate to the relatively small number of observations in these categories. Log energy expenditure is found to have relationship with service satisfaction significant at the $1 \%$ level in all the specifications in Table 4 . Across the regressions a 1 percent increase in energy expenditures is associated with a 12.3-17 percent reduction in the odds of an MSB reporting higher satisfaction with their energy supplier's overall service. Column 10 demonstrates this result is robust to relaxing the proportional odds assumption.

\begin{tabular}{|c|c|c|c|c|c|c|c|c|c|c|}
\hline Selected Explanatory Variables & (1) & (2) & (3) & (4) & (5) & (6) & (7) & (8) & $(9)^{\#}$ & $(10)^{\#}$ \\
\hline Energy Expenditure: $£ 500$ or less & 1.214 & & & & & 1.230 & & & 1.208 & \\
\hline Energy Expenditure: $f 501-1,000$ & 1.033 & & & & & 1.048 & & & 1.026 & \\
\hline Energy Expenditure: f1-2.5k & - & & & & & - & & & - & \\
\hline Energy Expenditure: $f 2.5-5 \mathrm{k}$ & $0.731^{*}$ & & & & & $0.729 *$ & & & 0.785 & \\
\hline Energy Expenditure: $f 5-10 \mathrm{k}$ & $0.653^{* *}$ & & & & & $0.637^{* *}$ & & & $0.676^{* *}$ & \\
\hline Energy Expenditure: f10-15k & $0.571^{* *}$ & & & & & $0.511^{* * *}$ & & & $0.589 * *$ & \\
\hline Energy Expenditure: f15-25k & $0.463^{* * *}$ & & & & & $0.435^{* * *}$ & & & $0.504^{* * *}$ & \\
\hline Energy Expenditure: $£ 25-50 k$ & 0.597 & & & & & 0.568 & & & 0.677 & \\
\hline Energy Expenditure: f50k+ & 0.838 & & & & & 0.667 & & & 0.988 & \\
\hline $\begin{array}{l}\text { Energy Expenditure: Don't } \\
\text { Know/Refused }\end{array}$ & 0.774 & & & & & 0.690 & & & 0.790 & \\
\hline 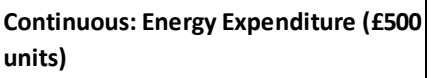 & & 0.997 & & & & & 0.996 & & & \\
\hline $\begin{array}{l}\text { Continuous: Energy Expenditure } \\
\text { Squared ( } ₫ 500 \text { units) }\end{array}$ & & 1.000 & & & & & 1.000 & & & \\
\hline Continuous: Log Energy Expenditure & & & $0.850 * * *$ & $0.857^{* * *}$ & $0.851^{* * *}$ & & & $0.830 * * *$ & & $0.877^{* * *}$ \\
\hline Not switched in last 5 years & & & & - & - & - & - & - & - & - \\
\hline Has Switched in Last 5 Years & & & & $0.741^{* *}$ & $0.729 * *$ & $0.688^{* * *}$ & $0.668 * * *$ & $0.673^{* * *}$ & $0.698^{* * *}$ & $0.682^{* * *}$ \\
\hline No. Broker Approaches: None & & & & & 1.274 & 1.162 & 1.353 & 1.288 & 1.175 & 1.315 \\
\hline No. Broker Approaches: 1-5 & & & & & - & - & - & - & - & - \\
\hline No. Broker Approaches: 6-10 & & & & & 0.956 & 0.933 & 0.955 & 0.944 & 0.985 & 0.999 \\
\hline No. Broker Approaches: $11-20$ & & & & & 0.931 & 0.879 & 0.863 & 0.878 & 0.942 & 0.962 \\
\hline No. Broker Approaches: 21-30 & & & & & 1.065 & 1.116 & 1.078 & 1.010 & 1.236 & 1.115 \\
\hline No. Broker Approaches: 31 to 50 & & & & & 1.399 & 2.063 & 1.371 & 1.419 & 2.041 & 1.572 \\
\hline $\begin{array}{l}\text { No. Broker Approaches: } 50+/ \text { too many } \\
\text { to remember }\end{array}$ & & & & & 0.868 & 0.886 & 0.853 & 0.846 & 0.961 & 0.938 \\
\hline No. Broker Approaches: Don't know & & & & & 1.110 & 1.052 & 1.111 & 1.114 & 1.139 & 1.246 \\
\hline Main choice method: Broker & & & & & - & - & - & - & - & - \\
\hline $\begin{array}{l}\text { Main choice method: PCW/telephone } \\
\text { service }\end{array}$ & & & & & 1.015 & 1.023 & 1.064 & 1.004 & 1.050 & 1.022 \\
\hline $\begin{array}{l}\text { Main choice method: Range of } \\
\text { suppliers }\end{array}$ & & & & & 1.166 & 1.193 & 1.184 & 1.184 & 1.162 & 1.132 \\
\hline $\begin{array}{l}\text { Main choice method: Current supplier } \\
\text { only }\end{array}$ & & & & & 0.952 & 1.036 & 1.050 & 1.000 & 1.011 & 0.973 \\
\hline Main choice method: Other & & & & & $0.357^{* * *}$ & $0.380^{* * *}$ & $0.358^{* * *}$ & $0.353^{* * *}:$ & $0.394^{* * *}$ & $0.349^{* * *}$ \\
\hline Main choice method: Don't know & & & & & 0.889 & 1.119 & 1.122 & 1.009 & 1.075 & 1.195 \\
\hline Log likelihood & -1453.51 & -1356.57 & -1352.27 & -1349.43 & -1342.2 & -1423.99 & -1330.05 & -1325.31 & -1439.27 & -1340.45 \\
\hline P-value, LR test joint significance & 0.026 & 0.080 & 0.021 & 0.007 & 0.007 & 0.000 & 0.001 & 0.000 & 0.000 & 0.000 \\
\hline Firm Demographic Controls & Yes & Yes & Yes & Yes & Yes & Yes & Yes & Yes & Yes" & Yes ${ }^{\#}$ \\
\hline Engagement Controls & No & No & No & No & No & Yes & Yes & Yes & Yes" & Yes $^{\#}$ \\
\hline $\mathrm{N}$ & 1083 & 1011 & 1010 & 1010 & 1011 & 1082 & 1012 & 1011 & 1082 & 1011 \\
\hline
\end{tabular}

Notes: ${ }^{*}$ indicates statistical significance at the $10 \%$ level, ${ }^{* *}$ indicates significance at the $5 \%$ level, and ${ }^{* * *}$ indicates signifcance at the $1 \%$ level. Bold indicates the base category for categorical variables. \# indicates only the categories in the control variables that showed some statistical significance in column 6 are retained (specifically country, whether jointly responsible for energy, whether company is a franchise, whether has a smart meter, payment method and whether read their contract were retained). Columns 1-8 report odds ratios from ordered logit regressions where the odds are defined as the probability of an MSB being more satisfied with their current supplier's overall service relative to the probability of being less satisfied. Columns 9 and 10 report odds ratios from a generalised ordered logit model where a partial parallel odds assumption is allowed and the reported odds ratios relate to whether MSBs are Very Satisfied with their current supplier's overall service or are less satisfied. In columns where no figures for a particular variable are reported, the variable was not included in the relevant column's regression. In columns 2-4, 6 and 9 one observation is dropped for being perfectly determined. In columns 2-5, 7, 8 and 10 where a continuous energy expenditure variable is used 71 observations are dropped as responses of Don't Know/Refused can no longer be used. In columns $3-5,8$ and 10 where the log of energy expenditure is taken one observation is dropped for having a value of zero. When treating energy expenditure as continuous 224 observations involved taking the mid-point of a category. Variables frequently significant across regressions at the $5 \%$ level or above but not reported are (direction of association reported in brackets): located in Wales (positive); jointly responsible for energy supply (positive); payment method standard credit (negative, columns 6-10); and has read contract (positive, columns 6-10).

Table 4: Odds ratios for reporting greater satisfaction with an MSB's current energy supplier's overall service 
Considering the 2015 data in Table D4, the relationship between electricity expenditure and service satisfaction appears somewhat weaker than the results for energy expenditure in 2014. While in the 2015 univariate regression four of the electricity expenditure categories have reduced odds of reporting higher service satisfaction significant at the $5 \%$ level, when all the control variables are included (column 4) only two of the electricity expenditure categories remain significant at the $5 \%$ level.

Turning to energy expenditures' salience, it appears energy expenditures in absolute terms have the stronger association with service satisfaction. In a univariate regression the log of energy expenditure as a percentage of turnover is associated with reduced odds of higher service satisfaction at the $1 \%$ level. ${ }^{38}$ However, when log turnover and log energy expenditures are included as separate variables in the same regression, log turnover is statistically insignificant, while log energy expenditure has an association significant at the $1 \%$ level.

Moving beyond energy expenditures, an interesting result in 2014 is that having switched in the last five years is associated with a reduction, by up to a third, in the odds of higher service satisfaction, after controlling for the full range of engagement variables. That switching is associated with lower service satisfaction has a number of potential explanations. First, if price is the main determinant of switching it could be that firms attracting switchers offer a lower price by delivering a lower quality of service $^{39}$. Second, firms that switch could be those with higher service expectations so the negative association results from the type of firms that are motivated to switch. Third, it could be that the switching process itself results in customer service issues. However, it may be inappropriate to place great weight on this finding, since no association exists between having switched and service satisfaction in the 2015 regressions (Table D4).

\section{Conclusions and Policy Implications}

There are three main conclusions from the evidence presented in section 5. First, while there may be room to improve the retail energy market for MSBs, the descriptive statistics do not show clear problems, with one notable exception: the marketing of suppliers and brokers, with which there is clear dissatisfaction. Regarding MSB engagement, the survey evidence suggests that MSBs' 12-month switching rate is noticeably higher than for domestic consumers. When evaluating MSB engagement the main point to recognise is that many firms have multi-year contracts and so only a subset of MSBs can switch in any given year. Assessments of MSB engagement either have to look at a longer time period, for example 5 years, or the 12-month switching rate must be suitably adjusted.

Second, MSBs' dissatisfaction with energy brokers is correlated with the number of approaches an MSB recalls having received in the previous 12 months. An increase in the number of approaches recalled is associated with a reduction in the odds of an MSB reporting a positive view of brokers. Significantly, this relationship is robust to the inclusion of a variable recording whether an MSB used a broker as the main method to select their current energy supplier. In other words, even after controlling for firms who obtained a useful service from brokers, the view of brokers is negatively affected by the number of approaches recalled. There is also some evidence that recalling a greater number of approaches reduces the odds of being satisfied with the ease of comparing prices in the market.

Third, MSBs with low energy expenditures have higher odds of higher satisfaction with their current supplier's value for money and overall service than those with higher energy expenditures. This

\footnotetext{
${ }^{38}$ Again, for brevity, the full results are not reported.

${ }^{39}$ The quality variations would relate to customer support functions e.g. call centres and billing.
} 
relationship is non-linear with there appearing to be a step down in satisfaction for moderate and high energy expenditures. The simplest explanation for this observation is that the salience of energy matters: if energy expenditure is low, a firm may rationally give little thought to the cost of energy compared to other aspects of running a business. The hypothesis is that as long as a basic service is provided these firms are unlikely to report negative satisfaction. These relatively high levels of satisfaction may also mean that low usage MSB customers are unlikely to engage in the market, and that these MSBs are comfortable with their non-engagement. That low usage MSBs are less likely to engage receives support from Table $A 1$ where firms with higher energy expenditures are associated with a higher probability of having in the 5 years prior to the survey.

Below three policy issues are considered in detail: (i) how policymakers should treat energy brokers, (ii) that Ofgem's current survey only collects data from a subset of MSBs, and (iii) how regulators can maximise the benefits from customer surveys.

\subsection{Policy towards intermediaries}

Section 5 makes MSBs' widespread annoyance with brokers and, in particular, the number of marketing approaches, clear. Equally, Appendix A shows firms using a broker as their main choice method are associated with being more likely to have switched. This suggests the core regulatory task is limiting the quantity of unsolicited broker contact, while preserving the value of brokers for those firms choosing to use them.

MSBs' dissatisfaction with broker and energy suppliers' sales approaches is particularly notable as one of the CMA's proposed remedies for the MSB energy market is a database of 'disengaged' microbusinesses' contact details ${ }^{40}$ that rival suppliers could access so as to send microbusinesses marketing materials to encourage them to switch. While suppliers and brokers are distinct, our evidence suggests the quantity of marketing contact is key to MSBs' dislike of brokers. If the disengaged database leads to a large quantity of additional marketing contact, even if from suppliers rather than brokers, it seems likely to generate negativity among MSBs. Also, the distinction between the marketing of suppliers and brokers should not be overplayed: Figure 3 shows that MSBs' satisfaction with the sales approach of suppliers is also negatively skewed. Where the distinction between suppliers and brokers may be more meaningful is that there are fewer suppliers than brokers/intermediaries which may lead to a lower a volume of marketing contact. However, Table 1 shows that even a moderate increase in broker contact, from 1-5 approaches to 6-10 approaches is associated with more than a $40 \%$ drop in the odds of reporting a more positive opinion of brokers. These results indicate that if Ofgem proceeds with the database proposal they need to choose a design that provides the most relevant information and the greatest prompt to act on this information while also minimising the quantity of contact.

Two features of the database proposal potentially limit MSBs' annoyance, although, they also likely limit its ability to increase engagement. First, disengaged customers have the opportunity to opt-out from the database. Second, the proposed marketing communications involve letters ${ }^{41}$; throwing a letter in the bin is probably less frustrating than dealing with a cold caller. Nevertheless, it is striking that the CMA seems to have largely overlooked the evidence on MSBs' dissatisfaction with brokers' marketing contact. The CMA's approach is consistent with an assumption that remedies in the domestic market can be straightforwardly applied to the MSB market. The evidence in this paper suggests such an assumption is not appropriate.

\footnotetext{
40 Pg1193-1204, CMA (2016a)

${ }^{41}$ Para 17.241(b)(vi), pg1200, CMA (2016a)
} 
The current paper's evidence also suggests that greater regulation of energy brokers may be beneficial if it can separate brokers' useful search services from the nuisance of their marketing efforts. The CMA backed away from directly intervening in intermediaries' information provision on the basis that Ofgem would introduce a Code of Practice ${ }^{42}$ for intermediaries backed by a licence condition requiring suppliers only work with code-accredited intermediaries. As of December 2018, it is unclear where Ofgem has reached with this Code of Practice.

Regarding stronger regulatory interventions, one possibility could be to offer MSBs the ability to join a list opting out of unsolicited phone contact by brokers. The main concern with such an approach is that it could reduce switching and leave firms paying more for their energy. However, the seriousness of this concern depends on the proportion of switching resulting from cold-calling. ${ }^{43}$ Understanding how MSBs choose the broker they use to actually switch would seem important, but this question is not addressed by the current Ofgem surveys. The more that switches are linked to MSBs pro-actively seeking out a broker, the lower are the risks from an opt-out list.

Rather than tackling the volume of broker contact directly, the CMA placed importance on the type of intermediaries MSBs use to navigate the market. The CMA concluded that increased price transparency ${ }^{44}$ from energy suppliers would not only enable MSBs to bypass brokers but also encourage price comparison websites (PCWs) to enter the market. ${ }^{45}$ This seems based on the premise that price transparency will encourage 'good' intermediaries (PCWs) to supplant 'bad' intermediaries (poorly behaved brokers). While not an unreasonable premise, it is not certain that brokers will exit the market as intended, indeed, if they face declining business, in the short run they may even increase the quantity of their marketing activity in an attempt to attract business. Furthermore, the proposal relies on any online intermediaries which benefit from receiving supplier tariffs not engaging in 'excessive' marketing contact, something which is difficult to guarantee without regulatory oversight.

\subsection{Defining the population of MSBs}

When surveying domestic energy consumers the population of interest is relatively well defined as the population of households in the UK. ${ }^{46}$ In contrast, defining the MSB population depends on the policy emphasis. since 2014 Ofgem MSB surveys have explicitly required respondents to be on a nondomestic contract that they control directly. While this emphasis is reasonable (contract type affects the extent of regulatory protections), it creates a blind spot. By only sampling firms with non-domestic supply contracts the current methodology does not allow one to answer the following questions:

1. What factors influence whether an MSB purchases energy through a domestic or non-domestic contract?

2. Do many MSBs consciously choose between the two contract types?

3. Do regulatory issues arise from having similar MSBs using different contract types?

\footnotetext{
42 Pg1209, CMA (2016a)

${ }^{43}$ One assumes cold calling generates sufficient switches (and commissions) to be profitable for the brokers involved.

44 Pg1143-1169, CMA (2016a)

${ }^{45}$ As an alternative to providing details of tariffs on their own website, the CMA allows for suppliers to instead provide them to "third party online platforms", see paragraph 17.18, pg1144, CMA (2016a).

${ }^{46}$ Although there may still be sampling choices regarding households where landlords purchase energy and/or households that are 'off-grid'.
} 
4. Does running an MSB from a home influence how the household engages with the domestic energy market?

Using data from the Department for Business, Innovation and Skill's 2014 Small Businesses Survey, BMG $(2015)^{47}$ reports that the percentage of MSBs on non-domestic contracts varies by firms' sector and number of employees. According BMG (2015) the total population of firms with 49 or fewer employees is $2.1 \mathrm{~m}$, but the population on non-domestic contracts is only 940,000 . The issue is most dramatic for firms with no employees where only $28.6 \%$ use a non-domestic contract and the construction sector where only $23.1 \%$ use a non-domestic contract. Even among firms with 10-49 employees, $23.7 \%$ are judged to use domestic energy contracts. Overall, focusing on firms with nondomestic contracts implies a skew towards larger and, therefore, more established firms. If start-ups are thought to warrant a policy focus, for example, due to the role in economic growth, this may be a problem. Indeed, an issue unexplored by the survey is whether interactions with energy suppliers/the energy market (beyond high wholesale energy prices) ever impede firm growth.

\subsection{Maximising the value of market monitoring surveys}

For successful regulatory decision making it is essential that regulators have access to high quality data and analysis. High quality data and analysis should enable better decision making, leading to better outcomes for consumers, while poor or unexploited data risks regulatory mistakes. The current paper's findings regarding the dislike of broker contact illustrates the benefit of enabling wider access to datasets commissioned by regulators in terms of enabling new insights to be robustly identified through more in-depth analysis than the use of descriptive statistics.

As highlighted in Section 2, both Ofgem and Ofcom perform regular SME engagement surveys and UK regulators also perform regular surveys of domestic consumers. Since each survey is a costly exercise involving public money it is important to maximise the value and insights from these surveys. We suggest that to do this there should be a presumption that anonymised survey data commissioned by regulators is shared wherever legally possible. Where survey data cannot be shared, a public explanation should be provided. ${ }^{48}$

Ofgem and Ofcom are currently inconsistent in their approaches to sharing raw survey data. The current paper was made possible by Ofgem providing special access to its 2014 and 2015 surveys, although the identity of firms' energy suppliers was removed from the dataset made available to the authors. In contrast, raw survey data from Ofcom's 2016 SME can be freely downloaded from Ofcom's website, including the identity of SMEs' telecoms service providers. ${ }^{49}$ Ofcom's data sharing indicates at least one UK regulator believes the sharing of such data is legal.

The benefits of data sharing are twofold: (i) increased regulator transparency, and (ii) maximising the return on investment from surveys. Major government/national survey datasets are already routinely shared through the UK Data Archive ${ }^{50}$ and it would seem sensible for regulators' survey datasets to be made available through this managed route. Such an approach would be in keeping with the government's Open Data White Paper of 2012. ${ }^{51}$ While a regulator may have limited resources to interrogate datasets, allowing routine access to researchers and other parties should increase the use

\footnotetext{
${ }^{47}$ See Figure 3.2.

${ }^{48}$ Simply stating that a dataset "cannot be shared for legal reasons" lacks sufficient detail.

${ }^{49}$ See: https://www.ofcom.org.uk/research-and-data/multi-sector-research/generalcommunications/consumer-experience/sme-research (data accessed on 15/2/18).

50 See http://data-archive.ac.uk/

${ }^{51}$ HM Government (2012).
} 
of sophisticated statistical techniques to provide new and robust insights that can inform regulatory decisions.

It is notable that the CMA energy market investigation appears not to have used the raw data from Ofgem's 2014 MSB survey. Indeed, the CMA sometimes suggests evidence was unavailable to assess particular claims. For example, regarding whether larger firms were more likely to be contacted by brokers, the CMA states: "The 2014 survey did not provide a breakdown of the number of approaches by business size"52. Our analysis shows this is not strictly true: while the 2014 survey report (BMG, 2015) may not have broken down the number of approaches by business size, the raw data does enable this question to be answered. Having a common approach to data sharing across UK regulators may help to avoid this type of error.

Detailed exploration of survey data may also reveal methodological improvements to surveys. For example, the present analysis shows there are advantages to recording as many variables as possible in continuous rather than categorical form. Recording a potentially continuous variable as a categorical variable results in a loss of information. If possible, a survey should first seek a specific number as an answer, before using categories as a prompt for less informed respondents. In particular, only by collecting data for electricity and gas expenditures in a continuous can total energy expenditure variable be reliably constructed.

\section{Appendices}

\section{Appendix A - Factors associated with having switched}

\section{A1 A logit model for switching}

To analyse factors associated with firms switching in the five years prior to interview a logit model is used. The dependent variable, $z_{i}$, takes a value of 1 when a firm has switched energy supplier at least once and a value of 0 when a firm has not switched. ${ }^{53}$ For each firm the probability, $p_{i}$, of at least one switch having occurred is:

$$
z_{i}=\left\{\begin{array}{llr}
1 & \text { with probability } & p_{i} \\
0 & \text { with probability } & 1-p_{i}
\end{array}\right\}
$$

where the probability of a switch having taken place, $p_{i}$, is modelled as:

$$
p_{i}=\operatorname{Prob}\left(z_{i}=1 \mid \boldsymbol{x}_{\boldsymbol{i}}\right)=F\left(\boldsymbol{x}_{\boldsymbol{i}}^{\prime} \boldsymbol{\gamma}\right)
$$

Here $p_{i}$ is the probability a switch has occurred given the vector of explanatory values for firm $i, \boldsymbol{x}_{\boldsymbol{i}}$. This probability can be expressed as a function of $\boldsymbol{x}_{\boldsymbol{i}}$ multiplied by the coefficients for each variable found through the regression process, $\gamma$. Using the logit model assumes the error process for the latent variable behind the model is logistically distributed and $F($.$) is the logistic cumulative$ distribution function. The model is estimated using maximum likelihood estimation.

\footnotetext{
52 Paragraph 105, pg34, CMA (2016b).

${ }^{53}$ The switching variable only relates to the single fuel (electricity or gas) referenced in the survey questionnaire.
} 
In Table A1 average marginal effects are reported indicating the average percentage point increase in the probability of a switch having occurred associated with a change in a particular explanatory variable.

When interpreting the switching regressions the risk of reverse causality needs to be recognised. The dependent variable refers to switching behaviour over the five years prior to interview, while the explanatory variables refer to the time of interview or the 12 months before it. This issue is particularly likely for some of the engagement control variables. For example, while a respondent reporting having recently read their contract may indicate a savvy respondent who is particularly likely to have switched, it could also be that switching makes a respondent more likely to read their contract as they want to check their new contract details are correct. Due to the large number of variables potentially suffering from this issue and the limited data available we do not attempt any correction.

\section{A2 Likelihood of switching in the last 5 years}

When debating the marketing methods of energy brokers and whether there should be additional regulation, the first thing to note from Table $A 1$ is that a firm using any method other than a broker as the main method to select their current energy supply deal is associated with a reduction in the probability of having switched. Consulting a range of suppliers rather than using a broker as the main choice method reduces the probability of having switched by 18.5-19.8 percentage points (columns 4 to 7 of Table A1), significant at the $1 \%$ level. A firm only engaging with their current supplier is associated with the probability of having switched falling by 38.4-42.0 percentage points. This confirms the important association between broker use and MSB switching.

The next question is whether receiving a large amount of contact from brokers stimulates switching. In our data, receiving a large number of broker approaches, i.e. more than 6 , is not associated with a higher probability of having switched compared to receiving 1-5 broker approaches. This lack of significance is shown in both the univariate regression (column 5, Table B6) and the multivariate regressions in Table A1. However, recalling no broker approaches in the last 12 months is associated with a drop in the probability of having switched in the univariate regression and in the multivariate regressions where only firm demographic controls are included (columns 3 and 5, Table A1). Where the number of broker approaches is the only variable beyond the firm demographic controls (column 3 ), receiving no broker approaches is associated with an 11.0 percentage point drop in the probability of having switched in the previous 5 years, significant at the $5 \%$ level. However, this statistical significance is lost when the full set of engagement controls is included. Overall, these results suggest that limiting, but not banning, broker communications may have a limited negative impact on switching.

Turning to the association between energy expenditure and having switched, the existing literature from the residential energy market (e.g. Deller et al, 2017; Waddams Price and Zhu, 2016; Flores and Waddams Price, 2013) suggests firms with higher energy expenditures (who, on average, are likely to have larger savings) are more likely to switch. ${ }^{54}$ This is because firms with higher energy expenditures will have greater returns to allocating a fixed amount of time to seeking cheaper energy.

The results in Tables A1 and B4 provide partial support for this idea. While there is some evidence of a positive association between energy expenditure and having switched, it appears non-linear.

\footnotetext{
${ }^{54}$ Assuming they are not already with the cheapest supplier.
} 
Looking at the univariate regressions in Table B4, energy expenditure as a continuous linear variable is statistically significant at the $5 \%$, but the log of energy expenditure is significant at the $1 \%$ level.

Comparing columns 4-5 with columns 1-3 in Table A1, once the main choice method is included in the regressions the statistical significance of energy expenditure effectively disappears. This is perhaps unsurprising if we think different forms of engagement (e.g. comparing prices through a broker and switching) are strongly correlated, but energy expenditures are a motivation for firms to engage. In other words, if a firm has used a broker, knowing a firm's energy expenditure adds no additional information about the likelihood of switching, but higher energy expenditures may nevertheless increase the likelihood of both using a broker and switching.

The results based on the 2015 data in Table D5 largely mirror the 2014 results. One notable feature of the 2015 results is the number of employees has a statistically significant relationship with having switched, even after controlling for other factors. ${ }^{55}$ In 2015, having more than 5 employees, compared to having no employees, is associated with an increase of at least 14 percentage points in the probability of having switched in the previous five years, significant at the $1 \%$ level. $^{56}$

\footnotetext{
55 In 2014, while a continuous number of employees variable is significant at the $1 \%$ level in a univariate regression (column 5 , table $\mathrm{B} 1$ ), the same variable was insignificant at the $10 \%$ level in all the regressions in Table A1.

${ }^{56}$ When all the engagement controls are included (column 8, Table D4), the significance level of having 10-49 employees falls to $5 \%$.
} 


\begin{tabular}{|c|c|c|c|c|c|c|c|}
\hline Selected Explanatory Variables & (1) & (2) & (3) & (4) & (5) & (6) & (7) \\
\hline Energy Expenditure: $f 500$ or less & -0.083 & & & & & -0.049 & \\
\hline Energy Expenditure: $£ 501-1,000$ & 0.055 & & & & & 0.066 & \\
\hline Energy Expenditure: $£ 1-2.5 k$ & - & & & & & - & \\
\hline Energy Expenditure: $f 2.5-5 \mathrm{k}$ & $0.094^{* *}$ & & & & & $0.074^{*}$ & \\
\hline Energy Expenditure: f5-10k & $0.114^{* *}$ & & & & & $0.075^{*}$ & \\
\hline Energy Expenditure: f10-15k & $0.115^{*}$ & & & & & 0.065 & \\
\hline Energy Expenditure: $£ 15-25 k$ & $0.129 *$ & & & & & 0.065 & \\
\hline Energy Expenditure: $£ 25-50 \mathrm{k}$ & 0.057 & & & & & -0.038 & \\
\hline Energy Expenditure: f50k+ & 0.013 & & & & & -0.008 & \\
\hline \multicolumn{8}{|l|}{ Energy Expenditure: Don't } \\
\hline Know/Refused & 0.046 & & & & & 0.022 & \\
\hline Continuous: Log Energy Expenditure & & $0.033^{* *}$ & $0.031 * *$ & 0.016 & 0.015 & & 0.012 \\
\hline No. Broker Approaches: None & & & $-0.110^{* *}$ & & $-0.087^{*}$ & -0.048 & -0.045 \\
\hline No. Broker Approaches: 1-5 & & & - & & - & - & - \\
\hline No. Broker Approaches: 6-10 & & & -0.001 & & 0.005 & 0.008 & -0.001 \\
\hline No. Broker Approaches: 11-20 & & & -0.007 & & 0.018 & 0.005 & 0.023 \\
\hline No. Broker Approaches: 21-30 & & & 0.017 & & 0.040 & 0.036 & 0.049 \\
\hline No. Broker Approaches: 31 to 50 & & & -0.072 & & -0.048 & -0.074 & -0.045 \\
\hline No. Broker Approaches: 50+/too & & & -0.015 & & -0.009 & -0.016 & 0.001 \\
\hline No. Broker Approaches: Don't know & & & -0.039 & & 0.026 & 0.027 & 0.060 \\
\hline Main choice method: Broker & & & & - & - & - & - \\
\hline \multicolumn{8}{|l|}{ Main choice method: } \\
\hline PCW/telephone service & & & & $-0.096 * *$ & $-0.093 * *$ & $-0.090^{* *}$ & $-0.091^{* *}$ \\
\hline $\begin{array}{l}\text { Main choice method: Range of } \\
\text { suppliers }\end{array}$ & & & & $-0.187^{* * *}$ & $-0.190 * * *$ & $-0.185 * * *$ & $-0.198^{* * *}$ \\
\hline $\begin{array}{l}\text { Main choice method: Current } \\
\text { supplier only }\end{array}$ & & & & $-0.420 * * *$ & $-0.419^{* * *}$ & $-0.396 * * *$ & $-0.384 * * *$ \\
\hline Main choice method: Other & & & & $-0.223^{* *}$ & $-0.209 * *$ & $-0.233^{* * *}$ & $-0.212^{* *}$ \\
\hline Main choice method: Don't know & & & & $-0.415^{* * *}$ & $-0.426 * * *$ & $-0.342 * * *$ & $-0.355 * * *$ \\
\hline Log likelihood & -654.11 & -616.67 & -613.51 & -556.57 & -553.54 & -568.31 & -534.92 \\
\hline P-value, LR test joint significance & 0.000 & 0.000 & 0.000 & 0.000 & 0.000 & 0.000 & 0.000 \\
\hline Firm Demographic Controls & Yes & Yes & Yes & Yes & Yes & Yes & Yes \\
\hline Engagement Controls & No & No & No & No & No & Yes & Yes \\
\hline $\mathrm{N}$ & 1079 & 1008 & 1008 & 1008 & 1008 & 1078 & 1007 \\
\hline
\end{tabular}

Notes: * indicates statistical significance at the $10 \%$ level, ${ }^{* *}$ indicates significance at the $5 \%$ level, and ${ }^{* * *}$ indicates signifcance at the $1 \%$ level. Bold indicates the base category for categorical variables. The figures reported are average marginal effects associated with the probability of a firm having switched in the 5 years prior to interview. In columns where no figures for a particular variable are reported, the variable was not included in the column's regression. 71 observations are dropped in columns 2 to 5 and 7 as responses of Don't Know/Refused can no longer be used when energy expenditure is treated as continuous. When treating energy expenditure as continuous 224 observations involved taking the mid-point of a category. Variables frequently significant across regressions at the $5 \%$ level or above but not reported are (direction of association in brackets): with single supplier (negative), survey referenced gas supply (negative, columns 1-3) and turnover - f1-1.5m (positive, columns 1-5); the following variables were only significant in columns 6 and 7: sector - business services (positive), payment method - standard credit (negative), payment method - prepayment/other (positive), does not know when contract ends (negative) and does not have a fixed term contract (negative). In all columns one observation was dropped due to 'Franchise: Don't Know' perfectly predicting not switching and two or three observations were dropped for 'Single Supplier: Unsure' perfectly predicting switching. In columns 6 and 7 one observation was dropped due to 'Payment Method: Refused' perfectly predicting not switching.

Table A1: Average Marginal Effects on the Probability of Having Switched in the Previous 5 Years

\section{Appendix B - 2014 Univariate Regression Results}

In tables B1-B7, columns 1-4 report odds ratios from univariate ordered logit regressions where the ratios relate to the odds of being in a higher satisfaction category/having a more positive opinion. Column 5 in each table reports the average marginal effect on the probability of having switched supplier at least once in the previous five years. 


\begin{tabular}{l|cccc|c} 
& $\begin{array}{c}\text { (1) Overall } \\
\text { view of energy } \\
\text { brokers }\end{array}$ & $\begin{array}{c}\text { (2) Satisfaction with } \\
\text { current supplier's } \\
\text { value for money }\end{array}$ & $\begin{array}{c}\text { (3) Satisfaction } \\
\text { with current } \\
\text { supplier's overall } \\
\text { service }\end{array}$ & $\begin{array}{c}\text { (4) Satisfaction } \\
\text { with market's ease } \\
\text { of comparing } \\
\text { prices }\end{array}$ & $\begin{array}{c}\text { (5) Switched } \\
\text { in Last 5 Years }\end{array}$ \\
\hline Continuous Variable & & & & & \\
Number of Employees: & $1.023^{* * *}$ & 1.004 & 1.002 & 1.004 & $0.005^{* * *}$ \\
\hline No. of Observations & 1083 & 1083 & 1083 & 1083 & 1083 \\
\hline Categorical Variable & & & & & \\
Base Category: Employees: None & & & & 1.091 & $0.080^{*}$ \\
Employees: 1-4 & 0.896 & 0.978 & 1.180 & 0.968 & $0.159^{* * *}$ \\
Employees: 5-9 & 0.829 & 0.927 & 1.169 & 0.989 & $0.168^{* * *}$ \\
\hline Employees: $10-49$ & $1.359^{*}$ & 0.950 & 1.100 & 0.849 & 0.001 \\
\hline P-value, LR test joint significance & 0.004 & 0.972 & 0.778 & 1083 & 1083 \\
No. of Observations & 1083 & 1083 & 1083 & 0.983 \\
\hline
\end{tabular}

Notes: ${ }^{*}$ indicates statistical significance at the $10 \%$ level, ${ }^{* *}$ indicates significance at the $5 \%$ level, and ${ }^{* * *}$ indicates signifcance at the $1 \%$ level. Columns 1 4 report odds ratios from ordered logit regressions where the ratios relate to the odds of reporting higher satisfaction/a more positive opinion, column 5 reports average marginal effects on the probability of switching from a binary logit model. The odds ratios/average marginal effect for the continuous variable report the change associated with a 1 person increase in the number of employees.

Table B1 - Univariate regressions on number of employees

\begin{tabular}{|c|c|c|c|c|c|}
\hline & $\begin{array}{l}\text { (1) Overall } \\
\text { view of } \\
\text { energy } \\
\text { brokers }\end{array}$ & $\begin{array}{l}\text { (2) Satisfaction } \\
\text { with current } \\
\text { supplier's value } \\
\text { for money }\end{array}$ & $\begin{array}{l}\text { (3) Satisfaction } \\
\text { with current } \\
\text { supplier's } \\
\text { overall service }\end{array}$ & $\begin{array}{l}\text { (4) Satisfaction with } \\
\text { market's ease of } \\
\text { comparing prices }\end{array}$ & $\begin{array}{l}\text { (5) Switched } \\
\text { in Last } 5 \\
\text { Years }\end{array}$ \\
\hline \multicolumn{6}{|l|}{ Continuous Variable } \\
\hline Turnover (£100k units) & $1.010^{*}$ & 1.004 & 0.999 & 1.002 & $0.003 * *$ \\
\hline Turnover Squared ( $€ 100 k$ units) & 1.000 & 1.000 & 1.000 & 1.000 & -0.000 \\
\hline$P$-value, LR test joint significance & 0.055 & 0.561 & 0.394 & 0.587 & 0.015 \\
\hline No. of Observations & 807 & 807 & 807 & 807 & 807 \\
\hline \multicolumn{6}{|l|}{ Categorical Variable } \\
\hline Turnover: Below $f 73 \mathrm{k}$ & 1.115 & 1.012 & 0.878 & 0.990 & -0.043 \\
\hline Turnover: $£ 73-99 k$ & 1.152 & 1.376 & 1.204 & 1.599 & $-0.180^{*}$ \\
\hline \multicolumn{6}{|l|}{ Base Category - Turnover: $£ 100-249 k$} \\
\hline Turnover: f250-499k & 0.932 & $0.670 * *$ & 0.768 & 0.842 & 0.007 \\
\hline Turnover: $£ 500-999 k$ & 1.181 & 1.075 & 0.951 & 1.229 & 0.069 \\
\hline Turnover: $f 1-1.5 \mathrm{~m}$ & $1.756^{* *}$ & 1.282 & 0.991 & 0.992 & $0.229 * * *$ \\
\hline Turnover: $£ 1.5-2.8 \mathrm{~m}$ & 0.956 & 1.015 & 0.976 & 0.737 & 0.089 \\
\hline Turnover: $f 2.8-4.99 \mathrm{~m}$ & 1.009 & 1.372 & 1.370 & 0.941 & 0.004 \\
\hline Turnover: $£ 5-9.99 m$ & $3.035 * *$ & 1.301 & 0.833 & 1.778 & 0.168 \\
\hline Turnover: $\mathrm{f} 10 \mathrm{~m}+$ & 1.057 & 1.257 & 1.160 & 1.319 & $0.201^{*}$ \\
\hline Turnover: Don't Know & 1.394 & 1.063 & 1.077 & 1.403 & -0.015 \\
\hline Turnover: Refused & 1.017 & 1.105 & 1.086 & 1.240 & -0.001 \\
\hline $\begin{array}{l}\text {-value, } L R \text { test joint significance } \\
\text {. }\end{array}$ & 0.235 & 0.327 & 0.908 & 0.270 & 0.001 \\
\hline No. of Observations & 1083 & 1083 & 1083 & 1083 & 1083 \\
\hline
\end{tabular}

Notes: ${ }^{*}$ indicates statistical significance at the $10 \%$ level, ${ }^{* *}$ indicates significance at the $5 \%$ level, and ${ }^{* * *}$ indicates signifcance at the $1 \%$ level. Columns 1 . 4 report odds ratios from ordered logit regressions where the ratios relate to the odds of reporting higher satisfaction/a more positive opinion, column 7 reports average marginal effects on the probability of switching from a binary logit model. When treating turnover as continuous 140 observations involved taking the mid-point of a category. The lower number of observations when turnover is treated as continuous reflects the observations of don't know/refused that have to be dropped.

Table B2: Univariate regressions on turnover 


\begin{tabular}{|c|c|c|c|c|c|}
\hline & $\begin{array}{l}\text { (1) Overall } \\
\text { view of } \\
\text { energy } \\
\text { brokers } \\
\end{array}$ & $\begin{array}{c}\text { (2) Satisfaction } \\
\text { with current } \\
\text { supplier's value for } \\
\text { money } \\
\end{array}$ & $\begin{array}{l}\text { (3) Satisfaction } \\
\text { with current } \\
\text { supplier's } \\
\text { overall service } \\
\end{array}$ & $\begin{array}{c}\text { (4) Satisfaction } \\
\text { with market's ease } \\
\text { of comparing } \\
\text { prices }\end{array}$ & $\begin{array}{c}\text { (5) Switched } \\
\text { in Last } 5 \\
\text { Years }\end{array}$ \\
\hline \multicolumn{6}{|l|}{ Continuous Variable } \\
\hline Electricity Expenditure ( $₫ 500$ units) & $1.006^{*}$ & 0.995 & 0.997 & 0.999 & $0.002 * *$ \\
\hline $\begin{array}{l}\text { Electricity Expenditure Squared ( } ₫ 500 \\
\text { units) }\end{array}$ & 1.000 & 1.000 & 1.000 & 1.000 & -0.000 \\
\hline P-value, LR test joint significance & 0.086 & 0.275 & 0.629 & 0.964 & 0.112 \\
\hline No. of Observations & 1014 & 1014 & 1014 & 1014 & 1014 \\
\hline \multicolumn{6}{|l|}{ Continuous Variable } \\
\hline Log Electricity Expenditure & 1.056 & $0.862 * * *$ & $0.894 * *$ & $0.921 *$ & $0.045^{* * *}$ \\
\hline No. of Observations & 1013 & 1013 & 1013 & 1013 & 1013 \\
\hline \multicolumn{6}{|l|}{ Categorical Variable } \\
\hline Electricity Expenditure: Below f500 & 1.066 & 1.105 & 1.033 & 0.996 & -0.100 \\
\hline Electricity Expenditure: $£ 500-1,000$ & 1.115 & 1.064 & 1.071 & 0.977 & -0.014 \\
\hline \multicolumn{6}{|l|}{ Base Category - Electricity } \\
\hline \multicolumn{6}{|l|}{ Expenditure: $f 1-2.5 k$} \\
\hline Electricity Expenditure: $£ 2.5-5 \mathrm{k}$ & $0.697^{* *}$ & $0.642 * * *$ & 1.042 & 0.773 & 0.038 \\
\hline Electricity Expenditure: $f 5-10 \mathrm{k}$ & 1.332 & $0.606^{* * *}$ & $0.625^{* *}$ & $0.719^{*}$ & $0.113^{* *}$ \\
\hline Electricity Expenditure: $f 10-15 k$ & 0.792 & $0.444 * * *$ & $0.483^{* * *}$ & $0.563^{* *}$ & $0.125^{* *}$ \\
\hline Electricity Expenditure: $£ 15-25 k$ & $1.613^{*}$ & 0.677 & $0.594^{*}$ & 0.801 & $0.130 *$ \\
\hline Electricity Expenditure: $f 25-50 \mathrm{k}$ & $2.463^{* *}$ & 0.987 & 1.196 & 1.151 & 0.102 \\
\hline Electricity Expenditure: f50k+ & 1.636 & 1.143 & 1.563 & 1.155 & 0.011 \\
\hline Electricity Expenditure: Don't Know & 1.500 & $0.617^{*}$ & 0.640 & 0.678 & 0.024 \\
\hline Electricity Expenditure: Refused & $0.313^{* *}$ & $2.522 *$ & $3.363^{* *}$ & 1.130 & 0.042 \\
\hline P-value, LR test joint significance & 0.001 & 0.001 & 0.001 & 0.333 & 0.069 \\
\hline No. of Observations & 1083 & 1083 & 1083 & 1083 & 1083 \\
\hline
\end{tabular}

Table B3: Univariate regressions on electricity expenditure 


\begin{tabular}{|c|c|c|c|c|c|}
\hline & $\begin{array}{l}\text { (1) Overall } \\
\text { view of } \\
\text { energy } \\
\text { brokers }\end{array}$ & $\begin{array}{c}\text { (2) Satisfaction } \\
\text { with current } \\
\text { supplier's value for } \\
\text { money }\end{array}$ & $\begin{array}{c}\text { (3) Satisfaction } \\
\text { with current } \\
\text { supplier's overall } \\
\text { service }\end{array}$ & $\begin{array}{c}\text { (4) Satisfaction } \\
\text { with market's } \\
\text { ease of } \\
\text { comparing prices }\end{array}$ & $\begin{array}{l}\text { (5) Switched } \\
\text { in Last } 5 \\
\text { Years }\end{array}$ \\
\hline \multicolumn{6}{|l|}{ Continuous Variable } \\
\hline Energy Expenditure ( $₫ 500$ units) & 1.003 & $0.995^{*}$ & 0.997 & 0.998 & $0.002 * *$ \\
\hline Energy Expenditure Squared ( $₫ 500$ units) & 1.000 & 1.000 & 1.000 & 1.000 & -0.000 \\
\hline P-value, LR test joint significance & 0.021 & 0.041 & 0.122 & 0.132 & 0.011 \\
\hline No. of Observations & 1012 & 1012 & 1012 & 1012 & 1012 \\
\hline \multicolumn{6}{|l|}{ Continuous Variable } \\
\hline Log Energy Expenditure & $1.084^{*}$ & $0.851 * * *$ & $0.886 * * *$ & $0.914^{* *}$ & $0.047^{* * *}$ \\
\hline No. of Observations & 1011 & 1011 & 1011 & 1011 & 1011 \\
\hline \multicolumn{6}{|l|}{ Categorical Variable } \\
\hline Energy Expenditure: $f 500$ or less & 1.083 & 1.299 & 1.141 & 0.985 & -0.102 \\
\hline Energy Expenditure: $f 501$ to $f 1000$ & 0.998 & 0.985 & 0.971 & 0.876 & 0.034 \\
\hline \multicolumn{6}{|l|}{$\begin{array}{l}\text { Base Category - Energy Expenditure: } f 1 \text { - } \\
2.5 \mathrm{k}\end{array}$} \\
\hline Energy Expenditure: $f 2.5-5 \mathrm{k}$ & 0.897 & $0.646 * * *$ & 0.791 & 0.822 & $0.088^{*}$ \\
\hline Energy Expenditure: $f 5-10 \mathrm{k}$ & 1.151 & $0.582 * * *$ & $0.678 * *$ & $0.631 * * *$ & $0.122^{* * *}$ \\
\hline Energy Expenditure: $f 10-15 k$ & 0.967 & $0.522 * * *$ & $0.607^{* *}$ & 0.767 & $0.139 * *$ \\
\hline Energy Expenditure: $f 15-25 \mathrm{k}$ & 1.048 & $0.646 *$ & $0.549 * *$ & $0.505^{* * *}$ & $0.168 * * *$ \\
\hline Energy Expenditure: f25-50k & $2.747^{* * *}$ & 0.627 & 0.696 & 0.77 & $0.143^{*}$ \\
\hline Energy Expenditure: f50k+ & 1.676 & 0.748 & 0.874 & 0.977 & 0.106 \\
\hline Energy Expenditure Don't Know/ Refused & 1.169 & 0.788 & 0.823 & 0.710 & 0.04 \\
\hline P-value, LR test joint significance & 0.093 & 0.005 & 0.134 & 0.176 & 0.008 \\
\hline No. of Observations & 1083 & 1083 & 1083 & 1083 & 1083 \\
\hline
\end{tabular}

Notes: ${ }^{*}$ indicates statistical significance at the $10 \%$ level, ${ }^{* *}$ indicates significance at the $5 \%$ level, and ${ }^{* * *}$ indicates signifcance at the $1 \%$ level. Columns 1-4 report odds ratios from ordered logit regressions where the ratios relate to the odds of reporting higher satisfaction/a more positive opinion, column 5 reports average marginal effects on the probability of switching from a binary logit model. When treating energy expenditure as continuous 224 observations involved taking the mid-point of a category and 71 observations are dropped where respondents refused to give their electricity/gas expenditure or responded 'Don't Know'. When using log energy expenditure one observation is dropped where the energy expenditure is $£ 0$.

\section{Table B4: Univariate regressions on energy expenditure}

\begin{tabular}{|c|c|c|c|c|}
\hline & $\begin{array}{c}\text { (1) Overall } \\
\text { view of energy } \\
\text { brokers }\end{array}$ & $\begin{array}{l}\text { (2) Satisfaction } \\
\text { with current } \\
\text { supplier's value } \\
\text { for money }\end{array}$ & $\begin{array}{c}\text { (3) Satisfaction } \\
\text { with current } \\
\text { supplier's overall } \\
\text { service }\end{array}$ & $\begin{array}{l}\text { (4) Satisfaction } \\
\text { with market's ease } \\
\text { of comparing } \\
\text { prices }\end{array}$ \\
\hline \multirow{2}{*}{\multicolumn{5}{|c|}{$\begin{array}{l}\text { Categorical Variable } \\
\text { Base Category - Not switched in } \\
\text { last } 5 \text { years }\end{array}$}} \\
\hline & & & & \\
\hline Has Switched in Last 5 Years & $1.328^{* *}$ & 0.882 & $0.715^{* * *}$ & 0.958 \\
\hline No. of Observations & 1083 & 1083 & 1083 & 1083 \\
\hline
\end{tabular}

Notes: ${ }^{*}$ indicates statistical significance at the $10 \%$ level, ${ }^{* *}$ indicates significance at the $5 \%$ level, and ${ }^{* * *}$ indicates signifcance at the $1 \%$ level. Columns 1-4 report odds ratios from ordered logit regressions where the ratios relate to the odds of reporting higher satisfaction/a more positive opinion.

Table B5: Univariate regressions on whether switched in last 5 years 


\begin{tabular}{|c|c|c|c|c|c|}
\hline & $\begin{array}{l}\text { (1) Overall } \\
\text { view of } \\
\text { energy } \\
\text { brokers }\end{array}$ & $\begin{array}{l}\text { (2) Satisfaction } \\
\text { with current } \\
\text { supplier's value } \\
\text { for money }\end{array}$ & $\begin{array}{l}\text { (3) Satisfaction } \\
\text { with current } \\
\text { supplier's } \\
\text { overall service }\end{array}$ & $\begin{array}{c}\text { (4) Satisfaction } \\
\text { with market's } \\
\text { ease of } \\
\text { comparing prices }\end{array}$ & \begin{tabular}{|c} 
(5) \\
Switched \\
in Last 5 \\
Years
\end{tabular} \\
\hline \multicolumn{6}{|l|}{ Continuous Variable } \\
\hline Number of Broker Approaches & $0.989 * * *$ & 1.000 & 1.001 & $0.998 * *$ & 0.000 \\
\hline No. of Observations & 1028 & 1028 & 1028 & 1028 & 1028 \\
\hline $\begin{array}{l}\text { Categorical Variable } \\
\text { No. of Approaches: None } \\
\text { Base Category - No. of Approaches: } \\
1-5\end{array}$ & 0.862 & 1.203 & 1.034 & $1.414^{*}$ & $-0.155^{* * *}$ \\
\hline No. of Approaches: 6-10 & $0.543 * * *$ & 0.918 & 1.028 & $0.723 *$ & 0.011 \\
\hline No. of Approaches: $11-20$ & $0.353^{* * *}$ & 0.949 & 0.875 & 0.791 & 0.013 \\
\hline No. of Approaches: $21-30$ & $0.241^{* * *}$ & 1.248 & 0.864 & $0.446 * * *$ & 0.033 \\
\hline No. of Approaches: $31-50$ & $0.160 * * *$ & 2.035 & 1.351 & 1.307 & -0.123 \\
\hline $\begin{array}{l}\text { No. of Approaches: } 50+/ \text { too many to } \\
\text { remember }\end{array}$ & $0.201 * * *$ & 0.912 & 0.772 & $0.611 * * *$ & -0.006 \\
\hline No. of Approaches: Don't know & $0.507^{* *}$ & 1.222 & 0.935 & 0.998 & -0.060 \\
\hline P-value, LR test joint significance & 0.000 & 0.702 & 0.493 & 0.000 & 0.032 \\
\hline No. of Observations & 1083 & 0.001 & 1083 & 1083 & 1083 \\
\hline $\begin{array}{l}\text { Notes: }{ }^{*} \text { indicates statistical significance at } \\
\text { level. Columns } 1-4 \text { report odds ratios from } \\
\text { more positive opinion, column } 5 \text { reports a } \\
\text { ratios/average marginal effect for the cont } \\
\text { number of observations when the number }\end{array}$ & $\begin{array}{l}\text { he } 10 \% \text { level, }{ }^{* *} \\
\text { rdered logit reg } \\
\text { erage marginal } \\
\text { quous variable } r\end{array}$ & $\begin{array}{l}\text { indicates significance } \\
\text { essions where the ra } \\
\text { effects on the proba } \\
\text { eport the change ass }\end{array}$ & $\begin{array}{l}\text { at the } 5 \% \text { level, anc } \\
\text { ios relate to the odd } \\
\text { ility of switching } \mathrm{fr} \\
\text { ociated with one add }\end{array}$ & $\begin{array}{l}\text { is* indicates signifcan } \\
\text { of a binary logit mode }\end{array}$ & $\begin{array}{l}\text { nce at the } 1 \% \\
\text { satisfaction/a } \\
\text { el. The odds }\end{array}$ \\
\hline
\end{tabular}

Table B6: Univariate regressions on reported number of broker approaches

\begin{tabular}{|c|c|c|c|c|c|}
\hline & $\begin{array}{l}\text { (1) Overall } \\
\text { view of } \\
\text { energy } \\
\text { brokers }\end{array}$ & $\begin{array}{l}\text { (2) Satisfaction } \\
\text { with current } \\
\text { supplier's value } \\
\text { for money }\end{array}$ & $\begin{array}{c}\text { (3) Satisfaction } \\
\text { with current } \\
\text { supplier's overall } \\
\text { service }\end{array}$ & $\begin{array}{c}\text { (4) Satisfaction } \\
\text { with market's } \\
\text { ease of } \\
\text { comparing prices }\end{array}$ & $\begin{array}{c}(5) \\
\text { Switched } \\
\text { in Last } 5 \\
\text { Years }\end{array}$ \\
\hline \multicolumn{6}{|l|}{ Categorical Variable } \\
\hline Base Category - Main Choice & & & & & \\
\hline Method: Broker & & & & & \\
\hline $\begin{array}{l}\text { Main Choice Method: } \\
\text { PCW/telephone service }\end{array}$ & $0.277^{* * *}$ & $1.384^{*}$ & 1.203 & 1.200 & $-0.120 * * *$ \\
\hline $\begin{array}{l}\text { Main Choice Method: Range of } \\
\text { suppliers }\end{array}$ & $0.170 * * *$ & 1.202 & 1.248 & 0.823 & $-0.184 * * *$ \\
\hline $\begin{array}{l}\text { Main Choice Method: Current } \\
\text { supplier only }\end{array}$ & $0.191 * * *$ & 1.238 & 1.176 & 0.852 & $-0.466 * * *$ \\
\hline Main Choice Method: Other & $0.079 * * *$ & 0.631 & $0.440 * *$ & $0.513^{* *}$ & $-0.249 * * *$ \\
\hline Main Choice Method: Don't know & 0.597 & 1.291 & 1.456 & 0.903 & $-0.475 * * *$ \\
\hline P-value, LR test joint significance & 0.000 & 0.187 & 0.053 & 0.105 & 0.000 \\
\hline No. of Observations & 1083 & 1083 & 1083 & 1083 & 1083 \\
\hline
\end{tabular}

Table B7 - Univariate regressions on main method for choosing current deal

\section{Appendix C - Univariate regressions violating the proportional odds assumption}

Regressions in Tables B5 to B8 for the dependent variables (1)-(4) were re-run using the generalised ordered logit model. For almost all regressions the proportional odds assumption was not rejected at the $1 \%$ level, in other words, the results in Appendix B are valid. Below we report the small number of 
cases where the proportional odds assumption was violated. Even here, for categorical variables, the proportional odds assumption was violated only for a small subset of categories.

\begin{tabular}{|c|c|c|c|}
\hline $\begin{array}{l}\text { Dependent } \\
\text { Variable }\end{array}$ & $\begin{array}{l}\text { Explanatory } \\
\text { Variable }\end{array}$ & $\begin{array}{l}\text { Explanatory } \\
\text { Variable Category }\end{array}$ & Differences to results in Appendix B \\
\hline $\begin{array}{l}\text { Current } \\
\text { supplier's } \\
\text { value for } \\
\text { money }\end{array}$ & $\begin{array}{l}\text { Energy } \\
\text { Expenditure } \\
\text { (categorical) }\end{array}$ & $£ 5,000-10,000$ & $\begin{array}{l}\text { In all instances the odds ratio remains less } \\
\text { than one, but the effect becomes } \\
\text { insignificant at the } 10 \% \text { level when the odds } \\
\text { ratio involves being in the Very satisfied } \\
\text { category. }\end{array}$ \\
\hline $\begin{array}{l}\text { Current } \\
\text { supplier's } \\
\text { overall } \\
\text { service }\end{array}$ & $\begin{array}{l}\text { Log Energy } \\
\text { Expenditure } \\
\text { (continuous) }\end{array}$ & - & $\begin{array}{l}\text { In all instances the odds ratio remains less } \\
\text { than one, but the effect becomes } \\
\text { insignificant at the } 10 \% \text { level when the odds } \\
\text { ratio involves being in the Very satisfied } \\
\text { category. }\end{array}$ \\
\hline $\begin{array}{l}\text { Overall } \\
\text { opinion of } \\
\text { brokers }\end{array}$ & $\begin{array}{l}\text { Number of } \\
\text { broker } \\
\text { approaches } \\
\text { (categorical) }\end{array}$ & Not Approached & $\begin{array}{l}\text { When looking at being in the Very satisfied } \\
\text { category the odds ratio is above } 1 \text {. When } \\
\text { the odds ratio concerns being above Neither } \\
\text { satisfied nor dissatisfied, the odds ratio is } \\
\text { less than } 1 \text { but significant at the } 10 \% \text { level. }\end{array}$ \\
\hline $\begin{array}{l}\text { Current } \\
\text { supplier's } \\
\text { value for } \\
\text { money }\end{array}$ & $\begin{array}{l}\text { Number of } \\
\text { broker } \\
\text { approaches } \\
\text { (categorical) }\end{array}$ & Not Approached & $\begin{array}{l}\text { When the odds ratio concerns being above } \\
\text { Neither satisfied nor dissatisfied, the odds } \\
\text { ratio is less than } 1 . \text { However, in all instances } \\
\text { the odds ratios are insignificant at the } 10 \% \\
\text { level. }\end{array}$ \\
\hline $\begin{array}{l}\text { Current } \\
\text { supplier's } \\
\text { value for } \\
\text { money }\end{array}$ & $\begin{array}{l}\text { Number of } \\
\text { broker } \\
\text { approaches } \\
\text { (categorical) }\end{array}$ & 21-30 times & $\begin{array}{l}\text { Apart from when the odds ratio concerns } \\
\text { being in the Very satisfied category, the } \\
\text { odds ratio is below } 1 . \text { However, in all } \\
\text { instances the odds ratios are insignificant }\end{array}$ \\
\hline $\begin{array}{l}\text { Ease of } \\
\text { comparing } \\
\text { prices in the } \\
\text { market }\end{array}$ & $\begin{array}{l}\text { Number of } \\
\text { broker } \\
\text { approaches } \\
\text { (continuous) }\end{array}$ & - & $\begin{array}{l}\text { The overall statistical significance of this } \\
\text { variable is driven by looking at the odds } \\
\text { ratio of being above the Very dissatisfied } \\
\text { category, which is significant at the } 1 \% \text { level. } \\
\text { While all odds ratios are less than } 1 \text {, being } \\
\text { above the Neither satisfied nor dissatisfied } \\
\text { category is the only other significant odds } \\
\text { ratio, and here it is significant only at the } \\
10 \% \text { level. }\end{array}$ \\
\hline
\end{tabular}

Table C1: Instances in univariate regressions where the proportional odds assumption did not hold

\section{Appendix D - Results from 2015}

The following tables report regressions run using the 2015 data. The regressions have been specified so they match the 2014 regressions as far as possible, however, significant differences still remain. First, as the 2015 data does not identify whether the survey asked about an MSB's gas or electricity supplier, unlike in 2014, we drop those cases where a firm uses both electricity and gas but each fuel is supplied by different firms. We only consider firms supplied by a single energy company. Second, the 2015 data does not include electricity expenditure, gas expenditure or the number of broker approaches as continuous variables. Third, as electricity and gas expenditures are categorical variables where the categories have varying widths it is not possible to create a combined 'energy expenditure' variable. Last, in 2015 there is no variable indicating whether or not the MSB is based in a home. 


\begin{tabular}{|c|c|c|c|c|c|}
\hline Selected Explanatory Variables & (1) & (2) & (3) & (4) & (5) \\
\hline 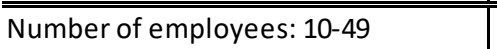 & & & $1.628^{* *}$ & $\overline{1.719^{* *}}$ & 1.597* \\
\hline Electricity Expenditure: $₫ 500$ or less & & & - & - & - \\
\hline Electricity Expenditure: $£ 501-1,000$ & & & 0.723 & 0.893 & $0.644^{*}$ \\
\hline Electricity Expenditure: $£ 1-2.5 \mathrm{k}$ & & & 0.805 & 0.814 & 0.724 \\
\hline Electricity Expenditure: $£ 2.5-5 \mathrm{k}$ & & & 0.870 & 0.928 & 0.858 \\
\hline Electricity Expenditure: $£ 5-10 k$ & & & 0.932 & 0.872 & 0.883 \\
\hline Electricity Expenditure: f10-15k & & & 0.664 & 0.684 & 0.557 \\
\hline Electricity Expenditure: f15-25k & & & 1.377 & 1.238 & 1.485 \\
\hline Electricity Expenditure: $£ 25-50 k$ & & & 2.011 & 1.505 & 2.043 \\
\hline Electricity Expenditure: $£ 50 k+$ & & & 1.091 & 0.710 & 0.969 \\
\hline Electricity Expenditure: Don't Know & & & 0.636 & 0.692 & 0.640 \\
\hline Electricity Expenditure: Refused & & & 0.114 & 0.345 & 0.263 \\
\hline Not switched in last 5 years & & & & & - \\
\hline Has Switched in Last 5 Years & & & & & 1.083 \\
\hline No. Broker Approaches: None & 0.758 & & 0.754 & & 1.101 \\
\hline No. Broker Approaches: 1-5 & - & & - & & - \\
\hline No. Broker Approaches: 6-10 & $0.566^{* * *}$ & & $0.541^{* * *}$ & & $0.599 * *$ \\
\hline No. Broker Approaches: $11-20$ & $0.272^{* * *}$ & & $0.256^{* * *}$ & & $0.287^{* * *}$ \\
\hline No. Broker Approaches: 21-30 & $0.150 * * *$ & & $0.143^{* * *}$ & & $0.148^{* * *}$ \\
\hline No. Broker Approaches: 31 to 50 & $0.251 * * *$ & & $0.240 * * *$ & & $0.234^{* * *}$ \\
\hline $\begin{array}{l}\text { No. Broker Approaches: } 50+/ \text { too many } \\
\text { to remember }\end{array}$ & $0.129 * * *$ & & $0.117 * * *$ & & $0.126^{* * *}$ \\
\hline No. Broker Approaches: Don't know & $0.447^{* *}$ & & $0.453^{* *}$ & & 0.574 \\
\hline Main choice method: Broker & & - & & - & - \\
\hline $\begin{array}{l}\text { Main choice method: PCW/telephone } \\
\text { service }\end{array}$ & & $0.341 * * *$ & & $0.273^{* * *}$ & $0.252^{* * *}$ \\
\hline $\begin{array}{l}\text { Main choice method: Range of } \\
\text { suppliers }\end{array}$ & & $0.207 * * *$ & & $0.176^{* * *}$ & $0.182^{* * *}$ \\
\hline $\begin{array}{l}\text { Main choice method: Current supplier } \\
\text { only }\end{array}$ & & $0.207 * * *$ & & $0.176^{* * *}$ & $0.177^{* * *}$ \\
\hline Main choice method: Other & & $0.144^{* * *}$ & & $0.124^{* * *}$ & $0.130^{* * *}$ \\
\hline Main choice method: Don't know & & $0.345^{* * *}$ & & $0.281^{* * *}$ & $0.306^{* * *}$ \\
\hline Log likelihood & -1338.37 & -1359.01 & -1314.63 & -1325.87 & -1238.94 \\
\hline P-value, LR test joint significance & 0.000 & 0.000 & 0.000 & 0.000 & 0.000 \\
\hline Firm Demographic Controls & No & No & Yes & Yes & Yes \\
\hline Engagement Controls & No & No & No & No & Yes \\
\hline $\mathrm{N}$ & 957 & 957 & 957 & 957 & 956 \\
\hline
\end{tabular}

Notes: ${ }^{*}$ indicates statistical significance at the $10 \%$ level, ${ }^{* *}$ indicates significance at the $5 \%$ level, and $* * *$ indicates signifcance at the $1 \%$ level. Bold indicates the base category for categorical variables. Odds ratios from ordered logit regressions are reported where the odds are defined as the probability of an MSB having a more positive overall view of energy brokers relative to the probability of having a less positive view. In columns where no figures for a particular variable are reported, the variable was not included in the relevant column's regression. In column 5 one observation is dropped for being perfectly determined. The set of control variables differs to that in the 2014 regressions due to the nature of the 2015 dataset. Variables often significant across regressions at the $5 \%$ level or above but not reported are (direction of association reported in brackets): sector - transport, food and accommodation (negative); turnover - f2.5-4.99m (negative); and gas expenditure $-£ 2,500-5,000$ (negative).

Table D1: Odds ratios for reporting a more positive overall view of energy brokers - 2015 data 


\begin{tabular}{|c|c|c|c|c|c|}
\hline Selected Explanatory Variables & (1) & (2) & (3) & (4) & (5) \\
\hline Number of employees: $10-49$ & & & 1.119 & 1.118 & 1.134 \\
\hline Electricity Expenditure: $f 500$ or less & & & $1.467^{*}$ & 1.340 & $1.619 * *$ \\
\hline Electricity Expenditure: $£ 501-1,000$ & & & 1.141 & 1.147 & 1.216 \\
\hline Electricity Expenditure: $₫ 1-2.5 k$ & & & - & - & - \\
\hline Electricity Expenditure: $£ 2.5-5 \mathrm{k}$ & & & 1.165 & 1.125 & 1.236 \\
\hline Electricity Expenditure: $£ 5$-10k & & & 1.348 & 1.316 & 1.441 \\
\hline Electricity Expenditure: $£ 10-15 k$ & & & 0.859 & 0.877 & 0.913 \\
\hline Electricity Expenditure: f15-25k & & & 1.311 & 1.254 & 1.378 \\
\hline Electricity Expenditure: $£ 25-50 k$ & & & 2.022 & 1.808 & 2.244 \\
\hline Electricity Expenditure: $f 50 \mathrm{k}+$ & & & 0.670 & 0.683 & 0.704 \\
\hline Electricity Expenditure: Don't Know & & & 0.928 & 0.920 & 0.973 \\
\hline Not switched in last 5 years & & & & & - \\
\hline Has Switched in Last 5 Years & & & & & 0.807 \\
\hline No. Broker Approaches: None & 0.815 & & 0.763 & & 0.839 \\
\hline No. Broker Approaches: 1-5 & - & & - & & - \\
\hline No. Broker Approaches: 6-10 & 0.889 & & 0.887 & & 0.878 \\
\hline No. Broker Approaches: 11-20 & 0.744 & & $0.721^{*}$ & & $0.698^{*}$ \\
\hline No. Broker Approaches: 21-30 & $0.361^{* * *}$ & & $0.343^{* * *}$ & & $0.338 * * *$ \\
\hline No. Broker Approaches: 31 to 50 & 0.683 & & $0.585^{*}$ & & $0.577^{*}$ \\
\hline $\begin{array}{l}\text { No. Broker Approaches: } 50+/ \text { too } \\
\text { many to remember }\end{array}$ & $0.756^{*}$ & & 0.774 & & 0.787 \\
\hline No. Broker Approaches: Don't know & 0.806 & & 0.916 & & 0.995 \\
\hline Main choice method: Broker & & - & & - & - \\
\hline $\begin{array}{l}\text { Main choice method: } \\
\text { PCW/telephone service }\end{array}$ & & 1.390 & & 1.291 & 1.323 \\
\hline $\begin{array}{l}\text { Main choice method: Range of } \\
\text { suppliers }\end{array}$ & & 1.023 & & 0.937 & 0.960 \\
\hline $\begin{array}{l}\text { Main choice method: Current } \\
\text { supplier only }\end{array}$ & & 1.128 & & 1.058 & 1.078 \\
\hline Main choice method: Other & & 0.893 & & 0.885 & 1.168 \\
\hline Main choice method: Don't know & & 1.321 & & 1.152 & 1.208 \\
\hline Log likelihood & -1505.94 & -1513.01 & -1474.09 & -1482.69 & -1460.1 \\
\hline$P$-value, LR test joint significance & 0.012 & 0.575 & 0.002 & 0.037 & 0.001 \\
\hline Firm Demographic Controls & No & No & Yes & Yes & Yes \\
\hline Engagement Controls & No & No & No & No & Yes \\
\hline $\mathrm{N}$ & 957 & 957 & 957 & 957 & 957 \\
\hline
\end{tabular}

Notes: ${ }^{*}$ indicates statistical significance at the $10 \%$ level, ${ }^{* *}$ indicates significance at the $5 \%$ level, and $* * *$ indicates signifcance at the $1 \%$ level. Bold indicates the base category for categorical variables. Odds ratios from ordered logit regressions are reported where the odds are defined as the probability of an MSB being more satisfied with the ease of comparing prices in the market relative to the probability of being less satisfied. In columns where no figures for a particular variable are reported, the variable was not included in the relevant column's regression. The set of control variables differs to that in the 2014 regressions due to the nature of the 2015 dataset. Variables often significant across regressions at the $5 \%$ level or above but not reported are (direction of association reported in brackets): turnover - $f 5 \mathrm{~m}+$ (positive); gas expenditure - has connection, but below $f 500$ (positive) and, in column 5 , does not know contract end date or does not have a fixed term contract (negative).

\section{Table D2: Odds ratios for reporting higher satisfaction with the ease of comparing prices in the market - 2015 data}




\begin{tabular}{|c|c|c|c|c|}
\hline Selected Explanatory Variables & (1) & $(2)$ & (3) & (4) \\
\hline Electricity Expenditure: $f 500$ or less & - & - & - & - \\
\hline Electricity Expenditure: $£ 501-1,000$ & 0.805 & 0.786 & 0.745 & 0.674 \\
\hline Electricity Expenditure: $£ 1-2.5 \mathrm{k}$ & 0.713 & 0.709 & 0.679 & $0.645^{*}$ \\
\hline Electricity Expenditure: $£ 2.5-5 \mathrm{k}$ & $0.618^{* *}$ & $0.621^{*}$ & $0.583^{* *}$ & $0.548^{* *}$ \\
\hline Electricity Expenditure: $£ 5-10 \mathrm{k}$ & $0.529 * *$ & $0.524^{* *}$ & $0.485^{* *}$ & $0.452^{* * *}$ \\
\hline Electricity Expenditure: $£ 10-15 k$ & $0.421^{* * *}$ & $0.424^{* *}$ & $0.429 * *$ & $0.376^{* * *}$ \\
\hline Electricity Expenditure: $f 15-25 \mathrm{k}$ & $0.356^{* *}$ & $0.355^{* *}$ & $0.330^{* *}$ & $0.272^{* * *}$ \\
\hline Electricity Expenditure: $£ 25-50 k$ & 0.526 & 0.460 & 0.438 & $0.376^{*}$ \\
\hline lectricity Expenditure: f50k+ & $0.343^{*}$ & $0.326^{*}$ & $0.311^{*}$ & $0.300^{*}$ \\
\hline Electricity Expenditure: Don't Know & 0.784 & 0.792 & 0.718 & 0.674 \\
\hline Not switched in last 5 years & & & - & - \\
\hline las Switched in Last 5 Years & & & 0.908 & 0.819 \\
\hline No. Broker Approaches: None & & & $0.522 * * *$ & $0.587^{* *}$ \\
\hline o. Broker Approaches: 1-5 & & & - & - \\
\hline o. Broker Approaches: 6-10 & & & $0.706^{*}$ & $0.691^{*}$ \\
\hline o. Broker Approaches: 11-20 & & & 0.900 & 0.873 \\
\hline o. Broker Approaches: 21-30 & & & 0.757 & 0.669 \\
\hline o. Broker Approaches: 31 to 50 & & & 0.934 & 0.986 \\
\hline $\begin{array}{l}\text { lo. Broker Approaches: 50+/too } \\
\text { nany to remember }\end{array}$ & & & $0.695^{* *}$ & $0.724^{*}$ \\
\hline No. Broker Approaches: Don't know & & & 0.697 & 0.704 \\
\hline Main choice method: Broker & & & - & - \\
\hline $\begin{array}{l}\text { lain choice method: } \\
\text { CW/telephone service }\end{array}$ & & & 1.108 & 1.132 \\
\hline $\begin{array}{l}\text { Main choice method: Range of } \\
\text { suppliers }\end{array}$ & & & $1.383^{*}$ & $1.365^{*}$ \\
\hline $\begin{array}{l}\text { Main choice method: Current } \\
\text { supplier only }\end{array}$ & & & $1.491^{* *}$ & $1.497^{* *}$ \\
\hline Main choice method: Other & & & 1.142 & 1.058 \\
\hline Main choice method: Don't know & & & 1.017 & 1.097 \\
\hline Log likelihood & -1384.82 & -1372.63 & -1363.68 & -1346.69 \\
\hline -value, LR test joint significance & 0.051 & 0.460 & 0.294 & 0.019 \\
\hline Firm Demographic Controls & No & Yes & Yes & Yes \\
\hline Engagement Controls & No & No & No & Yes \\
\hline $\mathrm{N}$ & 957 & 957 & 957 & 957 \\
\hline \multicolumn{5}{|c|}{$\begin{array}{l}\text { Notes: * indicates statistical significance at the } 10 \% \text { level, }{ }^{* *} \text { indicates significance at } \\
\text { the } 5 \% \text { level, and }{ }^{* * *} \text { indicates signifcance at the } 1 \% \text { level. Bold indicates the base } \\
\text { category for categorical variables. Odds ratios from ordered logit regressions are } \\
\text { reported where the odds are defined as the probability of an MSB being more satisfied } \\
\text { with their current supplier's value for money relative to the probability of being less } \\
\text { satisfied. In columns where no figures for a particular variable are reported, the } \\
\text { variable was not included in the relevant column's regression. The set of control } \\
\text { variables differs to that in the } 2014 \text { regressions due to the nature of the } 2015 \text { dataset. } \\
\text { Variables often significant across regressions at the } 5 \% \text { level or above but not reported } \\
\text { are (direction of association reported in brackets): payment method - cash/cheque } \\
\text { (negative, column } 4 \text { ) and has read contract (positive, column } 4 \text { ). }\end{array}$} \\
\hline
\end{tabular}

Table D3: Odds ratios for reporting higher satisfaction with current supplier's value for money 2015 data 


\begin{tabular}{|c|c|c|c|c|}
\hline Selected Explanatory Variables & (1) & (2) & (3) & (4) \\
\hline Electricity Expenditure: $f 500$ or less & - & - & - & - \\
\hline Electricity Expenditure: $£ 501-1,000$ & 0.870 & 0.865 & 0.867 & 0.781 \\
\hline Electricity Expenditure: f1-2.5k & 0.713 & 0.743 & 0.752 & 0.716 \\
\hline Electricity Expenditure: $£ 2.5-5 \mathrm{k}$ & $0.591 * *$ & $0.621^{*}$ & $0.608^{*}$ & $0.563^{* *}$ \\
\hline Electricity Expenditure: $f 5-10 k$ & $0.537^{* *}$ & $0.609 *$ & $0.605^{*}$ & $0.546^{* *}$ \\
\hline Electricity Expenditure: f10-15k & $0.488^{* *}$ & 0.590 & 0.628 & 0.554 \\
\hline Electricity Expenditure: f15-25k & $0.449 *$ & 0.547 & 0.553 & $0.450^{*}$ \\
\hline Electricity Expenditure: f25-50k & 0.657 & 0.764 & 0.785 & 0.674 \\
\hline Electricity Expenditure: f50k+ & $0.255^{* *}$ & $0.283^{*}$ & $0.297^{*}$ & $0.290^{*}$ \\
\hline Electricity Expenditure: Don't Know & $0.579^{*}$ & 0.639 & 0.635 & 0.567 \\
\hline Not switched in last 5 years & & & - & - \\
\hline Has Switched in Last 5 Years & & & 0.921 & 0.869 \\
\hline No. Broker Approaches: None & & & $0.638^{*}$ & 0.715 \\
\hline No. Broker Approaches: 1-5 & & & - & - \\
\hline No. Broker Approaches: 6-10 & & & 0.901 & 0.885 \\
\hline No. Broker Approaches: 11-20 & & & 0.832 & 0.859 \\
\hline No. Broker Approaches: 21-30 & & & 0.651 & $0.589^{* *}$ \\
\hline No. Broker Approaches: 31 to 50 & & & 0.809 & 0.837 \\
\hline $\begin{array}{l}\text { No. Broker Approaches: } 50+/ \text { too } \\
\text { many to remember }\end{array}$ & & & 0.787 & 0.803 \\
\hline No. Broker Approaches: Don't know & & & 0.642 & 0.643 \\
\hline Main choice method: Broker & & & 1.000 & 1.000 \\
\hline $\begin{array}{l}\text { Main choice method: } \\
\text { PCW/telephone service }\end{array}$ & & & 1.336 & 1.367 \\
\hline $\begin{array}{l}\text { Main choice method: Range of } \\
\text { suppliers }\end{array}$ & & & $1.642^{* * *}$ & $1.683^{* * *}$ \\
\hline $\begin{array}{l}\text { Main choice method: Current } \\
\text { supplier only }\end{array}$ & & & $1.938 * * *$ & $2.017^{* * *}$ \\
\hline Main choice method: Other & & & 1.260 & 1.185 \\
\hline Main choice method: Don't know & & & 1.548 & 1.676 \\
\hline Log likelihood & -1317.24 & -1299.96 & -1288.29 & -1275.11 \\
\hline P-value, LR test joint significance & 0.058 & 0.136 & 0.035 & 0.005 \\
\hline Firm Demographic Controls & No & Yes & Yes & Yes \\
\hline Engagement Controls & No & No & No & Yes \\
\hline $\mathrm{N}$ & 957 & 957 & 957 & 957 \\
\hline
\end{tabular}

Notes: ${ }^{*}$ indicates statistical significance at the $10 \%$ level, $* *$ indicates significance at the $5 \%$ level, and $* * *$ indicates signifcance at the $1 \%$ level. Bold indicates the base category for categorical variables. Odds ratios from ordered logit regressions are reported where the odds are defined as the probability of an MSB being more satisfied with their current supplier's overall service relative to the probability of being less satisfied. In columns where no figures for a particular variable are reported, the variable was not included in the relevant column's regression. The set of control variables differs to that in the 2014 regressions due to the nature of the 2015 dataset. Variables often significant across regressions at the $5 \%$ level or above but not reported are (direction of association reported in brackets): sector - construction (positive), has not received a bill in last 12 months (negative, column 4), payment method cash/cheque (negative, column 4).

Table D4: Odds ratios for reporting higher satisfaction with current supplier's overall service 2015 data 


\begin{tabular}{|c|c|c|c|c|c|c|c|c|}
\hline Selected Explanatory Variables & (1) & (2) & (3) & (4) & (5) & (6) & (7) & (8) \\
\hline Number of employees: None & & & & - & - & - & - & - \\
\hline Number of employees: 1-4 & & & & 0.056 & 0.054 & 0.065 & 0.064 & 0.062 \\
\hline Number of employees: 5-9 & & & & $0.151 * * *$ & $0.143^{* * *}$ & $0.160 * * *$ & $0.154^{* * *}$ & $0.144 * * *$ \\
\hline Number of employees: $10-49$ & & & & $0.172^{* * *}$ & $0.170^{* * *}$ & $0.164 * * *$ & $0.162^{* * *}$ & $0.143^{* *}$ \\
\hline Electricity Expenditure: $₫ 500$ or less & - & & & - & - & - & - & - \\
\hline Electricity Expenditure: $£ 501-1,000$ & 0.082 & & & 0.061 & 0.056 & 0.033 & 0.035 & 0.018 \\
\hline Electricity Expenditure: f1-2.5k & 0.094 & & & 0.060 & 0.049 & 0.021 & 0.016 & -0.001 \\
\hline Electricity Expenditure: $£ 2.5-5 \mathrm{k}$ & $0.142^{* *}$ & & & $0.111^{*}$ & $0.112^{*}$ & 0.082 & 0.090 & 0.074 \\
\hline Electricity Expenditure: f5-10k & $0.146^{* *}$ & & & 0.103 & 0.100 & 0.069 & 0.070 & 0.049 \\
\hline Electricity Expenditure: $f 10-15 \mathrm{k}$ & $0.188^{* *}$ & & & 0.140 & 0.120 & 0.089 & 0.073 & 0.056 \\
\hline Electricity Expenditure: $f 15-25 \mathrm{k}$ & $0.262 * * *$ & & & $0.211^{* *}$ & $0.204^{* *}$ & $0.178^{*}$ & $0.180^{*}$ & 0.151 \\
\hline Electricity Expenditure: f25-50k & 0.089 & & & -0.015 & -0.041 & -0.080 & -0.097 & -0.126 \\
\hline Electricity Expenditure: f50k+ & 0.089 & & & -0.024 & -0.046 & -0.103 & -0.120 & -0.135 \\
\hline Electricity Expenditure: Don't Know & -0.002 & & & -0.046 & -0.050 & -0.078 & -0.077 & -0.069 \\
\hline No. Broker Approaches: None & & $-0.143 * *$ & & & $-0.131 * *$ & & -0.050 & -0.031 \\
\hline No. Broker Approaches: 1-5 & & - & & & - & & - & - \\
\hline No. Broker Approaches: 6-10 & & -0.032 & & & -0.034 & & 0.020 & 0.018 \\
\hline No. Broker Approaches: $11-20$ & & 0.046 & & & 0.036 & & 0.065 & 0.058 \\
\hline No. Broker Approaches: $21-30$ & & -0.037 & & & -0.044 & & -0.005 & -0.011 \\
\hline No. Broker Approaches: 31 to 50 & & $-0.166^{* *}$ & & & $-0.182 * *$ & & $-0.144^{* *}$ & $-0.140^{*}$ \\
\hline $\begin{array}{l}\text { No. Broker Approaches: } 50+/ \text { too } \\
\text { many to remember }\end{array}$ & & -0.034 & & & -0.043 & & 0.008 & 0.015 \\
\hline No. Broker Approaches: Don't know & & -0.110 & & & -0.070 & & -0.010 & -0.005 \\
\hline Main choice method: Broker & & & - & & & - & - & - \\
\hline $\begin{array}{l}\text { Main choice method: } \\
\text { PCW/telephone service }\end{array}$ & & & -0.036 & & & -0.035 & -0.038 & -0.034 \\
\hline $\begin{array}{l}\text { Main choice method: Range of } \\
\text { suppliers }\end{array}$ & & & $-0.101 * * *$ & & & $-0.101 * * *$ & $-0.107 * * *$ & $-0.108^{* * *}$ \\
\hline $\begin{array}{l}\text { Main choice method: Current } \\
\text { supplier only }\end{array}$ & & & $-0.380 * * *$ & & & $-0.385 * * *$ & $-0.384 * * *$ & $-0.371 * * *$ \\
\hline Main choice method: Other & & & $-0.283 * * *$ & & & $-0.298 * * *$ & $-0.286^{* * *}$ & $-0.252^{* * *}$ \\
\hline Main choice method: Don't know & & & $-0.300 * * *$ & & & $-0.315^{* * *}$ & $-0.319 * * *$ & $-0.279 * * *$ \\
\hline Log likelihood & -594.74 & -594.68 & -548.34 & -572.12 & -565.47 & -515.58 & -510.8 & -499.23 \\
\hline P-value, LR test joint significance & 0.107 & 0.042 & 0.000 & 0.027 & 0.010 & 0.000 & 0.000 & 0.000 \\
\hline Firm Demographic Controls & No & No & No & Yes & Yes & Yes & Yes & Yes \\
\hline Engagement Controls & No & No & No & No & No & No & No & Yes \\
\hline $\mathrm{N}$ & 957 & 957 & 957 & 956 & 956 & 956 & 956 & 955 \\
\hline
\end{tabular}

Notes: ${ }^{*}$ indicates statistical significance at the $10 \%$ level, ${ }^{* *}$ indicates significance at the $5 \%$ level, and ${ }^{* * *}$ indicates signifcance at the $1 \%$ level. Bold indicates the base category for categorical variables. The figures reported are average marginal effects associated with the probability of a firm having switched in the 5 years prior to interview. In columns where no figures for a particular variable are reported, the variable was not included in the column's regression. One observation is dropped from columns 4-8 as gas expenditure - $f 15-25,000$ perfectly predicted switching and another observation is dropped from column 8 as payment method - don't know/refused perfectly predicted non-switching. The set of control variables differs to that in the 2014 regressions due to the nature of the 2015 dataset. Variables often significant across regressions at the $5 \%$ level or above but not reported are (direction of association in brackets): sector - construction (negative), turnover - below $£ 73,000$ (negative), turnover - $£ 500-749,000$ (negative), gas expenditure - $£ 500-1,000$ (positive), gas expenditure - $£ 2,500-5,000$ (negative), payment method - cash/cheque (negative, column 8), does not know when contract ends (negative), and has read contract (positive).

Table D5 - Average Marginal Effects associated with the Probability of Having Switched in the Previous 5 Years - 2015 Data 
Appendix E - Firm Characteristics: Population Estimates vs Analysed Sample

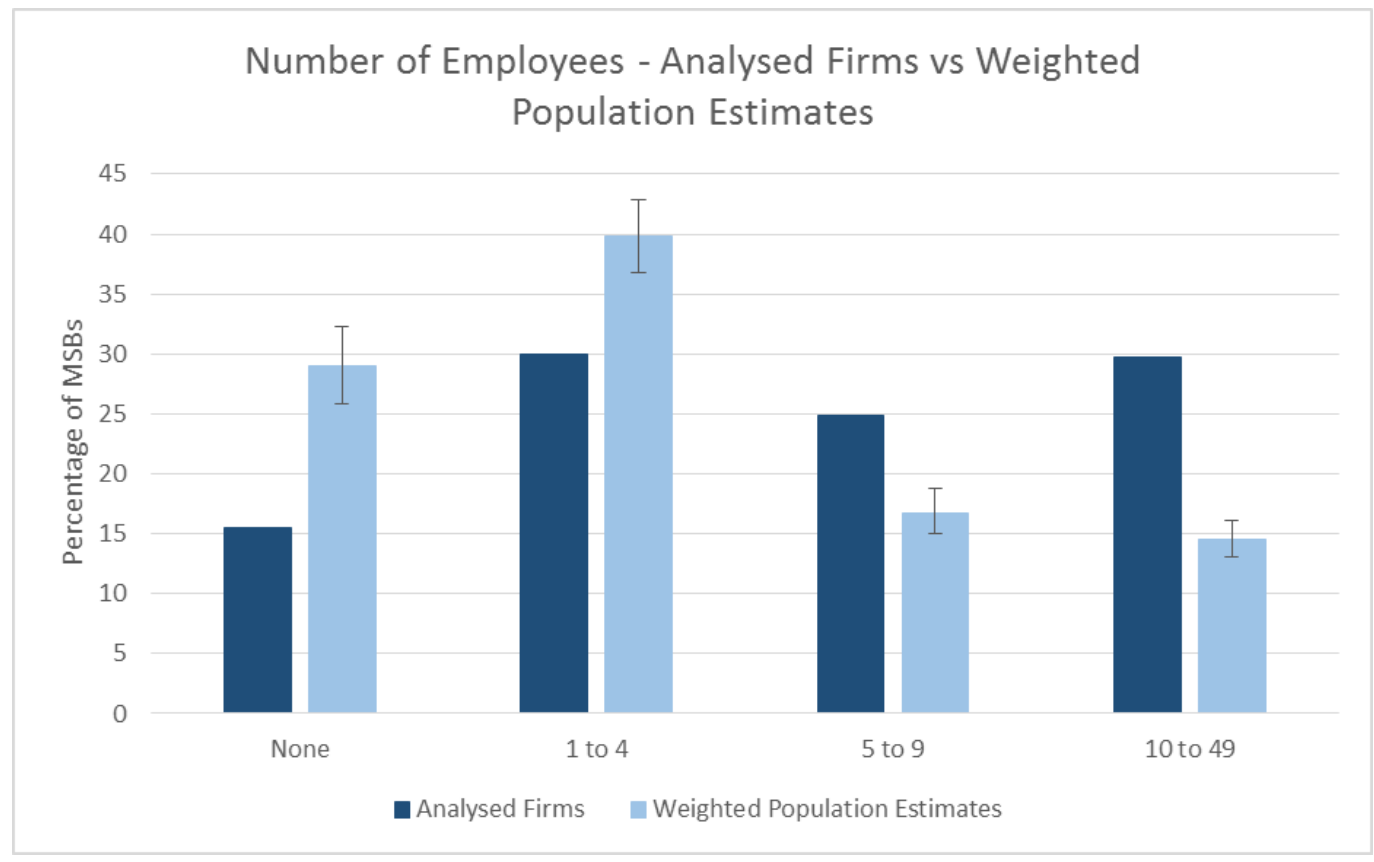

Figure E1: MSBs by number of employees

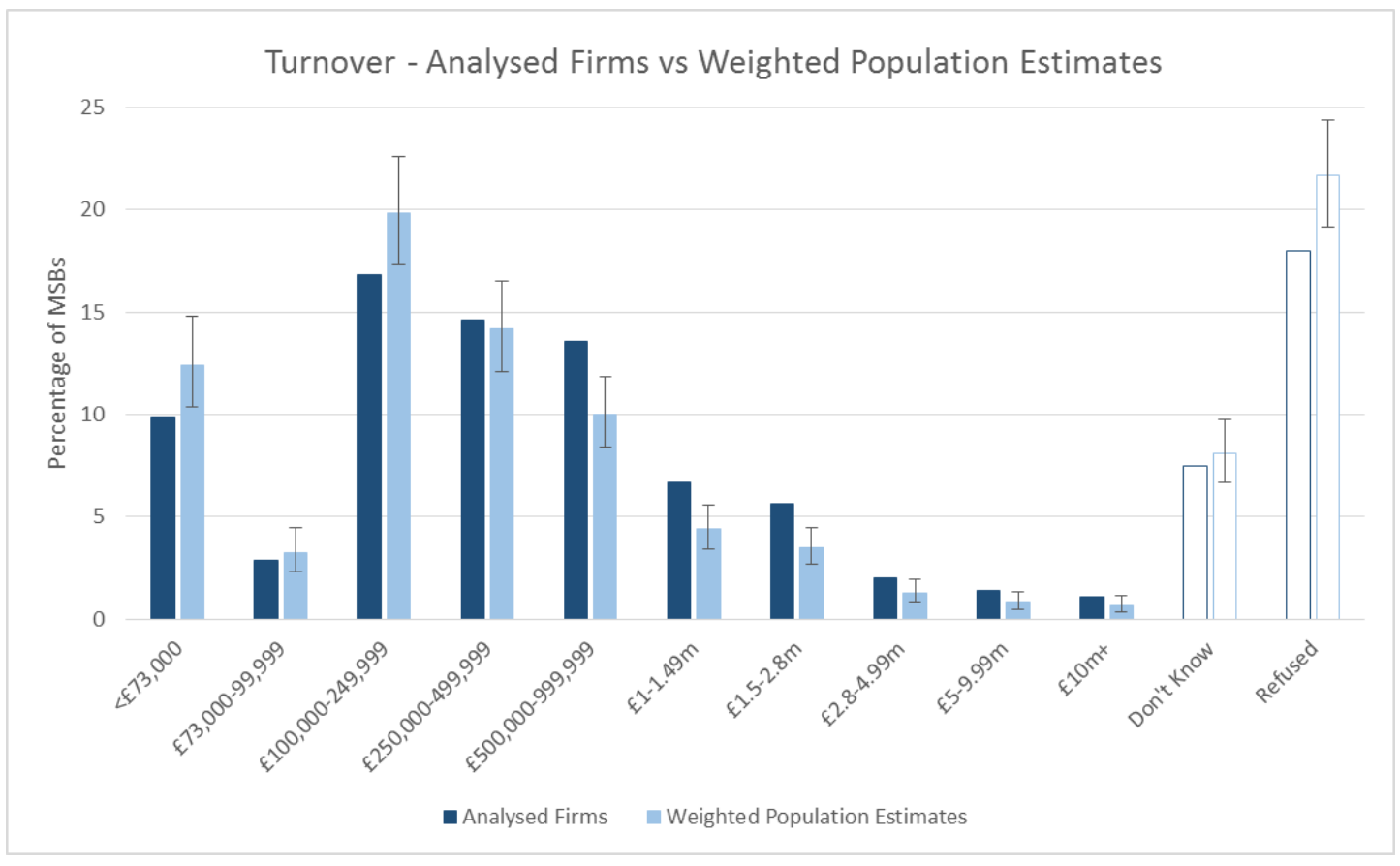

Figure E2: MSBs by turnover 


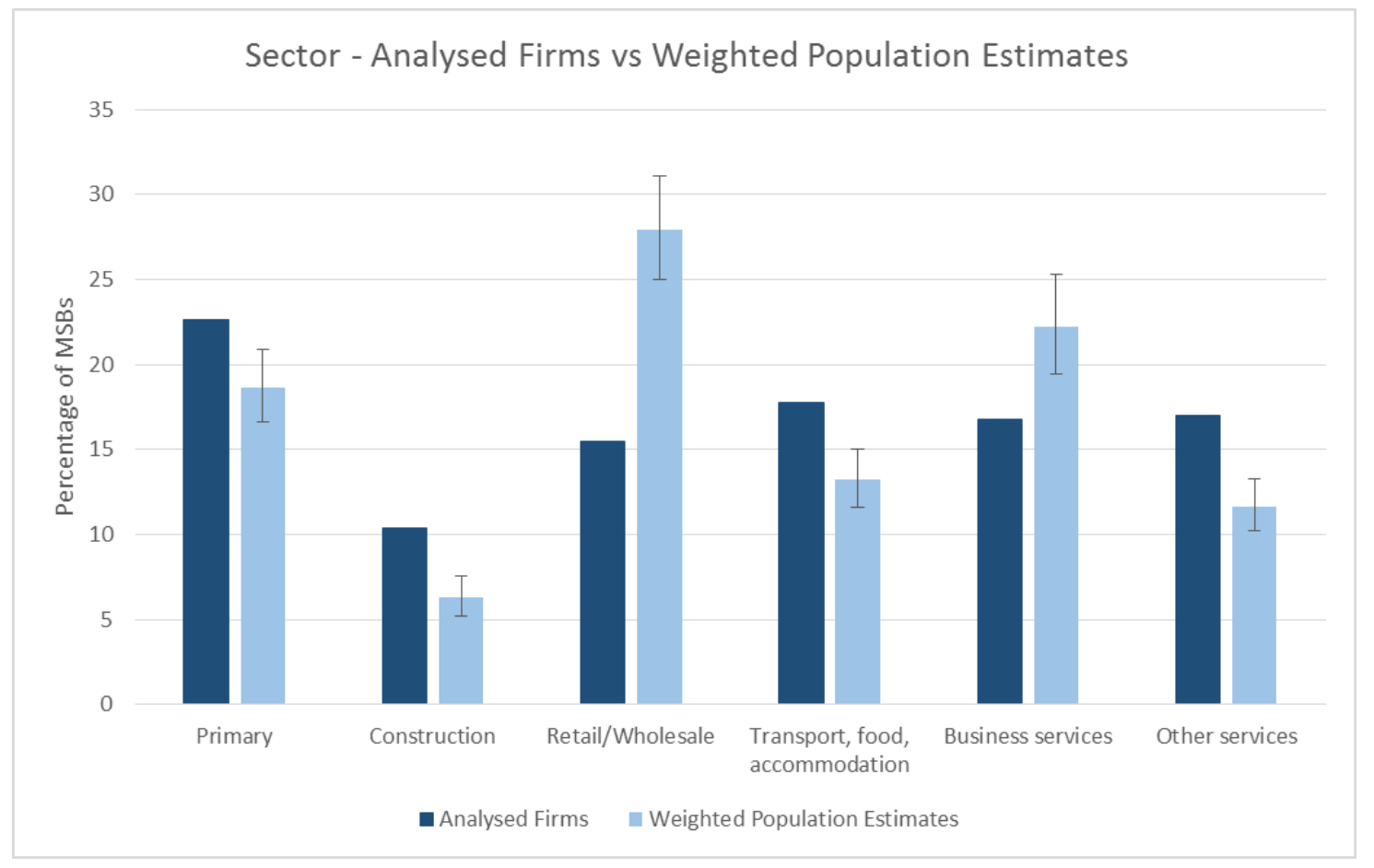

Figure E3: MSBs by sector

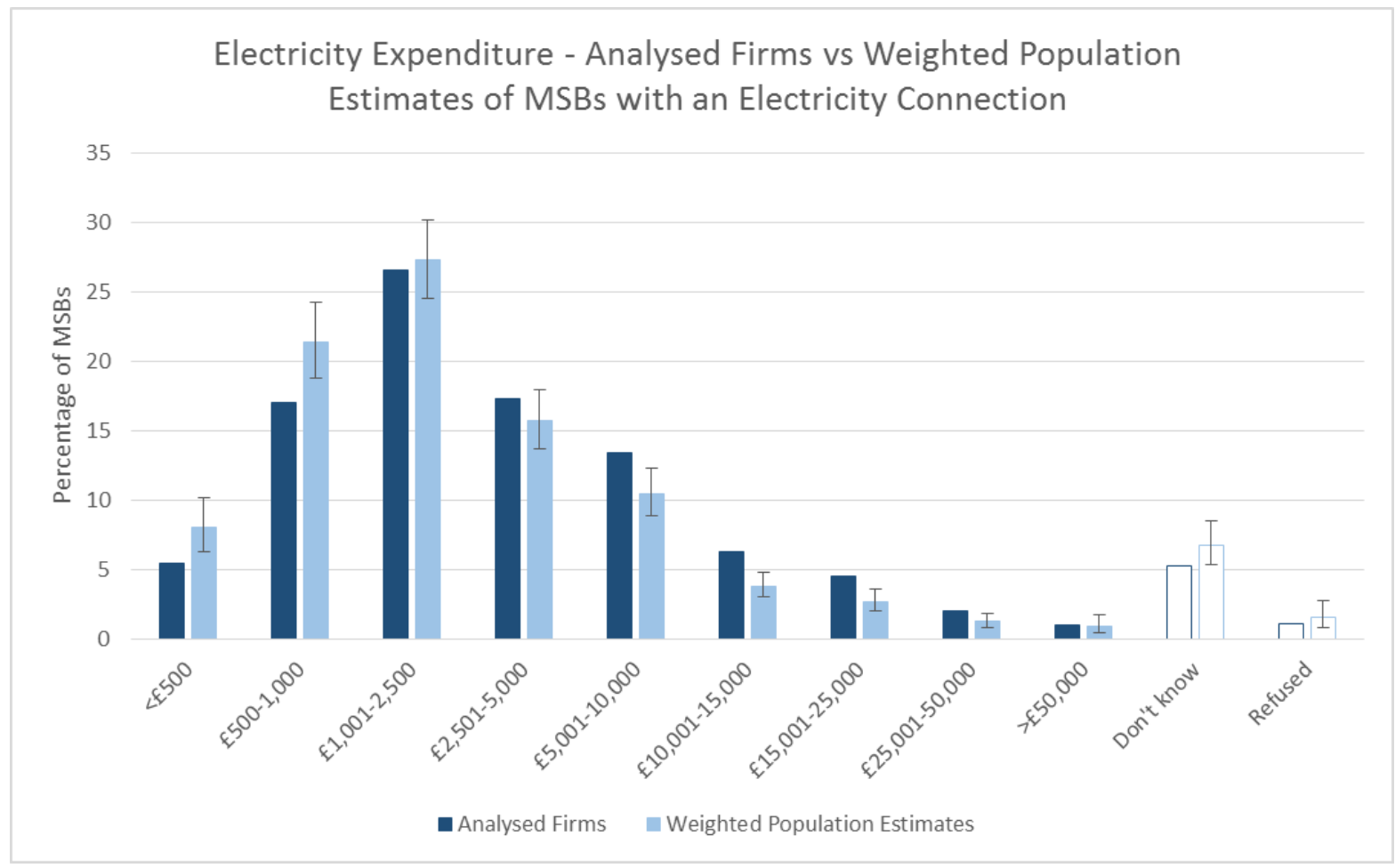

Figure E4: Electricity expenditures of MSBs using mains electricity ${ }^{57}$

$5799.1 \%$ of survey respondents used mains electricity. 


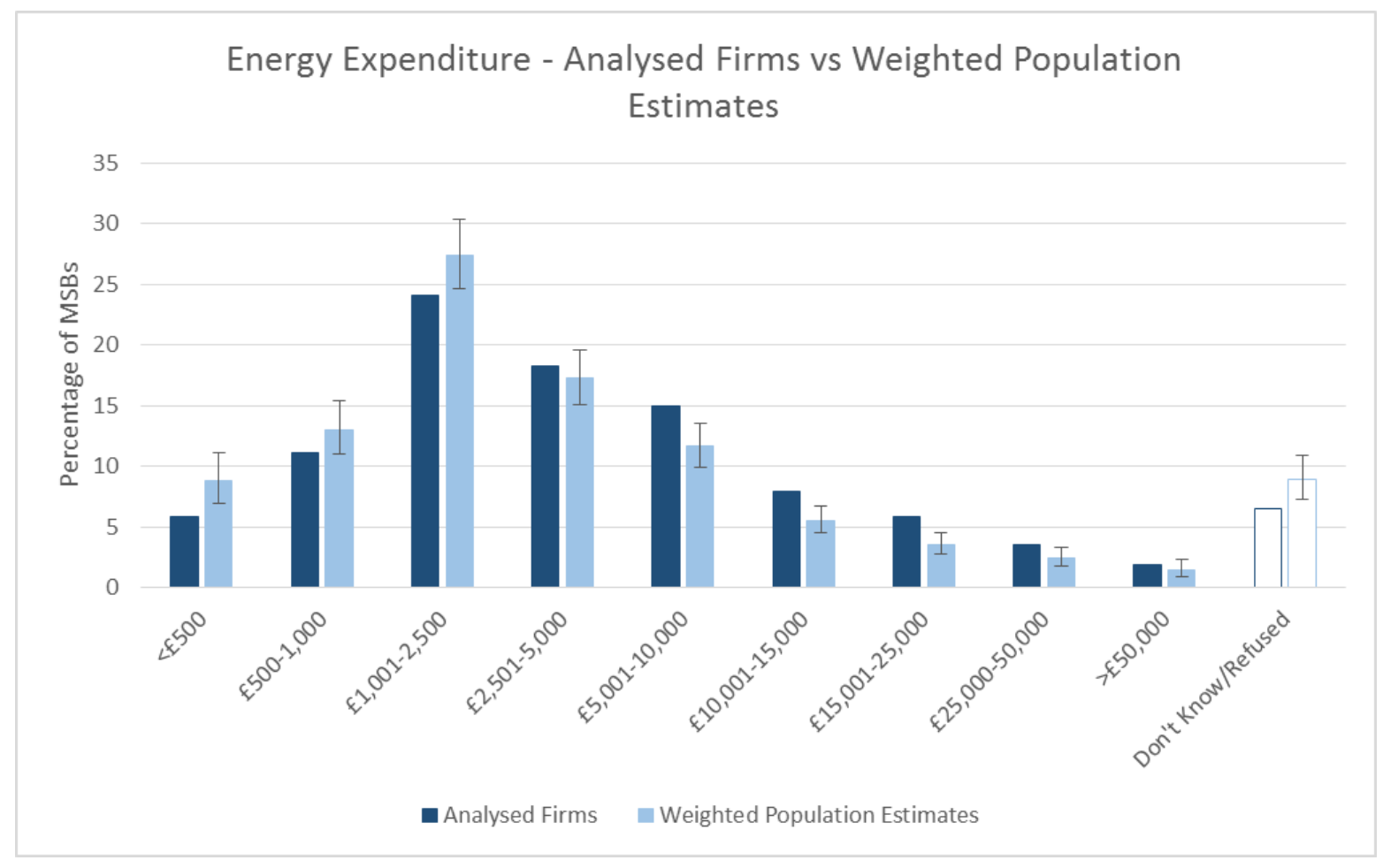

Figure E5: MSBs' energy expenditures

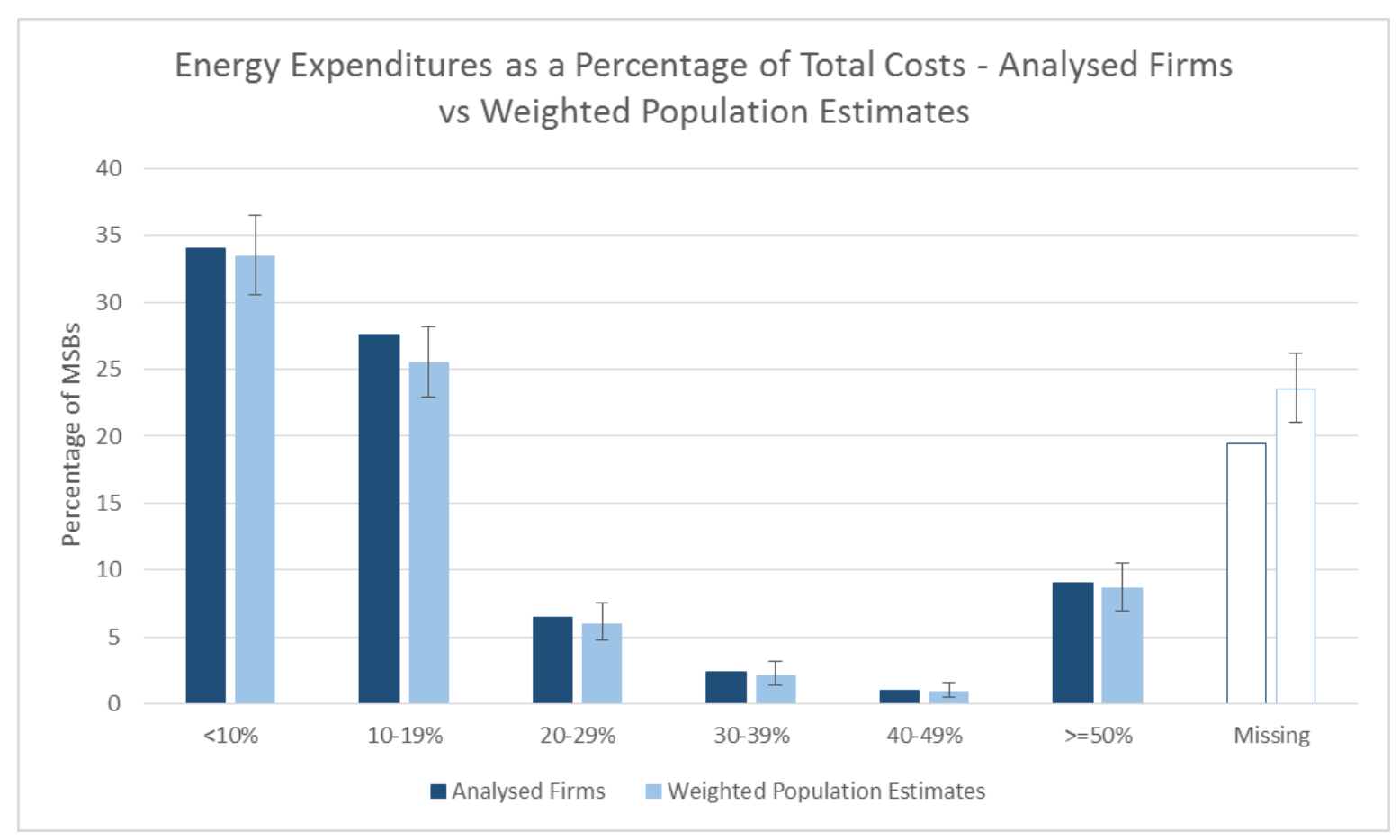

Figure E6: Energy as a percentage of MSBs' costs 


\begin{tabular}{|c|c|c|}
\hline & Analysed Firms & $\begin{array}{c}\text { Weighted Population } \\
\text { Estimates }\end{array}$ \\
\hline $\begin{array}{c}\% \text { with a fixed term } \\
\text { contract }\end{array}$ & $94.5^{* *}$ & 92.4 \\
\hline $\begin{array}{l}\% \text { with a fixed } \\
\text { contract lasting } 2 \\
\text { years or more }\end{array}$ & $58.1^{* *}$ & 53.9 \\
\hline$\%$ with smart meter & $33.6^{* *}$ & 29.6 \\
\hline $\begin{array}{c}\text { \% paying by Direct } \\
\text { Debit }\end{array}$ & $87.8^{* *}$ & 84.6 \\
\hline $\begin{array}{l}\% \text { with a gas } \\
\text { connection }\end{array}$ & 40.4 & 40.1 \\
\hline $\begin{array}{c}\% \text { of firms in } \\
\text { England }\end{array}$ & 71.4 & 73.5 \\
\hline $\begin{array}{l}\% \text { with a single } \\
\text { supplier }\end{array}$ & $87.3^{* * *}$ & 83 \\
\hline
\end{tabular}

Note: Two-tail test of equality between the statistics of analysed firms and the population estimates were performed: ${ }^{*}$ indicates a difference statistically significant at the $10 \%$ level, ${ }^{* *}$ indicates statistical significance at the $5 \%$ level and ${ }^{* * *}$ indicates statistical significance at the $1 \%$ level. Percentages are calculated including missing observations and Don't Know/Refused responses in the base.

Table E1: MSBs' energy contract characteristics

\begin{tabular}{|c|c|c|}
\hline & Analysed Firms & $\begin{array}{c}\text { Weighted Population } \\
\text { Estimates } \\
\end{array}$ \\
\hline $\begin{array}{c}\% \text { switched in last } 5 \\
\text { years }\end{array}$ & $65.7^{* * *}$ & 59.8 \\
\hline $\begin{array}{c}\% \text { switched in last } \\
12 \text { months }\end{array}$ & $26.3^{*}$ & 23.4 \\
\hline $\begin{array}{l}\% \text { recalls receiving } \\
\text { bill in last } 6 \text { months }\end{array}$ & $93.2^{* *}$ & 90.9 \\
\hline $\begin{array}{c}\% \text { reporting no } \\
\text { broker approaches }\end{array}$ & $13.6 * * *$ & 17.5 \\
\hline $\begin{array}{c}\text { many broker } \\
\text { approaches to } \\
\text { remember }\end{array}$ & 14.7 & 14.4 \\
\hline $\begin{array}{c}\% \text { Chose current } \\
\text { deal through broker }\end{array}$ & 28.3 & 25.9 \\
\hline $\begin{array}{c}\% \text { Knows month } \\
\text { when contract ends }\end{array}$ & $59.4^{* *}$ & 54.6 \\
\hline$\%$ has read contract & $52.8^{* *}$ & 47.8 \\
\hline
\end{tabular}

Note: Two-tail test of equality between the statistics of analysed firms and the population estimates were performed. ${ }^{*}$ indicates a difference statistically significant at the $10 \%$ level, $* *$ indicates statistical significance at the $5 \%$ level and ${ }^{* * *}$ indicates statistical significance at the $1 \%$ level. Percentages are calculated including missing observations and Don't Know/Refused responses in the base.

Table E2: Indicators of MSBs' engagement 


\section{Appendix F - Analysed Firms' Satisfaction with Suppliers and the Market}

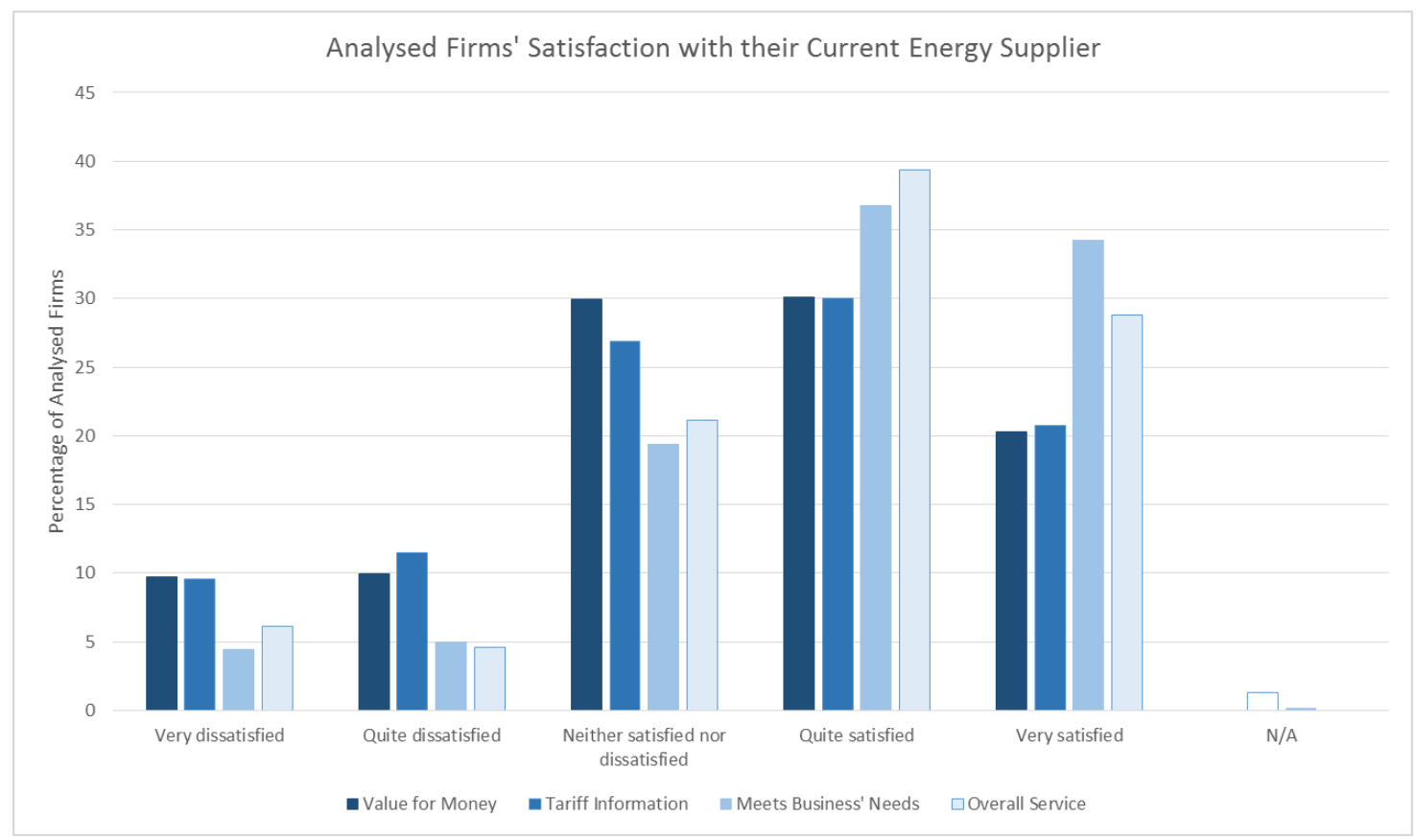

Figure F1: Analysed firms' satisfaction with their current supplier ${ }^{58}$

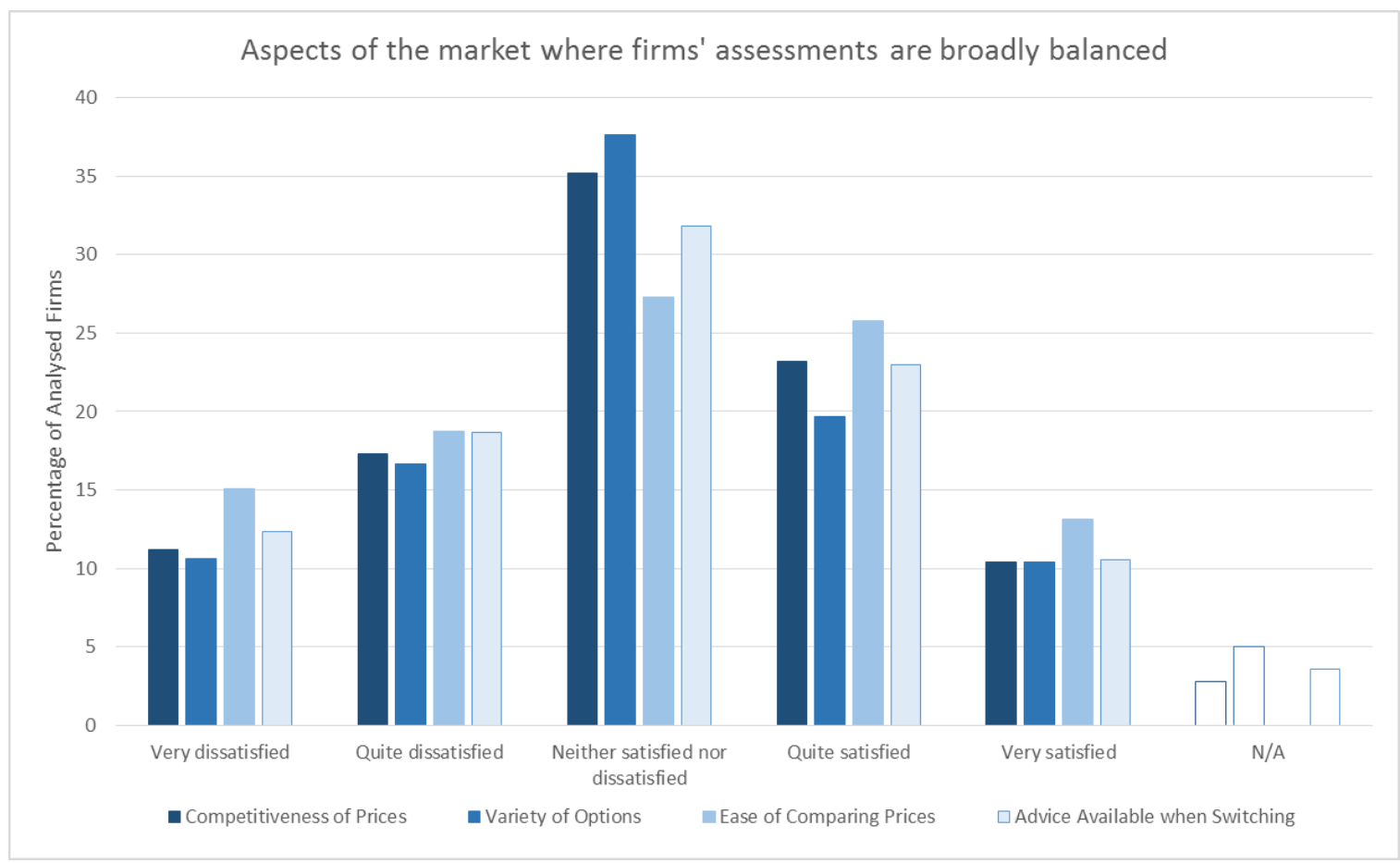

Figure F2: Aspects of the market where analysed firms' views are broadly balanced

${ }^{58}$ The definition of the analysed sample means there are no $N / A$ observations for those indicators used as dependent variables in the regressions. 


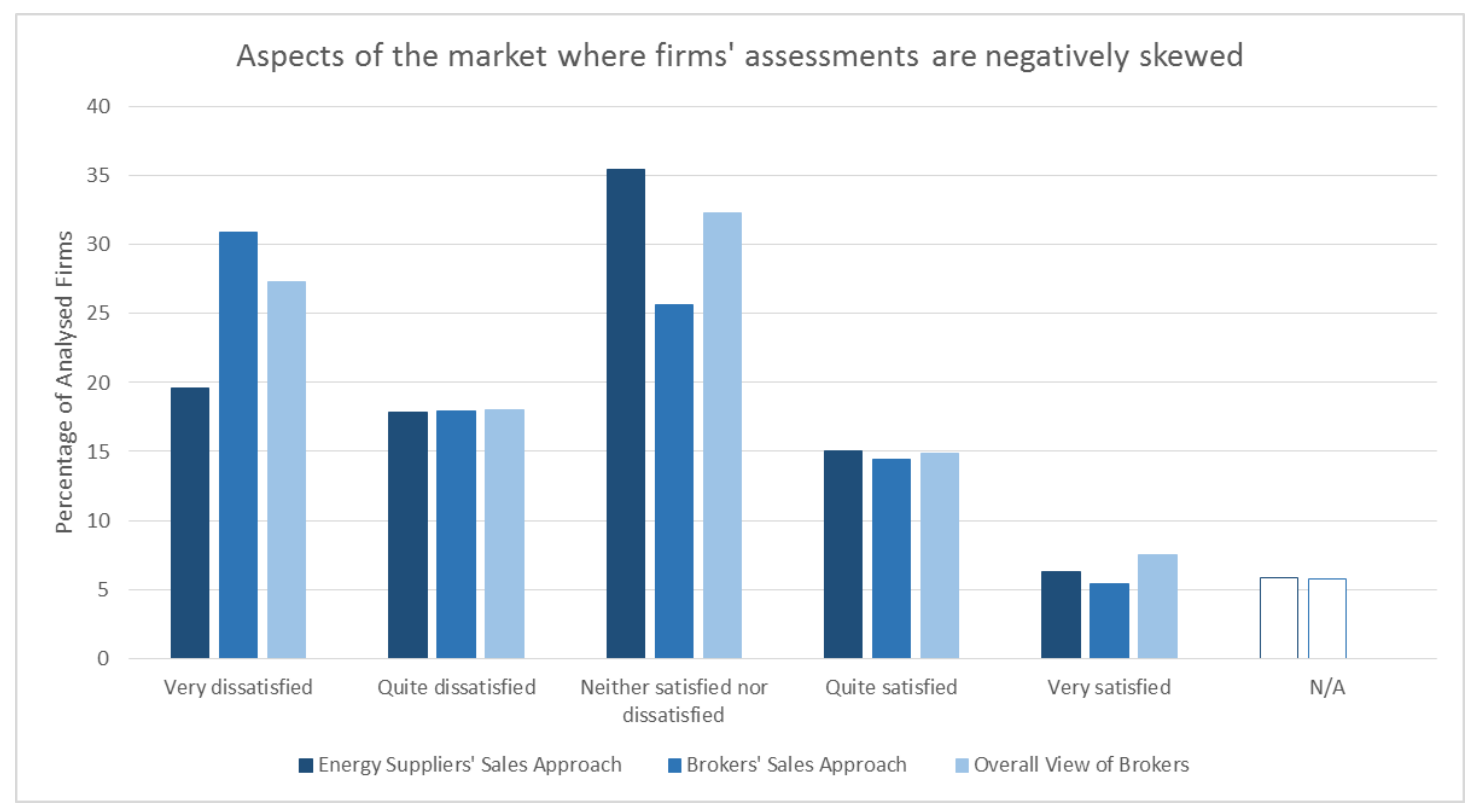

Figure F3: Aspects of the market where analysed firms' views show a negative skew ${ }^{59}$

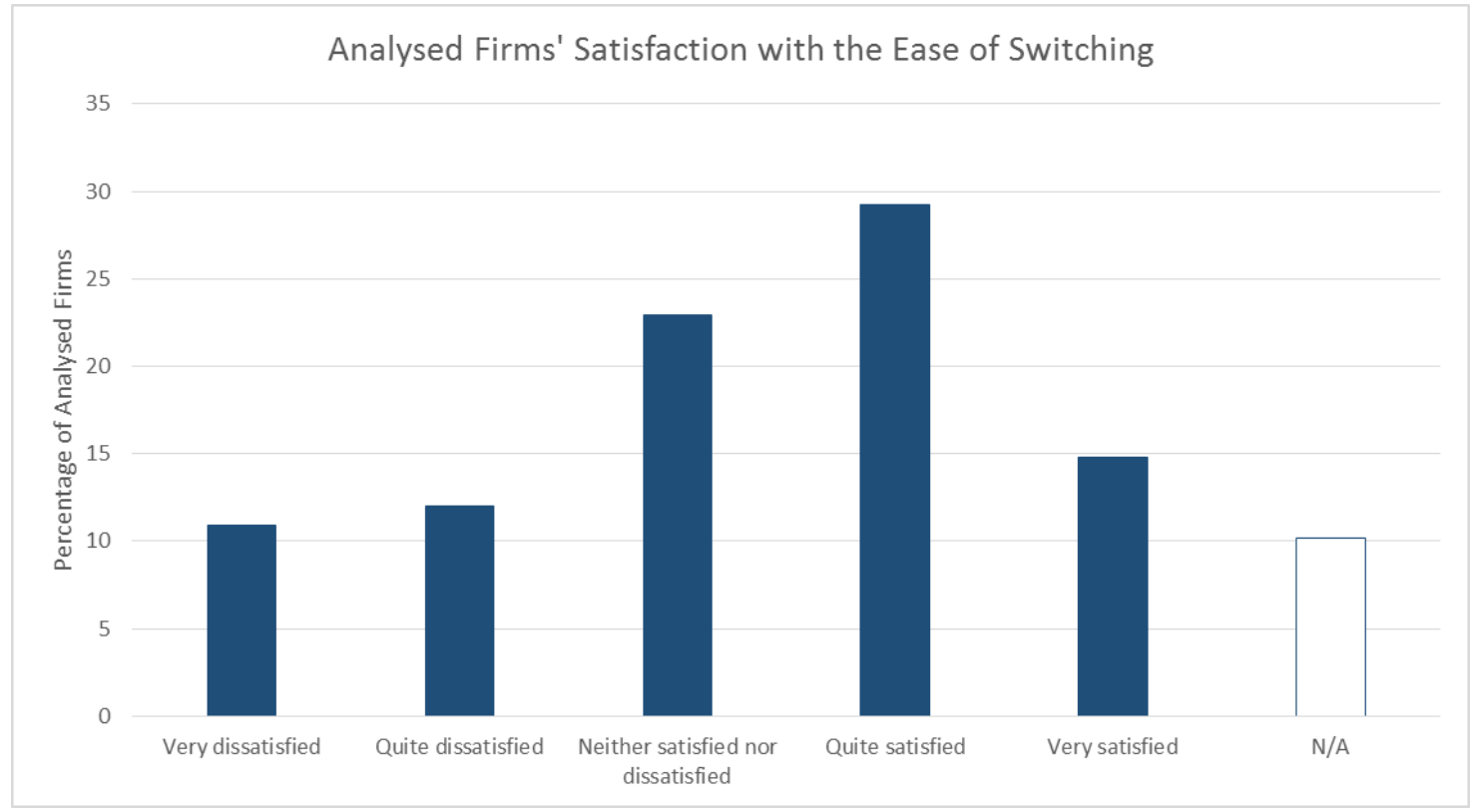

Figure F4: Analysed firms' satisfaction with the ease of switching suppliers

\section{Appendix G - The possible impact of differential VAT rates}

As suggested in Section 5.3 an intuitive explanation for the non-linear association between energy expenditure and satisfaction is the salience of energy costs to MSBs. An alternative, but considerably more complex, explanation relates to the VAT regime for energy.

In the UK there are two VAT rates for energy: $5 \%$ for domestic consumers and $20 \%$ for non-domestic consumers. For firms large enough to be VAT registered (in 2014 the turnover threshold for registering for VAT was $f 81,000$ ), the difference in VAT should not matter as VAT can be reclaimed so that the effective rate is $0 \%$. However, for non-VAT registered firms on non-domestic contracts whether the

\footnotetext{
59 In the survey the scale for Overall View of Brokers ran from Very negative to Very positive and N/A was replaced with Don't Know.
} 
$5 \%$ or $20 \%$ tax rate applies depends on the quantity of energy they consume. ${ }^{60}$ The change in VAT rate also coincides with the point where the Climate Change Levy is applied to qualifying firms. ${ }^{61}$ It could be that firms experiencing a higher headline price (due to the higher VAT rate/Climate Change Levy) are responding to the satisfaction questions about their current supplier without distinguishing between the part of the final price attributable to tax and the part controlled by suppliers. Looking at columns 1 and 6 of Table 3, the downward step in satisfaction occurs first for the category of $f 2,501$ 5,000 which is roughly the point where VAT rises from $5 \%$ to $20 \%$.

Additionally, the differential VAT rates potentially make it harder for firms to navigate the energy market. It appears different suppliers take different approaches to applying the 20\% VAT rate. EDF Energy applies the $5 \%$ rate automatically ${ }^{62}$ when consumption is low, whereas Gazprom applies the $20 \%$ rate unless notified otherwise ${ }^{63}$. For firms who claim back VAT, price comparisons should be straightforward, as long as they ask for ex-VAT prices. For non-VAT registered firms, if energy suppliers do not make the VAT rate being applied clear in quotations two potential problems arise. First, if different energy suppliers quote prices inclusive of VAT, but use different VAT rates, it is possible that MSBs will fail to identify the supplier offering the lowest ex-VAT energy price. Second, if suppliers routinely quote the ex-VAT price ${ }^{64}$, there is a risk that those MSBs who are not VAT registered will experience 'bill shock', i.e. an energy bill higher than they expected, potentially leading to dissatisfaction.

\section{References}

Accent Scotland (2012), 'Quantitative Research into Non Domestic Customer Engagement of the Energy Market', Report prepared for Ofgem, November 2012, available at: https://www.ofgem.gov.uk/sites/default/files/docs/2012/10/quantitative-research-into-nondomestic-customer-engagement-and-experience-of-the-energy-market.pdf

Analysys Mason (2015), 'Understanding the demand for communications services by SMEs', Final report for Ofcom, Ref 20002312-176, 27 April 2015, available at: https://www.ofcom.org.uk/_data/assets/pdf_file/0025/74482/annex_3_analysys_mason_of com_sme_study.pdf

Andrews, R.N.L. and E. Johnson (2016), 'Energy use, behavioural change, and business organizations: Reviewing recent findings and proposing a future research agenda', Energy Research \& Social Science, 11, pp. 195-208

Bennett, R.J. and P.J.A. Robson (2005), 'The Advisor-SME Client Relationship: Impact, Satisfaction and Commitment', Small Business Economics, 25, pp. 255-271

\footnotetext{
${ }^{60}$ The $20 \%$ VAT rate starts when annual consumption exceeds $12,000 \mathrm{kWh}$ of electricity or $52,674 \mathrm{kWh}$ of gas. Using a price of 14.14 pence per $\mathrm{kWh}$ for electricity, the 20\% VAT rate applied once electricity expenditure exceeded $£ 1,697.22$ and, using a price of 4.56 pence per $\mathrm{kWh}$ for gas, the $20 \%$ rate applied once gas expenditure exceeded $£ 2,402.57$. These unit prices have a 5\% VAT rate applied and come from Table 3.4.1 (annual), 'Prices for fuels purchased by non-domestic consumers in the UK', Department for Business, Energy and Industrial Strategy, available at: https://www.gov.uk/government/statistical-data-sets/gas-and-electricityprices-in-the-non-domestic-sector

${ }^{61} \mathrm{pg} 2$, EDF Energy (2018)

${ }^{62}$ pg3, EDF Energy (2018)

${ }^{63} \mathrm{https}$ ///www.gazprom-energy.co.uk/help-and-support/bills-payments/vat/

${ }^{64}$ This seems a likely approach if suppliers and brokers believe quoting the lowest price generates additional sales.
} 
Binks, M.R. and C.T. Ennew (1997), 'The Relationship Between UK Banks and Their Small Business Customers', Small Business Economics, 9, pp. 167-178

BMG (2015), 'Research Report: Micro and Small Business Engagement in Energy Markets', a report for Ofgem, March 2015, available at: https://www.ofgem.gov.uk/ofgempublications/94051/nondomquantfinalv4-pdf

BMG (2016), 'Research Report: Micro and Small Business Engagement in Energy Markets', a report for Ofgem, May 2016, available at: https://www.ofgem.gov.uk/system/files/docs/2016/05/microsurvey_final.pdf

Cagno, E. and A. Tiranni (2013), 'Exploring drivers for energy efficiency within small and medium-sized enterprises: First evidence from Italian manufacturing enterprises', Applied Energy, 104, pp. 276-285

Chaston, I. (1993), 'Delivering Customer Satisfaction within the SME Client-Banker Relationship', The Service Industries Journal, 13(1), pp. 98-111

Coles, T., C. Dinan and N. Warren (2016), 'Energy practices among small- and medium-sized tourism enterprises: a case of misdirected effort?', Journal of Cleaner Production, 111, pp. 399-408

Competition and Markets Authority (2015), 'Retail banking market investigation: SME follow-up survey results', presentation slides, 20 August 2015, available at: https://assets.publishing.service.gov.uk/media/55d5c7c540f0b61525000001/SME_followup_survey_results.pdf

Competition and Markets Authority (2016a), 'Energy market investigation: Final report', available at: https://assets.publishing.service.gov.uk/media/5773de34e5274a0da3000113/final-reportenergy-market-investigation.pdf

Competition and Markets Authority (2016b), 'Energy Market Investigation: Final Report - Appendix 16.1: Microbusinesses', available at: https://assets.publishing.service.gov.uk/media/576bccc4e5274a0da9000084/appendix-16-1microbusiness-aec-finding-fr.pdf

Cooremans, C. (2011), 'Make it strategic! Financial investment logic is not enough', Energy Efficiency, 4, pp. 473-492

Cooremans, C. (2012), 'Investment in energy efficiency: do the characteristics of investments matter?', 5, pp. 497-518

Cornwall Energy (2013), 'Business and broker interaction in the energy market: A review by Cornwall Energy', August 2013

Deller, D., M. Giulietti, G. Loomes, C. Waddams Price, A. Moniche Bermejo and J.Y. Jeon (2017), 'Switching Energy Suppliers: It's Not All About the Money', Centre for Competition Policy, CCP Working Paper 17-5

Department for Energy and Climate Change (2012), 'What are the factors influencing energy behaviours and decision-making in the non-domestic sector? A Rapid Evidence Assessment', Report by the Centre for Sustainable Energy (CSE) and the Environmental Change Institute (ECI), University of Oxford, November 2012, available at: https://www.gov.uk/government/uploads/system/uploads/attachment_data/file/65601/6925 -what-are-the-factors-influencing-energy-behaviours.pdf 
Department for Energy and Climate Change (2014), 'Research to Assess the Barriers and Drivers to Energy Efficiency in Small and Medium Sized Enterprises', London, November 2014, available at:

https://www.gov.uk/government/uploads/system/uploads/attachment_data/file/392908/Bar riers_to_Energy_Efficiency_FINAL_2014-12-10.pdf

EDF Energy (2018), 'Value Added Tax and Climate Change Levy explained', e-guide, available at: https://www.edfenergy.com/sites/default/files/sme_vat_guide_1212.pdf

Ennew, C.T. and M.R. Binks (1996), 'The Impact of Service Quality and Service Characteristics on Customer Retention: Small Businesses and their Banks in the UK', British Journal of Management, 7, pp. 219-230

Federation of Small Businesses (2014), 'Voice of Small Business' Survey Panel - April/May 2014 Energy Survey', presentation slides, available at: https://www.fsb.org.uk/docs/default-source/fsb-orguk/frontpage/assets/fsb-2014-energy-survey-for-web.pdf?Status=Master\&sfvrsn=1

Fleiter, T., J. Schleich and P. Ravivanpong (2012), 'Adoption of energy-efficiency measures in SMEs An empirical analysis based on energy audit data from Germany', Energy Policy, 51, pp. 863-875

Fletcher, A., A. Karatzas and A. Kreutzmann-Gallasch (2014), 'Small Businesses As Consumers: Are They Sufficiently Well Protected?', A Report for The Federation of Small Businesses, Centre for Competition Policy, January 2014, available at: http://competitionpolicy.ac.uk/documents/8158338/8264594/fsb+project_small_businesses_ as-consumers.pdf/f1ed4da5-14cf-4b80-a1d8-ff76a0781def

Jigsaw (2014), 'The SME experience of communications services: research report', 16 October 2014, available https://www.ofcom.org.uk/_data/assets/pdf_file/0015/51036/sme_research_report.pdf

Jigsaw (2015), 'SME Experience of communications services: Focus on SMEs facing problems of availability, reliability and switching', 18 June 2015, available at: https://www.ofcom.org.uk/__data/assets/pdf_file/0018/71901/annex_2_ofcom_consumer_e xperience.pdf

Jigsaw (2017), 'The SME experience of communications services: research report', January 2017, available at: https://www.ofcom.org.uk/_data/assets/pdf_file/0030/96348/Ofcom-SMEconsumer-experience-research-2016-Report.pdf

HM Government (2012), 'Open Data White Paper - Unleashing the Potential', Cm8353, London, June 2012, available at: https://www.gov.uk/government/uploads/system/uploads/attachment_data/file/78946/CM8 353_acc.pdf

Howarth, C., M.J. Peel and N. Wilson (2003), 'An Examination of the Factors Associated with Bank Switching in the UK Small Firm Sector', Small Business Economics, 20, pp. 305-317

Ibbotson, P. and L. Moran (2003), 'E-banking and the SME/bank relationship in Northern Ireland', International Journal of Bank Marketing, 21(2), pp 94-103

International Energy Agency (2015), 'Accelerating Energy Efficiency in Small and Medium-Sized Enterprises: Powering SMEs to catalyse economic growth', IEA Policy Pathway series, available at: https://www.iea.org/publications/freepublications/publication/SME_2015.pdf 
Lam, R. and S. Burton (2005), 'Bank selection and share of wallet among SMEs: Apparent differences between Hong Kong and Australia', Journal of Financial Services Marketing, 9(3), pp. 204-213

Lam, R. and S. Burton (2006), 'SME banking loyalty (and disloyalty): a qualitative study in Hong Kong', International Journal of Bank Marketing, 24(1), pp. 37-52

Lam, R., S. Burton and H-P. Lo (2009), 'Customer tradeoffs between key determinants of SME banking loyalty', International Journal of Bank Marketing, 27(6), pp. 428-445.

Lundahl, N., F. Vegholm and L. Silver (2009), 'Technical and functional determinants of customer satisfaction in the bank-SME relationship', Managing Service Quality: An International Journal, 19(5), pp. 581-594

Madill, J.J., L. Feeney, A. Riding, G.H. Haines Jr (2002), 'Determinants of SME owners' satisfaction with their banking relationships: a Canadian study', International Journal of Bank Marketing, 20(2), pp. $86-98$

Ofgem (2015), 'Retail Energy Markets in 2015', 9 September 2015, available at: https://www.ofgem.gov.uk/sites/default/files/docs/2015/09/retail_energy_markets_in_2015 _report_0.pdf

Quadrangle (2017), 'Micro and small business customer engagement in the energy market, 2016', Research Report, Prepared for Ofgem, Apri 2017, available at: https://www.ofgem.gov.uk/system/files/docs/2017/04/ofgem__micro_and_small_business_engagement_2016_-_research_report.pdf

Ramsden, M. and R.J. Bennett (2005), 'The benefits of external support to SMEs: 'Hard' versus 'Soft' outcomes and satisfaction levels', Journal of Small Business and Enterprise Development, 12(2), pp. 227-243

Research Works (2015), 'Small and Medium Enterprise Customer Research into the Retail Banking Market - Qualitative Research Report', July 2015, available at: https://assets.publishing.service.gov.uk/media/559fe1cced915d1592000058/SME_Customer_ Research_into_the_Retail_Banking_Market.pdf

The Research Perspective/Element Energy (2013), 'Quantitative Research into Non-Domestic Consumer Engagement in, and Experience of, the Energy Market - Final Report', for Ofgem, December 2013, available at: https://www.ofgem.gov.uk/publications-andupdates/quantitative-research-non-domestic-consumer-engagement-energy-market

Suarez, D., B. Garcia-Marinoso and I. Santos (2016), 'Satisfaction of business customers with mobile phone and internet services in Spain', Telecommunications Policy, 40, pp. 52-61

Trianni, A. and E. Cagno (2012), 'Dealing with barriers to energy efficiency and SMEs: Some empirical evidence', Energy, 37, pp. 494-504

Trianni, A., E. Cagno, E. Worrell and G. Pugliese (2013a), 'Empirical investigation of energy efficiency barriers in Italian manufacturing SMEs', Energy, 49, pp. 444-458

Trianni, A., E. Cagno and E. Worrell (2013b), 'Innovation and adoption of energy efficient technologies: An exploratory analysis of Italian primary metal manufacturing SMEs', Energy Policy, 61, pp. $430-440$ 
Trianni, A., E. Cagno and S. Farne (2016), 'Barriers, drivers and decision-making process for industrial energy efficiency: A broad study among manufacturing small and medium-sized enterprises', Applied Energy, 162, pp. 1537-1551 